\title{
Imaging studies in renovascular hypertension
}

Citation for published version (APA):

de Haan, M. W. (2003). Imaging studies in renovascular hypertension. [Doctoral Thesis, Maastricht University]. Datawyse / Universitaire Pers Maastricht. https://doi.org/10.26481/dis.20030619mh

Document status and date:

Published: 01/01/2003

DOI:

10.26481/dis.20030619mh

Document Version:

Publisher's PDF, also known as Version of record

\section{Please check the document version of this publication:}

- A submitted manuscript is the version of the article upon submission and before peer-review. There can be important differences between the submitted version and the official published version of record.

People interested in the research are advised to contact the author for the final version of the publication, or visit the DOI to the publisher's website.

- The final author version and the galley proof are versions of the publication after peer review.

- The final published version features the final layout of the paper including the volume, issue and page numbers.

Link to publication

\footnotetext{
General rights rights.

- You may freely distribute the URL identifying the publication in the public portal. please follow below link for the End User Agreement:

www.umlib.nl/taverne-license

Take down policy

If you believe that this document breaches copyright please contact us at:

repository@maastrichtuniversity.nl

providing details and we will investigate your claim.
}

Copyright and moral rights for the publications made accessible in the public portal are retained by the authors and/or other copyright owners and it is a condition of accessing publications that users recognise and abide by the legal requirements associated with these

- Users may download and print one copy of any publication from the public portal for the purpose of private study or research.

- You may not further distribute the material or use it for any profit-making activity or commercial gain

If the publication is distributed under the terms of Article $25 \mathrm{fa}$ of the Dutch Copyright Act, indicated by the "Taverne" license above, 
Imaging studies in renovascular hypertension 
(c) M.W. de Haan, Maastricht 2003

mdehaan@radiology.azm.nl

ISBN 90-5278-378-0

Printed by: Datawyse / Universitaire Pers Maastricht 


\title{
Imaging studies in renovascular hypertension
}

\author{
Proefschrift
}

ter verkriging van de graad van doctor

aan de Universiteit Maastricht,

op gezag van de Rector Magnificus

Prof. Dr. A.C. Nieuwenhuijzen Kruseman,

volgens het besluit van het College van Decanen,

in het openbaar te verdedigen

op donderdag 19 juni 2003 om 16.00 uur

door

Michiel Willem de Haan

geboren 9 maart 1959

te 's Gravenhage

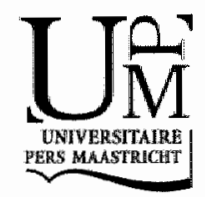




\section{Promotores}

Prof. Dr. J.M.A. van Engelshoven

Prof. Dr. P.W. de Leeuw

\section{Beoordelingscommissie}

Prof. Dr. P.J.E.H.M. Kitslaar (voorzitter)

Prof. Dr. F.W.H.M. Bär

Prof. Dr. K.M.L. Leunissen

Prof. Dr. J.A. Reekers (Universiteit Amsterdam) 
Voor: de jongens 



\section{Contents}

Chapter 1

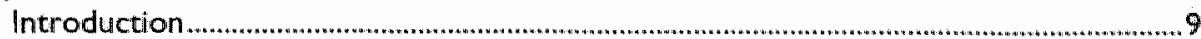

Chapter 2

Renovascular disease in patients with hypertension: detection with duplex

ultrasound.

de Haan MW, Kroan AA, Flobbe K, Kessels AGH, Tordoir JH, wan Engelshoven $J M A$, de

Leeuw PW.

Journal of Human Hypertension 2002; 16:501-507

Chapter 3

Renovascular disease in patients with hypertension: detection with systolic and

diastolic gating in three-dimensional, phase-contrast MR angiography.

de Haan MW, Kouwenhoven M, Thelissen GRP, Koster D, Kessels AGH, de Leeuw PW, van Engelshoven JMA.

Rodiology 1996; 198:449-456

Chapter 4

Fibromuscular dysplasia of the renal arteries: comparison of spiral CT angiography,

$M R$ angiography and conventional angiography...

de Haan MW, Kessels AGH, Vasbinder GBC, Beek FIA, Korst MBIM

Leiner $T$, Maki JH, van Zwam WH, de Leeuw PW, van Engelshoven MMA.

Submitted for publication

Chapter 5

Renal artery blood flow: quantification with breath-hold or respiratory triggered phase-contrast MR imaging.

de Haan MW, Kouwenhoven M, Kessels AGH, van Engelshoven JMA.

European Radiology 2000; 10:1133-1137.

Chapter 6

PC-MR flow quantification in renal arteries; comparison with ${ }^{133}$ Xenon washout measurements.

de Haan MW, van Engelshoven JMA, Houben AJHM, Kaandorp DW,

Kessels $A G H$, Kroon $A A_{\text {, de }}$ Leeuw PW.

Hypertension 2003; 41:114-118.

Chaipter 7

General discussion 85

Chapter 8

Summary

Samervatting

Dankwoord.

Curricullum vitea 103

Appendix 105 



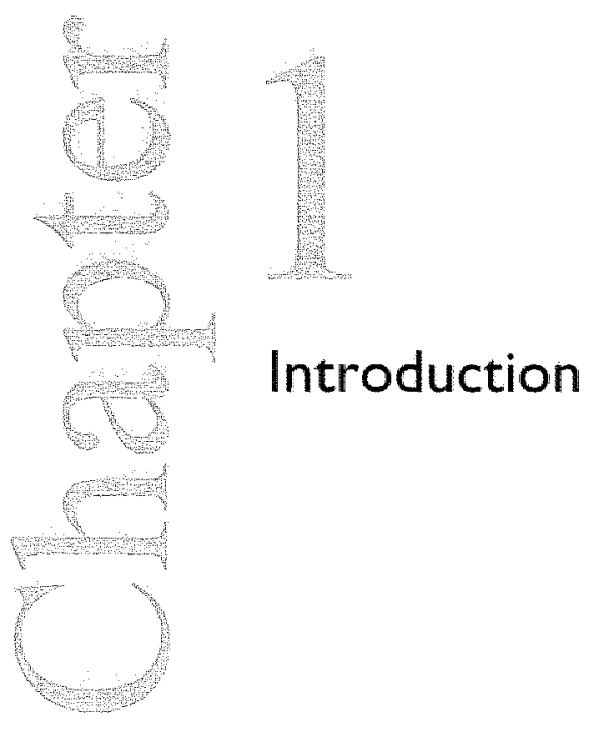




\section{Introduction}

The clinical presentation of renovascular disease varies significantly between patients, ranging from Incidental findings of renal artery stenosis on angiography to severe hypertension and progressive loss of renal function. Renovascular disease is in approximately two thirds of the adult population caused by atherosclerosis, whereas the second most common cause is fibromuscular dysplasia (1).

Renal artery stenosis leading to renovascular hypertension is the most frequent cause of secondary hypertension with an estimated prevalence of $3-5 \%$ in the general population of hypertensive patients (2). Progression of atherosclerotic renovascular disease can lead to loss of renal volume and subsequent deterioration of renal function in a considerable percentage of patients and when present bilaterally, result in end-stage renal faillure (3). Early identification of renal artery stenosis in (hypertensive) patients poses an important clinical challenge, since surgical or percutaneous treatment of these lesions may improve blood pressure control and/or stabilize renal function, even though this has been disputed in a recent publication $(1,2,4,5)$.

To date, conventional $x$-ray angiography still is considered as the most accurate method to assess the presence and severity of renal artery stenosis. However, its invasive nature and high costs, in addition to the requirement to use nefrotoxic contrast medium and radiation, make this procedure less appropriate as a screening modality in the general hypertensive population with its relatively low prevalence of renal artery stenosis.

The ideal screening procedure to select patients for renal angiography should be simple, easy applicable, non- (or minimally) invasive and highly accurate both for the detection of renovascular disease and for assessment of its clinical significance. In search of such a test, several non-invasive imaging methods (e.g. intravenous pyelography and intravenous digital subtraction angiography) were proposed but were later discarded because of insufficient results $(1,2,6)$. Likewise, reported results concerning captoprill renography have shown contradictory results, especially in patients with bilateral disease (7-9).

Duplex ultrasound has the potential to combine direct visualization of the renal arteries with acquisition of flow velocity profilles, thus providing both anatomical and functional information and has been advocated as the optimal screening test. However, the results of studies concerning the walidity of duplex ultrasound are sometimes conflicting and there is no general agreement about its value as a screening test for renovascular disease $(10,11)$. In chapter 2 the accuracy of duplex ultrasound for the diagnosis of renal artery stenosis in a group of hypertensive patients is evaluated.

Early studies on magnetic resomance (MR) angiography of the renal arteries performed without the use of paramagnetic contrast medium, such as time-of-flight (TOF MRA) and phase-contrast MR angiography (PC-MRA), yielded variable results with respect to detection of renal artery disease $(12,13)$. Artefacts caused by the pulsatility of blood flow, that hinder image interpretation could, at least partially, be responsible for this variation in test accuracy. In chapter 3 a prospective study is described in which cardiac synchronization is introduced in a three-dimensional phase-contrast $M R$ angiographic technique (3D PC-MRA) as a possible sollution to overcome these pulsatility artefacts.

In recent publications dedicated computed tomography $(C T)$ and magnetic resonance (MR) protocols were introduced for volumetric data acquisition with high contrast-enhancement of the renal vessels yielding high sensitivities and specificities for detection of main renal 
artery stenosis (14-19). However, most publications on CT and MR angiography of the renall arteries address primarily atherosclerotic renovascular pathology. The presence of fibromuscular dysplasia is mentiomed in only a few publications and, with the exception of Bergri et al $(20)$, no separate assessment of the test performance in this subgroup is indicated. Yet, the good long-term results for renal revascularisation of stenoses secondary to fibromuscular dysplasia make early and accurate identification of these patients imperative (21). Results of a prospective multicenter study (RADISH-study) concerning the validity of MR angiography (MRA) and CT angiography (CTA) to diagnose renal artery stenosis in hypertensive patients show an overall poor performance of both tests, contrary to the results of all other published studies (22). A striking difference with the other studies was the relatively high proportion of patients. with fibromuscular dysplasia in this series, which may have contributed to the poor tests performances. In chapter 4, the phase-contrast MRA (PC-MRA), gadolinium enhanced MRA (CE-MRA) and CTA data of all patients from the RADISH-study with angiographically proven renal artery fibromuscular dysplasia are analysed. The feasibility of the MR angiography (MRA) and CT angiography (CTA) techniques was evaluated in the assessment of fibromuscular dysplasia and to identify possible sources of error in depiction of this renal artery disorder.

However, similar to other imaging methods employed in the diagnosis of renal artery stenosis, these techniques solely rely on the morphologic assessment of the renal arteries. In order to assess the hemodynamic, and possibly the therapeutic, consequences of a particular arterial lesion, additional functional tests are still required.

Phase-contrast MR imaging (PCMR), which goes beyond morphologic imaging by allowing quantitative evaluation of flow dynamics, has been suggested as a non-invasive modality for renall artery blood flow analysis. In combination with cardiac triggering, flow rates can be determined at specified phases of the cardiac cycle, which enables evaluation of the flow rates as a function of time. To date, published studies show varying success in renal blood flow measurement, in which respiratory motion appears to be a considerable source of error $(23,24)$. Synchronisation with respect to respiratory motion, along with cardiac triggering, seems to be necessary to obtain accurate, reproducible flow data $(25,26)$. Results concerning the feasibility and reproducibility of two respiration controlled PC MR techniques to measure the blood flow in the individual renal arteries in healthy volunteers are presented in chapter 5 .

In chapter 6, the accuracy of 2D PC MR flow quantification is further analysed in patients suspected of having renovascular hypertension by comparing the results of these measurements with those obtained by the intra-arterial ${ }^{133}$ Xenon washout technique. In the same chapter, the 2D PC MR flow data were related to functional renal information as obtained by selective arterial and venous renin sampling in order to assess the presence of renal artery stenosis.

\section{The objectives of this thesis are:}

1. To assess the accuracy of duplex ultrasound for the diagnosis of renovascular disease in a cohort of hypertensive patients.

2. To evaluate the usefulness of three-dimensional phase-contrast magnetic resonance angiography (3D PC-MRA) performed with cardiac synchronisation in the assessment of renal arteries. 
3. To investigate the accuracy of 3D PC-MRA, contrast-enhanced MRA (CE-MRA) and spiral CT angiography (CTA) in the diagnosis of renal artery fibromuscular dysplasia and to identify possible sources of error in this group of patients that may have contributed to the overall poor tests performances and to give suggestions for further improvement.

4. To study the accuracy and usefulness of 2 dimensional phase contrast magnetic resonance (2D PC MR) renal artery flow measurements.

\section{Outline of this thesis:}

- Chapter 2 describes the diagnostic accuracy of duplex ultrasound in detecting renal artery stenosis in seventy-eight hypertensive patients.

- Chapter 3 evaluates the accuracy of 3D PC-MRA of the renal arteries performed with cardiac synchronisation in a study with 38 patients, using intra-arterial angiography as standard of reference.

- Chapter 4 describes the analysis of MRA and CTA data of all patients from the RADISH study with angiographically proven renal artery fibromuscular dysplasia.

- In Chapter 5 the validity and reproducibility of cardiac gated, respiratory controlled $2 D$ PCMR renal artery flow quantification is assessed in 12 healthy volunteers.

- Chapter 6 addresses the accuracy of 2D PC MR renal artery flow measurements in hypertensive patients by comparing the results of these measurements with those obtained by ${ }^{133}$ Xenon washout; and relates $2 \mathrm{D}$ PC MR flow measurements to functional renal information as obtained by selective arterial and venouls renin sampling.

- Chapter 7 consists of the summary of this thesis, the conclusions and recommendations. 


\section{References}

1. Working group on renovascular hypertension. Detection, evaluation, and treatment of renowascular hypertension: finall report. Arch. Intern. Med. 1987; 147:820-829.

2. Hillman BJ. Imaging adwances in the diagnosis of renovascular thypertension. AJR 1989; 53: 5-14.

3. Schreiber MJ, Pohil MA, Nowick AC, The natural history of atherosclerotic and fibrous renal artery disease, Urol. Clinics of North America 1984: 11(3):383-392.

4. Kim D. Edelman RR, Kent $K C$, Porter $D H$. Skillman y. Abdominal aorta and renal stenosis: evaluation with MR angiography. Radiology 1990; 174:727.731.

5. van jaarsweld BC, Krijnen P, Pieterman $H$, Derkx FH, Deinum J,Postma CT. Dees A. Woittiez A. Bartelink AK, Man in 't Veld Al, Schalekamp MA. The effect of balloon angioplasty on hypertension in atherosclerotic renal-artery stenosis. Dutch Renal Artery Stenosis Intervention Comoperative Study Group. New England Journal of Medicine 2000; 342 (14):1007.14

6. Yucel KE. Magneric resonance angiography of the lower extremities and renal arteries. Semin. Ultrasound CT MR. 19:92; 13:291-302.

7. Mann SI. Pickering TG. Detection of renovascular hypertension; state of the art-1992. Ann. Intern Med $1992 ; 117: 845-853$.

8. Schreij G, van Kroonenburgh, Heidendal GK, van der Pol HA, de Leeuw PW. Interpretation of captopril renography by nuclear medicine physicians. J Nucl Med 1995; 36(12):2192-2195.

9. Huot SJ, Hansson JH, Dey $\mathrm{H}_{\text {, }}$ Concato J. Utility of captopril renal scans for detecting renal artery stenosis. Arch intern Med 2002; 162:1981-1984.

10. Baxter GM, Aitchison F, Sheppard D. Moss JG, McLeod MJ, Harden PN, Lowe IG, Robertson M, Taylor G. Colour Doppler ultrasound in renal artery stenosis: intrarenal waveform analysis. British Journal of Radialogy 1996; 69:810-815.

11. Breitenseher von M, Kainberger F. Hü bsch P. Trattnig S, Baldt M, Barton P. Karnel F. Screening of renal artery stenosis: early results of colour Doppler sonography. Fortschr. Röntgenstr. 1992; 156,3:228-231.

12. Debatin JF, Spritzer CE, Grist TM, Beam C, Svetkey LP, Newman GE, Sostman HD. Imaging of the renal arteries: value of MR angiography. AJR 1991; 157:981-990.

13. Loubeyre P, Revel $D$, Garcia $P$, Delignette A, Canet E, Chirossel P, Genin G, Amiel M. Sereening patients for renal artery stenosis: value of three-dimensional time-of-flight MR angiography. AJR 1994; 162:847. 852

14. Snidow Jl, Johnson MS, Harris VI. Margasian PM, Aisen AM, Lalka SG, Cikrit DF, Trerotola SO. Tregdimensional gadolilium-enhanced MR angiography for aortoillac inflow assiessnent pllus renal artery screening in a single breath-hold. Radiology 1996: 198:725-732.

15. Hahn U, Miller S, Nagele T, Schick F, Erdtmann B, Duda S, Claussen CD. Rerial MR angiography at 1,0 T: three-dimensional (3D) phasemcontrast techniques versus gadolinium-enhanced 3D fast low-angle shot breath-hold imaging. AJR 1999; 172:1501-1508.

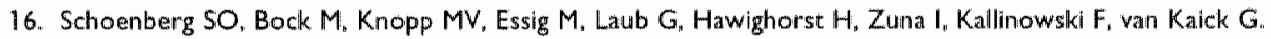
Renal arteries: optimization of three-dimensional gadolinium-enhanced $M R$ angiography with bolustiming-independent fast multiphase acquisition in a single breath-holld. Radiology 1999; 211:667-679.

17. De Cobelli F, Venturini M, Vanzulli A, Sironi S, Salvioni M. Angeli E, Scifo P, Garancini MP, Quartagno R, Bianchi G, Del Maschio A. Renal artery stenosis: prospective comparison of color-Doppler US and breath-hold, three-dimensional, dyramic, Gadolinium-enhanced MR angiography. Radiolog\%. 1997; 214:373-380. 
18. Kaatee R, Beek FJA, de Lamge EE, van Leeuwen MS, Smits HFM, van der Ven PJG, Beutler Jj, Mall WPTM. Renal artery stenosis: detection and quantification with spiral $\mathrm{CT}$ angiography versus optimised digital subtraction angiography. Radiology. 1997; 205: 121-127.

19. Bakker J. Beek FJA, Beutler 11. Henê RJ, de Kort GAP, de Lange EE, Moons KGM. Mali WPTM. Renal artery stenosis and accessory renal arteries: accuracy of detection and visualization with Gadoliniumenhanced breath-hold MR angiography. Radiology. 1998; 207:497-504:

20. Beregi J-P. Louwegny $S$; Gautier $C$, Mounier-Vehier $C$, Desmoucelle $F$, Wattinne $L$ n McFadden $E$. Fibromuscular dysplasiat of the renal arteries: comparison of helical CT angiography and arteriography. AJR 1999: 172:27-34.

21. Van Bockel JH, Weibull $H$. Fibrodysplastic disease of the renal arteries. Eur J Vasc Surg 1994; 8:655-657.

22. Vasbinder GBC, Nelemans PJ, Beek FJA, Flobbe $K$, de Haan MW. Kessels AGH, Korst MBJM. Kroon AA, Leiner T, Maki JH, Postma $C T$, van Zwam WH, de Leeuw PW. van Engelshoven JMA. Computed Tomographic Angiography and Magnetic Resonance Angiography for the Diagnosis of Remal-Artery Stenosis: a Comparative Study with Digital Subtraction Angiography. Results of the Renal Artery Diagnostic Imaging Study In Hypertension (RADISH) Study. Submitted.

23. Sommer $G$, Noorbehesht $B$, Palc $N$, Jamison R, Pinevich AJ, Newton L, Myers B. Niormal renal bload flow measurement using Phase-Contrast Cine Magnetic resonance. Imaging. Investigative Radiology 1992; 27:465-470.

24. Maier SE, Scheidegger MB, Lui K, Schneider E, Bolliger A Boesinger $P$. Renal artery welocity mapping with MR imaging. Journal of Magnetic Resonance Imaging 1995; 5: 669-676.

25. Debatin JF, Ting RH, Wegmüller $H$, Sommer F, Fredrickson JO, Brosnan TJ, Bowman BS. Myers BD, Herfkens RJ Pelc NJ. Renal artery blood flow: Quantification with Phase-Contrast MR imaging with and without breath hollding. Radiology 1994: 190:371-378.

26. Thomsen $C$. Corsten $M$, Söndergaard L, Hendriksen $O$, Stă hilberg. F. A segmented K-space Velocity mapping protocol for quantification of renal artery blood flow during breach-holding. Journal of Magnetic Resonance Imaging 1995: 5:393-401. 


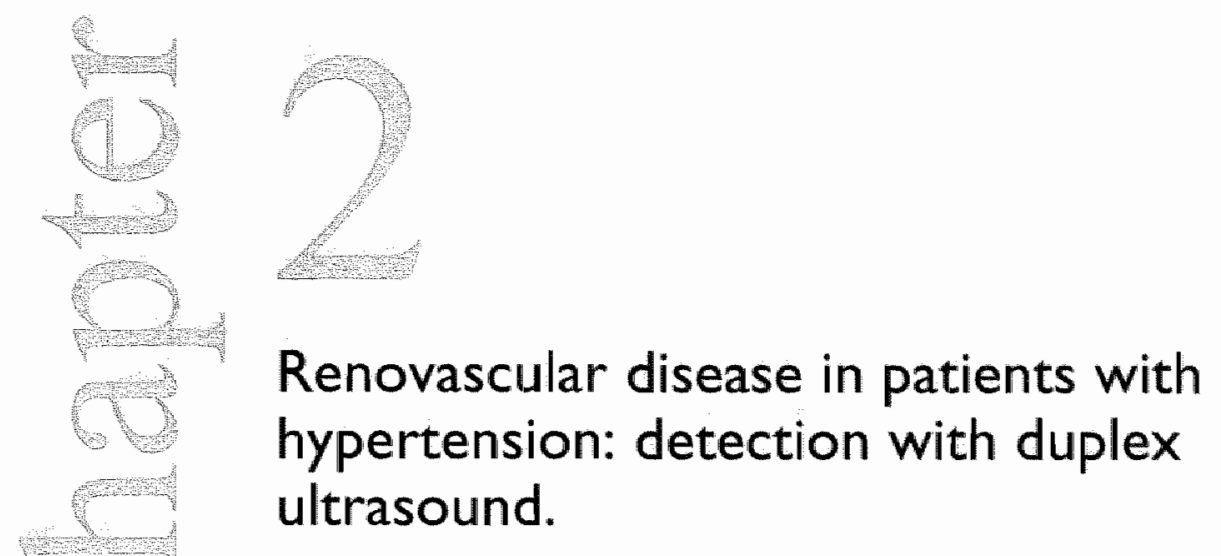

de Haan MW, Kroon AA, Flobbe K, Kessels AGH, Tordoir JH, van Engelshoven JMA, de Leeuw PW.

Journal of Human Hypertension 2002; 16:501-507 


\section{Abstract}

The aim of this study was to evaluate the accuracy of duplex ultrasound for the diagnosis of renovascular disease in a cohort of hypertensive patients. In seventy-eight patients suspected of renovascular hypertension on clinical grounds duplex ultrasound examination of the renal arteries was performed. Renal anglography was used as the standard of reference. Duplex ultrasound was inconclusive in 11 kidneys $(7 \%)$. None of the supernumerary renal arteries was detected with duplex ultrasound. The overall prevalence of significant renovascular disease ( $250 \%$ stenosis) was $20 \%$. Based on the combination of parameters at thresholds commonly applied in current literature. i.e. $P S V_{\max }>180 \mathrm{~cm} / \mathrm{sec}$ and RAR > 3.5, the overall sensitivity of duplex ultrasound for detection of hemodynamically significant renovascular disease was $50.0 \%$ with a specificity of $91.3 \%$ (PPV: $87.9 \%$; NPV: 59.1). Lowering the thresholds for both parameters ilmproved the test results at the cost of a significant increase of false positive examinations. In a population of hypertensive patients clinically suspected of renovascular hypertension, only limited results for duplex ultrasound could be acquired in the detection of renovascular disease. This result, in combination with the wide range of sensitivities and specificities published in international literature and the relativelly large number of incomplete examinations does not support the general application of duplex ultrasound as a screening procedure for detection and assessment of renovascular disease. 


\section{Introduction}

Identification of renovascular disease in hypertensive patients remains important as correction of renal artery stenosis may improve blood pressure control or stabilize renal function $(1,2,3)$. Conventional $x$-ray angiography still is the most accurate method to assess the presence and severity of renal artery stenosis. However, its invasive inature and high costs make this procedure unsuitable as a screening modality in apulation of patients with a low prevalence of renal artery stenosis. Several less invasive tests (including captopril renography) have been proposed to select patients for angiography $(4-7)$. Magnetic Resonance Angiography (MRA) has shown promising results as a non-invasive imaging modality for assessing the renal arteries, but to date fails to depict the hilar and parenchymal renal arteries. Also, CT angiography shows excellent depiction of the first segments of the renal arteries, at the expense of a relatively large amount of (nephrotoxic) contrast material and radiation.

Duplex ultrasound has the potential to combine direct visualization of the renal arteries with acquisition of flow velocity profiles, thus providing both anatomicall and functional information and has been advocated as the optimal screening test. However, the results of studies concerning the validity of duplex ultrasound are sometimes conflicting and there is no general agreement about its value as a screening test for renovascular disease $(8,9)$

The ailm of this study was to evaluate the accuracy of duplex ultrasound for the diagnosis of renal artery stenosis in a cohort of unselected hypertensive patients with clinical suspicion of renovascular disease using conventional renal angiography as standard of reference. In addition, we tried to determine the most useful combination of thresholds for the applied ultrasound parameters.

\section{Materials and methods}

\section{Patients}

Over a period of 3 years, 78 consecutive patients with malignant, accelerated and/or treatment-resistant hypertension (blood pressure $>160 / 100 \mathrm{~mm} \mathrm{Hg}$ despite treatment with 2 or more antihypertensive drugs), loss of renal function after angiotensin-converting enzyme (ACE) inhibition, unilateral loss of kidney volume or unexplained deterioration of renal function (change in serum creatinin $>20 \mu \mathrm{mol} / \mathrm{l}$ within 12 months) were examined by both colour duplex ultrasound and conventionall $x$-ray angiography of the renal arteries.

The results of 7 patients were excluded from analysis because duplex ultrasound was: performed only after endoluminal renal intervention. Thus, data of 71 patients was available for evaluation and comparison. Thirty-three (46\%) of these patients were men and thirty-eight women; mean age was 55 years (range $20-78$ years).

\section{Duplex ultrasound}

The ultrasound studies were performed using a colour duplex scanner with a 2.5 andior 5.0 $\mathrm{MHz}$ probe (Aloka Company Europe, Hoofddorp. The Netherlands) with the patient in supine position. Patients were either fasting or had received a clear-liquid diet since midnight on the day before the examination. The patients were examined in anterior, lateral and anterolateral position. The renal length was recorded for each kidney. Doppler samples were taken along the course of the renal arteries as well as in the abdominal aorta 
at the level of the renal arteries. Peak welocity readings were obtained by means of angle correction with Doppler-to-vessel angle of less than $60^{\circ}$ and a $2 \mathrm{~mm}$ Doppler gate width. Following published criteria, a peak systolic velocity in the renal artery (PSV maxix $_{\text {) }}$ of more than $180 \mathrm{~cm} / \mathrm{sec}$ and its ratio to the peak systolic velocity in the abdominal aorta (RAR) of 3.5 or more were used to discriminate a renal artery stenosis of $\geq 50 \%(10-12)$. A renal artery steniosis of $<50 \%$ was defined as $\mathrm{PSV}_{\max }>180 \mathrm{~cm} / \mathrm{sec}$ in combination with a RAR $<3.5$.

The grey-scalle images were not used to confirm or refute a diagnosis of renal artery stenosis. Renal artery occlusion was diagnosed when there was no flow signal in the renal artery and a low amplitude velocity signal from the renal parenchyma. The ultrasound studies were interpreted without knowledge of the results of angiography. Two vascular technicians experienced in the use of Doppler techniques performed all examinations. The technicians often sought the help of their colleague for patients who were difficult to examine. No difference was noted in the accuracy of the results or in the quality of the studies between the two technicians who participated in our study. The examination time lasted between 45 and 60 minutes for both sides.

\section{Conventional Angiography}

Angiography of the abdominal aorta and renal arteries was performed in the anteroposterior view with injection of $35 \mathrm{ml}$ contrast material through a $5-\mathrm{F}$ pigtail catheter (William Cook Europe, Bjæ verskow, Denmark) positioned at the level of the renal arteries. If the renal arteries were not adequately depicted, additional angiographic series were obtained in oblique projections and/or selective nenal angiography was performed with an end-hole catheter (William Cook Europe).

For the purpose of this study two independent observers, who were unaware of the duplex ultrasound results andlor clinical history interpreted the angiographic examinations agaim. The status of the renal artery was graded into four categories: normal; less than $50 \%$ stenosis; greater than $50 \%$ stenosis; or accluded. Renal arteries with evidence of fibromuscular dysplasia (FMD) were graded as significantly stenosed ( $\geq 50 \%$ ). The two obserwers reviewed discordant cases together to come to a consensus decision.

\section{Statistical Analysis}

Sensitivity and specificity and positive and negative predictive values regarding the detection of significant renal artery stenosis were calloulated at the level of the separate kidneys as well as at the level of patients with the results of conventional angiography as the standard of reference. Determination of the best threshold of the duplex ultrasound parameters included receiver-operator curve analysis (ROC) and calculation of sensitivity, specificity and positive and negative predictive values at various thresholds.

\section{Results}

A total of 141 kidneys were examined in 71 patients. One kidney could not be examined because it had previously been removed surgically.

The duplex ultrasound study was unsuccessful in 11 kidneys $(7 \%)$ due to the presence of bowel gas and/or obesity. Of the remaining 130 kidneys, $106(81.5 \%)$ showed a single renal artery. Twenty-four kidneys $(18.4 \%)$ had supernumerary renal arteries on angiography, one 
of which showed a significant stenosis. None of these accessory renal arteries were detected with duplex ultrasound.

On the basis of angiographic findings, 104 kidneys without stenotic lesions or with mild renal artery stenosis $(<50 \%$ ) were identified. In 24 kidneys (18.4\%) significant renal artery stenosis $(\geq 50 \%)$ was noted, including 9 arteries with fibromuscular dysplasia (7\%). Total occlusion of the renal artery was seen in 2 kidneys (1.5\%), resulting in an overall prevalence of significant renovascular disease of $20 \%$.

The range of renal size in the group of kidneys without or mild renal artery stenosis $(<50 \%$ ) was $8.4-12.9 \mathrm{~cm}$ (mean length $10.7 \mathrm{~cm}$ ), whereas the range in the group of kidneys with significant renal artery stenosis was $8.0-12.2 \mathrm{~cm}$ (imean length $10.6 \mathrm{~cm}$ ).

The mean values and standard deviations of a peak systolic velocity (PSV ${ }_{\max }$ ) and peak renal to aortic velocity ratio (RAR) in relation to the angiography results are presented in Table 1.

Table 1: Duplex ultrasound parameters recorded from the renal arteries.

\begin{tabular}{|c|c|c|c|c|c|c|}
\hline Results Duplex & Normal & 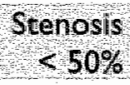 & $\begin{array}{l}\text { Stenosis } \\
>50 \%\end{array}$ & FMD & Occlusion & \\
\hline $\begin{array}{l}\mathrm{PSV} / \text { max } \\
(\mathrm{SD})\end{array}$ & $\begin{array}{r}199.0 \\
(59.33)\end{array}$ & $\begin{array}{r}1398 \\
(46.98)\end{array}$ & $\begin{array}{r}256.5 \\
(103.71)\end{array}$ & $\begin{array}{c}167.9 \\
(52.56)\end{array}$ & $\begin{array}{c}150.0 \\
(74.95)\end{array}$ & \\
\hline $\begin{array}{l}\mathrm{RAR} \\
(\mathrm{SD})\end{array}$ & $\begin{array}{l}1.75 \\
(0.9)\end{array}$ & $\begin{array}{r}2.13 \\
(0.88)\end{array}$ & $\begin{array}{c}4.66 \\
(2.71)\end{array}$ & $\begin{array}{c}2.41 \\
(1.06)\end{array}$ & $\begin{array}{c}2.8 \\
(1.97)\end{array}$ & \\
\hline Total number & 83 & 21 & 15 & 9 & 2 & 130 \\
\hline
\end{tabular}

Note: Data are presented as mean and standard deviations (sd"s). FMD= fibromuscular dysplasia; $P S V_{\max }=$ pealk systolic velocity; $R A R=$ ratio of pealk renal artery velocity to aortic velocity.

Table 2: Comparison between angiography and Duplex ultrasound in relation to the percentage of renall artery stenosis in hypertensive patients suspected of having removascular disease.

\begin{tabular}{|c|c|c|c|c|c|c|}
\hline Results Duplex & Normal & $\begin{array}{r}\text { Stenosis } \\
<50 \%\end{array}$ & $\begin{array}{r}\text { Stenosis } \\
>50 \%\end{array}$ & FMD & Occlusion & $\begin{array}{l}\text { Total } \\
\text { number }\end{array}$ \\
\hline Normal & 72 & 17 & 4 & 5 & 1 & 99 \\
\hline Stenosis $<50 \%$ & 4 & 2 & 0 & 3 & 0 & 9 \\
\hline Stenosis $\geq 50 \%$ & 7 & 2 & 11 & 1 & 0 & 21 \\
\hline Occlusion & 0 & 0 & 0 & 0 & $\mathbb{1}$ & 1 \\
\hline Total number & 83 & 21 & 15 & 9 & 2 & 130 \\
\hline
\end{tabular}

Note: Renal artery stenosis < 50\%: PSW $_{\text {max }}>180 \mathrm{~cm} / \mathrm{sec}$ and RAR $<3.5$; Renal artery stenosis $250 \%$ : $P S V_{\text {raxix }}>180 \mathrm{~cm} / \mathrm{sec}$ and $\mathrm{RAR}>3.5$. FMD $=$ fibromuscular dysplasia 
Based on the combination of these parameters at thresholds commonly applied in current literature: i.e. PSV $V_{\max }>180 \mathrm{~cm} / \mathrm{sec}$ and RAR $>3.5$, the results of the duplex ultrasound examination at the level of the separate kidneys compared to the angiographic findings are displayed in Table 2 (11-13). Excluding inconclusive examinations and using a $\geq 50 \%$ stenosis or the presence of fibromuscular dysplasia on anglography as the diagnostic criterion for hemodynamically significant renovascular disease, these results show an overall sensitivity of $50 \%$ and a specificity of $91 \%$. The overall positive (PPV) and negative (NPV) predictive values were $59 \%$ and $88 \%$ respectively. At the level of the individual patient the validity parameters show only marginal improvement with a sensitivity of $55 \%$ and a specificity of 84\% (PPV 57\%; NPV 82\%).

Figure 1. Receiver operating characteristic (ROO) curves showing sensitivity for detection of renal artery stenosis $(25 \%$ vs. 1specticity for different. PSV and RAR out-of values.

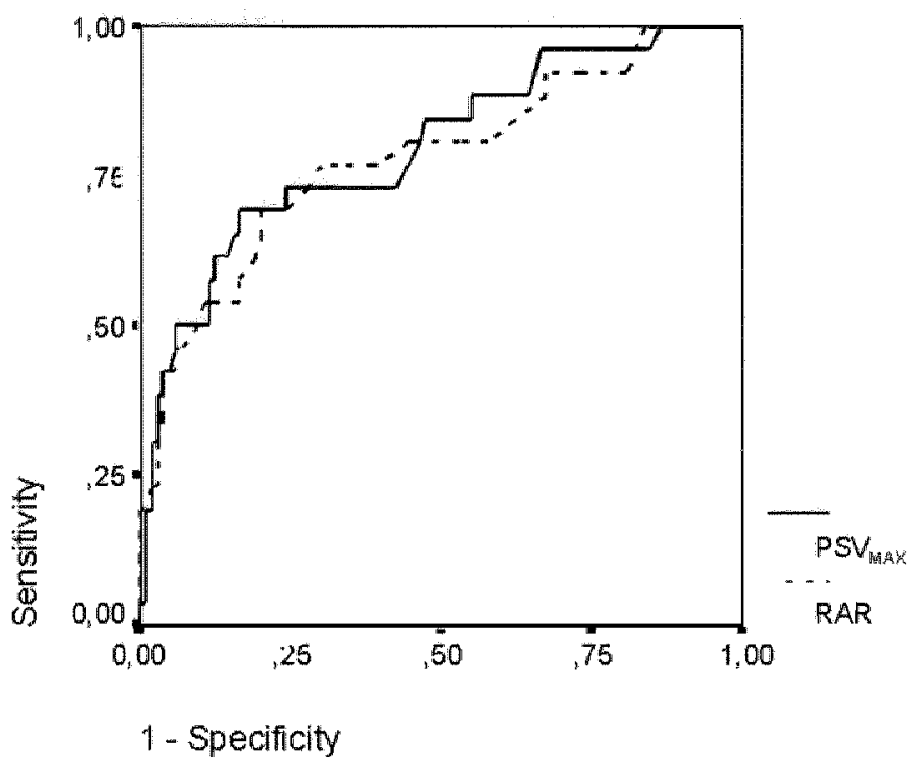

Receiver operating characteristic (ROC) analysis of the applied ultrasound parameters show comparable curves for both PSV max $_{\text {and }}$ anAR (Figure 1).

To improve the validity parameters of our duplex ultrasound examination, the results were also analysed for both the PSV max and RAR at other thresholds. At a constant threshold of the RAR the ROC-curve and its area under the curve (AUC) for the PSV max $_{\text {were }}$ determined. By calculating this AUC at different values of the RAR threshold the optimal RAR threshold was obtained. In the corresponding ROC-curve the optimal threshold of the PSV $\max$ could be derived.

This resulted in lower thresholds for both duplex ultrasound parameters. Lowering the peak systolic velocity threshold to $110 \mathrm{~cm} / \mathrm{sec}$ yielded a sensitivity of $85 \%$ and a specificity of $51 \%$. Similarly, lowering the threshold for the renal aortic ratio to 1.7 yielded a sensitivity of $81 \%$ and a specificity of $56 \%$. Combining these parameter thresholds resulted in a sensitivity of $81 \%$ and a specificity of $64 \%$ (Table 3 ). 
Table 3. Detection of renal artery stenosis: results for duplex ultrasoumd paranethers at differment thresholds and combinations.

\begin{tabular}{|c|c|c|c|c|}
\hline Parameter threshold & Sensitivity $(\%)$ & Specificity $(0)$ & PPV $(\%)$ & NeV $(\%)$ \\
\hline $\mathrm{PSV}>180 \mathrm{~cm} / \mathrm{sec}$ & 615 & 86.5 & 53.3 & 90,0 \\
\hline $\mathrm{RAR}>3.5$ & 50.0 & 90.4 & 56.5 & 879 \\
\hline $\begin{array}{l}\text { Combination } \\
\text { PSV }>180 \mathrm{~cm} / \mathrm{sec} \text { and RAR }>3.5\end{array}$ & 50.0 & 91.3 & 59.1 & 88.0 \\
\hline $\mathrm{PSV}>110 \mathrm{~cm} / \mathrm{sec}$ & 84,6 & 510 & 30.1 & 93.0 \\
\hline $\mathrm{RAR}>1.7$ & 80.8 & 558 & 313 & 92.1 \\
\hline $\begin{array}{l}\text { Combination } \\
\text { PSV }>110 \mathrm{~cm} / \mathrm{sec} \text { and RAR }>17\end{array}$ & 80.8 & 635 & 35,6 & 93.0 \\
\hline
\end{tabular}

Note: $P S V=$ peak systolic velocity: $R A R=$ renal aortic ratio: $P P V=$ positive predictive value; $N P V=$ negative predictive value.

Grading fibromuscular dysplasia (FMD) as significant renovascular disease $(\geq 50 \%)$, duplex ultrasound reached a sensitivity of $11 \%$ with a specificity of $81 \%$ in this subgroup of patients.

\section{Discussion}

The results of this study, carried out in a population of patients with clinically suspected renowascular disease, show only moderate results of colour duplex ultrasound in the detection of renal artery stenosis.

The clinical presentation of renovascular disease varies significantly between patients, ranging from incidental findings of renal artery stenosis on angiography to severe hypertension and progressive loss of renal function. Identification of renal artery stenosis still seems useful since surgical or percutaneous treatment of these lesions may improve blood pressure control and/or stabilize renal function, even though this has been disputed in a recent publication (14).

Numerous diagnostic tests have been proposed to identify patients with renovascular disease. However, none of them has received widespread clinical acceptance. The ideal screening procedure should be simple, non- (or minimally) invasive and highly accurate both for the detection of renovascular disease and for assessment of its clinical significance. Duplex ultrasound has been proposed as a promising modality in this respect, but reported data over the last 10 years have shown contradictory results in terms of its diagnostic accuracy. Some investigators report remarkable success, whille others have reported dismal results in large unselected patient groups $(15,16)$.

A recent study declared duplex ultrasound to be most valuable not only in the screening for renal artery disease but also to estimate its functional significance by means of determination of the resistive index (17). The duplex ultrasound performance in this study, however (i.e. sensitivity $97 \%$; specificity $98 \%$ ), was derived from a previous report by the same authors in a selected group of patients with a high prevalence of renovascular disease 


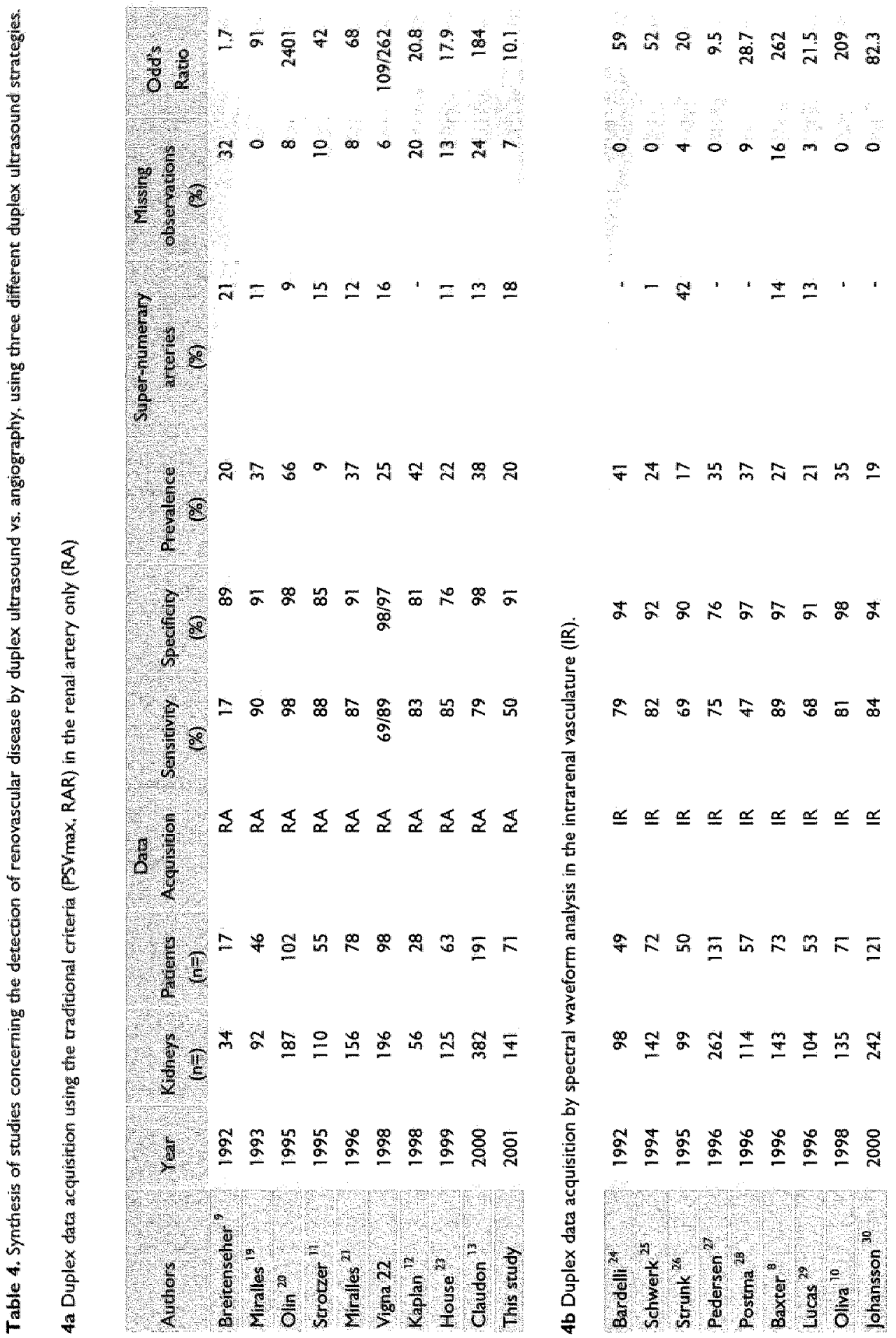




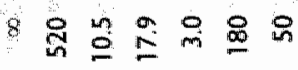

$\frac{5}{5}$

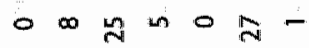

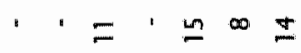

뜨ํํำ

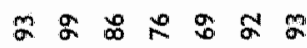

$\frac{5}{3}$

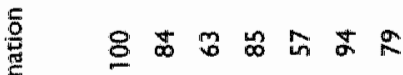

蓄

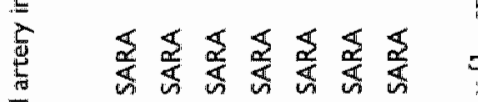

I

篦

$\stackrel{g}{5}$

옹

.

ลิ

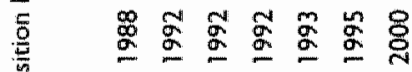

옳ำ

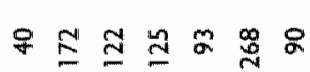

$\frac{x}{5}$ 
$(58 \%)(18)$. Therefore, implicit adoption of these test performance parameters to a nonselected population with a relatively low prevalence for renovascular disease $(2.3 \%)$ seems somewhat premature and raises doubts about whether the resistive index has the same prognostic significance for the remaining patients with stenosis not detected by duplex ultrasound.

In the present study, duplex ultrasound parameters at thresholds commonly applied in international literature were used: peak systolic velocity $>180 \mathrm{~cm} / \mathrm{sec}$ ( $\mathrm{PSV}_{\max }$ and peak. renal to aortic vellocity ratio $>3.5$ (RAR), resulting in an overall sensitivity of $50 \%$ and a specificity of $91 \%$ (PPV: $59 \%$ : NPV: $88 \%$ ). This relatively low positive predictive value is acceptable for a screening test since it reflects the fact that a degree of overcalling is desirable to minimize false-negative rates. However, the negative predictive value, which is a more important predictor of the usefulness of a parameter in this respect, may prove to be too low for general screening purposes.

Post-hoc improvement of our duplex ultrasound results could be obtained by lowering. both parameter thresholds. Based on ROC-curve analysis, including calculation of the respective area's under the curve, the preferred combination of the PSV max and RAR could be derived for the detection of renal artery stenosis. At thresholds for the PSV max and RAR of $110 \mathrm{~cm} / \mathrm{sec}$ and 1.7 respectively, this combination showed reasonable results in terms of sensitivity, specificity and predictive values (Table 3).

This reduction in duplex parameter thresholds contrasts with the otherwise wide range of established criteria published in international literature (13). The contrast can be explained by a systematic underestimation of the peak systolic velocity resulting in relatively low threshold values for both PSV max and RAR in our study group which in itself reflects the notorious operator dependency of the ultrasound examination in general. By using the combined parameters of peak systolic velocity and renal aortic ratio at these lower thresholds, we could have been $93 \%$ confident that a negative results means that a renal artery is free from significant stenosis with a consequential decrease in positive predictive value (Table 3). In our study, this would have resulted in a reduction of false negative examinations by eight patients at a cost of angiographic examinations in 38 patients with a false positive outcome. Yet, the clinical implementation of screening tests such as duplex. ultrasound is not determined by its vallidity results only. Other factor 5 ; such as population structure "pre-test likelihood and cost-effectiveness also influence the actual usefulness, which may lead to disparity in appreciation of test results in different clinical circumstances. All incomplete examinations ( 11 kidneys) were excluded from our results, whereas these data should be added as a positive result since they would require angiography in a screening setting. Based on the angiographic results in this sub-group of patients and on the traditional threshold parameters, sensitivity and specificity for duplex ultrasound would have been $57 \%$ and $86 \%$ respectively.

Supernimmerary renal arteries were noted on angiography in $18 \%$ of the kidneys $(n=24)$, but none of these were detected with duplex ultrasound. Visualization of a single normal renal artery does not exclude the possibility of a stenotic supernumerary renal artery. Although the influence of stenoses in small supernumerary renal arteries is not completely understood, the examination should be marked as inadequate and further limiting the outcome of our data and, therefore, the usefulness of duplex ultrasound.

Duplex ultrasound performed particularly poor in patients with fibromuscular dysplasia $(n=5)$, resulting in a sensitivity of $11 \%$ and specificity of $81 \%$, with duplex parameters which 
fall within the normal range of non-diseased vessels (Table 1). This observation might be caused by fundamental differences in underlying pathology compared to atherosclerotic renovascular disease. Also, the prerequisite to evaluate the entire length of the renal artery including the more peripheral segment, which, even in experienced hands is cumbersome, may be another explanation for this lack of discriminating power. However, the number of patients with FMD in our group is far too small to allow for a well-founded discussion in this matter.

Compared to other studies in which only patients sereened for renovascular hypertension were included, our results fall well within the wide range of reported data in terms of specificity, sensitivity and number of inadequate examinations. In our study as well as in others (Table 4a), the duplex ultrasound data of supernumerary renal arteries were excluded from evaluation, thereby accepting a number of inadequate examinations since these vessels may be as large as the main renal arteries and therefore of hemodynamic significance $(9,11-13,19-23)$.

In order to overcome these limitations, others have suggested the technique of duplex ultrasound examination of the intrarenal vasculature $(8,10,24-30)$. Analysis of the Doppler spectral waveform, with several criteria, i.e. mean resistive index, tardus-parvus phenomena and acceleration time, has been proposed as an alternative to detect upstream stenosis. With the lateral approach to the llkidney, duplex examination of the intrarenal arteries is easier to perform resulting in a higher number of complete examinations than with direct scanning of the renal arteries. Furthermore, recording of changes in Doppler velocity waveform pattern downstream in the segmental arteries makes it possible, at least in theory, to detect stenotic lesions in main, supernumerary and segmental arteries, although this hypothesis has been argued by others (31). Despite these theoretical advantages the range in sensitivities and specificities remains relatively wide: $57 \%-100 \%$ and $69 \%-99 \%$ respectively (Table $4 \mathrm{~b}$ ). These discrepancies can be partly attributed to the variability in criteria and degree of stenosis. However, the intrarenal parameters are probably influenced by several complex factors (i.e. pulse, diastalic blood pressure), which may also account for the differences in the tabulated results $(32,33)$.

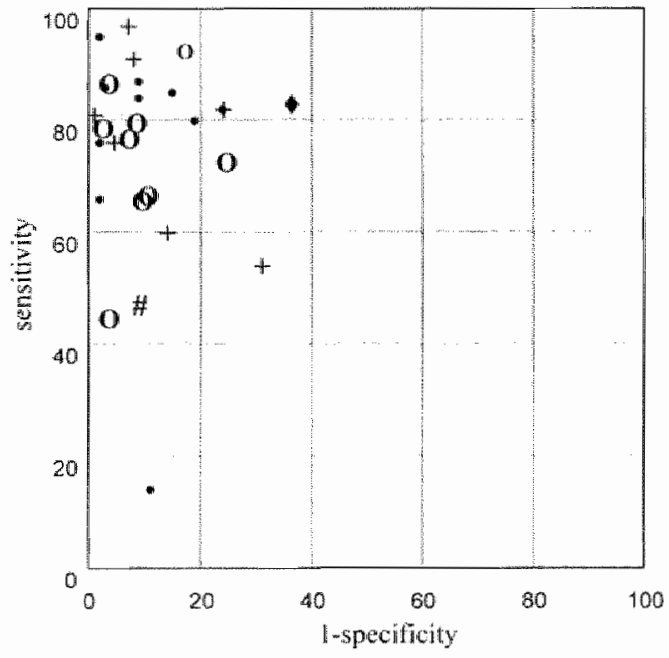

Figure 2. Sensitivity $\times 5$. 1 -specificity in 25 studier concerning detection of renovascular disease with duplex ultrasound vs. angiography; using throe different duplex ultrasound strategies.

Note: Duplex data acquisition using the traditional criteria (PSVmax, RAR) in the renal artery only (*); or by direct visualization of the renal artery in combination with spectral waveform analysis in the main and segmental arteries (+); or by spectral waveform analysis in the intrarenal wasculature (O). Present study using traditional parameter thresholds: $P S V_{\max x}>180$ cm/sec and RAR > 3.5 (H). Present study using lowered parameter thresholld: PSV $V_{\max }>110$ $\mathrm{cm} / \mathrm{sec}$ and RAR $>1.7(*)$ 
Direct visualization of the main renal arteries with duplex ultrasound combined with Doppler spectral waveform analysis in the main and segmental renal arteries $(31,43-39)$ does not seem to result in significantly better results with sensitivities ranging from $47-89 \%$ and specificities from 76-98\% (Table 4c).

The range and variety of sensitivities and specificities in the quoted studies cannot be explained by the application of different cut-off points. This is demonstrated in figure 2 , as it is not possible to fit one summary receiver-operating curve (SROC) over the marks representing the different studies and ultrasound strategies (40).

For quantitative analysis of the literature data the diagnostic Odds Ratio ( $=$ sensitivity $x$ specificity $/\{1$ - sensitivity $\} \times\{1$ - specificity $\}$ ) was calculated for each study (Table 4a-c). The Spearman rank correlation coefficients between diagnostic Odds Ratio's of the separate studies and a number of study variables, i.e. number of patients, prevallence of renovascular disease, year of publication, are less than 0.3, indicating a lack of influence of these variables on the diagnostic performance of duplex ultrasound. A sound explanation for the wide range of Odds Ratio's (Table 4) cannot be deducted from the indicated variables in the respective study protocols. Yet, apart from differences in composition of the study population, the different levels of experience with duplex ultrasound in the institutions concerned is likely to account for a substantial part of this variety in results.

In conclusion, in a population of hypertensive patients suspected of renovascular hypertension on clinical grounds, duplex ultrasound proved to have limited value for detection of renovascular disease when commonly applied parameter thresholds: $\mathrm{PSV}_{\max } 180 \mathrm{~cm} / \mathrm{sec}$ and RAR $>3.5$ were used. In addition, the relatively large number of incomplete examination in combination with the wide range of results published in international literature does not support the general application of duplex ultrasound as a screening procedure for detection and assessment of renovascular disease. 


\section{References}

1. Jensen G, Zachrisson BF, Delin K, Volkmann R, Aurell M. Treatment of renovascular hypertension: One year results of renal angioplasty. Kidney International 1995; 48:1936-1945.

2. Christensson A. Renowascular disease and renal insufficiency - diagnosis and treatment. Scandinavian Journal of Urology and Nephrology 1999; 33:400-405.

3. Erdoes LS, Berman SS. Hunter GC. Mills JL. Comparative analysis of percutaneous transluminal angioplasty and operation for renal revascularisation. American Journal of Kidney Disease 1996: 4:496503.

4. Hillman BJ. Imaging advances in the diagnosis of renovascular hypertension. AJR 1989; 153:5-14.

5. Kim D. Edelman RR, Kent KC. Porter DH. Skillman J]. Abdominal aorta and renal artery stenosis: evaluation with MR Angiography. Radiology 1990; 174: 727-731.

6. Yucel KE. Magnetic resonance angiography of the lower extremity and the renal arteries. Seininars in ultrasound, CT and MRI. 1992; 13:291-302.

7. Davidson RA, Wilcox CS. Newer tests for the diagnosis of renovascular disease JAMA 1992; 268:3353-3358.

8. Baxter GM, Aitchison F, Sheppard D, Moss JG, Meleod MJ. Harden PN, Love JG, Robertson M" Taylor G. Colour Doppler ultrasound in renal artery stenosis: intrarenal waweform analysis. British Journal of Radialogy 1996; 69:810-815.

9. Breitenseher von $M$, Kainberger $F$, Hü bsch P, Trattnig $S$, Balde M, Barton P. Karnel F. Screening of renal artery stenosis: early results of colour Doppler sonograpliy. Fortschr. Röntgenstr. 1992; 156,3:228-231

10. Oliva V, Soulez G, Lesage D, Nicolet V, Roy MC. Courteau M. Froment D. Rene PhC, Therasse E, Carignan $L$. Detection of renal artery stenosis with Doppler sonography before and after administration of captoprili: value of early systolic rise. AJR 1998; 170: 169-175.

11. Strotzer M, Fellner CM, Geissler A, Gmeinwieser J, Kohler B, Krämer BK, Kromer EP. Non-invasive assessment of renal artery stenosis: a comparison of MR angiography, color Doppller sonography, and intra-arterial angiography. Acta Radiologica 1995; 36:143-247.

12. Kaplan S. Nadja C. Captopril renography and duplex Doppler sonography in the diagnosis of renovascular hypertension. Nephrology, Dialysis and Transplantation 1998; 13:313-317.

13. Claudon M, Plouin PF, Baxter GM, Rohban T. Maniez Devos D. Renal arteries in patients at risk of renal artery stenosis: multicenter evaluation of the echo-enhancer $5 \mathrm{H}$ U $508 \mathrm{~A}$ at color and spectral Doppler US. Radiology 2000; 214:739-746.

14. van Jaarsveld $B C$. Krilinen $P$. Pieterman $H$, Derkx FH, Deinum J,Postma CT. Dees A. Wolttiez AJ. Bartelink AK. Man in "t Weld A]. Schalekamp MA. The effect of balloon angioplasty on hypertension in atherosclerotic renal-artery stemosis. Dutch Renal Artery Stenosis Intervention Co-operative Situdy Group. New England Journal of Medicine 2000; 342 (14):1007-14.

15. Berland $L$, Koslin D. Routh W, Keller F. Renal artery stenosis: prospective evaluation of diagnosis with color duplex ultrasound compared with angiography. Radiology 1990; 174:421-423.

16. Desberg A, Paushter D, Lammert G, Hale JC, Troy RB, Novick AC, Nally N. Weltevreden AM. Rerall artery stenosis: Evaluation with color doppler flow imaging. Radiology 1990; 177:749-753.

17. Radermacher J. Chavan A, Bleck J. Vitzthum A, Stroess B. Gebel MJ, Galanski M. Koch KM, Haller H. Use of Doppler Ultrasonography to predict the outcome of therapy for renal-artery stenosis. New England Journal of Medicine 2001; 3444:410-417. 
18. Radermather J. Chavan A, Schaeffer Ja Stroess B, Witzthum A, Kliem V Rademaker J. Bleck J, Gebel MJ, Galanski M. Brunkhorts R. Detection of significant renal artery stenosis with color Doppler sonography: combining extrarenal and intrarenal approaches to minimize technical failure. Clinical Nephrology 2000; $53: 333.343$.

19. Miralles M, Santiso A, Giménez A, Riambau V, Saez A, Daumal J, Cairols MA. Renal duplex scanning: correlation with angiography and isotopic renography. European Journal of Vascular Surgery 1993; 7:188194 .

20. Olin JW, Piedmonte MR, Young JR, DeAnna S, Grubb M, Childs MB. The utility of duplex ultrasound scarning of the renal arteries for diagnosing significant renal artery stenosis. Annals of internal Medicine 1995: $122: 833-838$.

21. Miralles M, Calrols M, Cotillas MD, Gimenez A, Santiso A. Value of Doppler parameters in the dliagnosis of renal artery stenosis. Journal of Vascular Surgery 1996: 23:428-435.

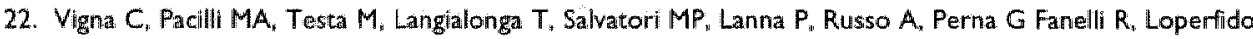
$F$. Comparison of steerable continuouls-wave versus pulsed-wave Doppler ultrasound to renal artery angiograpliy in diagnosing renal artery stenosis. American Journal of Cardiology; 1998; 81:365-367.

23. House MK. Dowling R, King P, Gibson RN. Using Doppler sonography to reweal renal artery stenosis: An evaluation of optimal imaging parameters. AJR 1999: 173:761-765.

24. Bardelli M, Jensen G. Vlokmann R, Aurell M. Non-invasive ultrasound assessment of renal artery stenosis by means of the Gosling pulsatility index. Journal of Hypertension 1992: 10:985-989.

25. Schwerk WB, Restrepo IK, Stellwaag $M_{v}$ Klose KJ, Schade B. Renal artery stenosis: grading with imagedirected Doppler US evaluation of renal resistive index. Radiology 1994; 190:786-790.

26. Strunk $H_{\text {, Jager }} U_{1}$ Telifke $A$. Intrarenal colour-coded duplex sonography in the diagnosis of renal artery stenosis with special regard to multiple renal arteries: Analysis of Doppler waveform and "tardus-parvus" phenomenon. Ulitraschall in Med. 1995; 16:172-179.

27. Pedersen EB, Egeblad M Jørgensen J, Nielsen SS, Spencer ES, Rehling M. Diagnosing renal artery stenosis: a comparison between conventional renography, captopril renography and ultrasound Doppler in a large consecutive series of patients with arterial hypertension. Blood Pressure 1996; 5:342-348.

28. Postma $C T$, Bijlstra PJ, Rosenbusch G. Thien Th. Pattern recognition of loss of early systolic peak by Doppler ultrasound has a low sensitivity for the detection of renal artery stenosis. Journal of Human Hypertension 1996; 10:181-184.

29. Lucas P. Blome S, Roche J. Intra-renal Doppler wave-form analysis as a screening test for renal artery stenosis. Australlian Radiology 1996; 40:276-282.

30. Johansson $M$, Jensen $G$. Aurell $M$, Friberg $P$, Herlitz $H$, Klingenstierna $H$. Volkmann R. Evaluation of duplex ultrasound and captopril renography for detection of renovascular hypertension. Kidney incernational 2000:58:774-782.

31. Klliewer MA, Tupler RH, Carroll BA, Paine SS, Kriegshauser JS, Hertzberg BS, Svetkey LP. Renal artery stenosis: analysis of Doppler waveform parameters and parvus-tardus pattern. Radiology 1993; 189:779787.

32. Malatino LS, Polizzi G, Garozzo M. Rapisarda F, Fatuzzo P, Bellanuova I, Cataliotti A, Brozzetti A, Neri S, Malfa PA Cotroneo GB. Diagnosis of renovascular disease by extra and intrarenal Doppler parameters. Angiology 1998; 49:707-721.

33. Grenier $\mathrm{N}$, Trillaud $\mathrm{H}$. Comparison of imaging methods for renal artery stenosis. BjU International 2000; 86 (Suppl 1) $84-94$

34. Handa N. Fukanaga R, Ogawa S, Matsumoto M. Kimura K, Karnada T. A new accurate and non-invasive sereening method for renovascular hypertension: the renal artery Doppler rechnique. Journal of Hypertension 1988:6:5458-5460. 
35. Zoller WG, Hermans $H_{4}$ Bogner JR, Hahn D. Middeke M. Duplex sonography in the diaguosim of renowascular hypertension. Klinische Wochenschift 1990;68.830.834.

36. Postma CT. Aalen van J. Boo de T. Rosembusch G, Thien Th. Dopplet withasoumd scaning in the detecion of renal arcery stenosis in hypertensive patients. British Journal of Radlology 1992; 65:857-860.

37. Dondi M, Fanti $S$, Barozzi L, De Fabritis A, Losinno F, Pavlica P, Monete N. Zuccalla A. Evaluation by captopril renal scintigraphy and echom Doppler flowmetry of hypertensive patients at high risk for renal artery stenosis. Journal of nuclear biology and medicine 1992; 36:309-314.

38. Spies KP, Fobbe F. El-Bedew M, Wolf KI. Disther A, Schulte KL. Color-coded duplex sonography for non-invasive diagnosis and grading of renal artery stenosis. American Journal of hpertension 1995: 8:1222-1231.

39. De Cobelli $F$, Venturini M, Vanzulli A, Sironi S, Angeli $E$, Seifo $P$, Garancini MP, Quartagno $R$, Bianchi $G$, Del Maschio A. Renal artery stenosis: prospective comparison of color Doppler US and breath-hold. three-dimensional, dynamic, gadolinium-enhanced MR. Angiography. Radiology 2000; 214:373-380.

40. Moses LE. Shapiro D. Littenberg B. Combining independent studie of a diagnostic test in a summary ROC curve: data-analytic approaches and some additional considerations. Stat Med. 1993:12:1293-1316. 


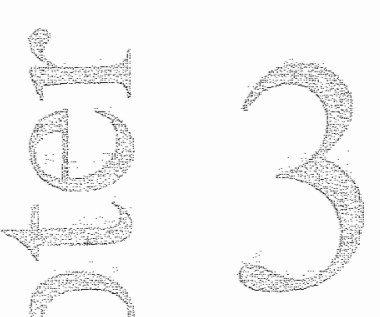

Renovascular disease in patients with hypertension: detection with systolic and diastolic gating in threedimensional, phase-contrast MR angiography.

de Haan MW, Kouwenhoven M, Thelissen GRP, Koster D, Kessels AGH, de Leeuw PW, van Engelshoven JMA.

Radiology 1996; 198:449-456. 


\section{Abstract}

Objective: To evaluate the usefulness of three-dimensional phase-contrast magnetic resonance (MR) angiography performed with cardiac synchronisation in the assessment of renal arteries.

Materials and methods: Thirty-eight patients, 24 men (mean age 60.0 years), 14 women (mean age 55.0 years) underwent three-dimensional, phase-contrast MR angiography performed without gating, with systolic gating, and with diastolic gating. Conventional angiography was used as standard of reference.

Results: The sensitivity for the detection of all stenoses $(>0 \%)$ was $93 \%$ with systolic gating, $92 \%$ with diastolic gating, and $77 \%$ without gating. However, there was no statistically significant difference between the three techniques in the diagnosis of hemodynamic

significant stenoses $(>50 \%)$. The mean arterial length depicted was significantly better with diastollic gating than with either of the other techniques $(p<.0001)$. Vascular disease was significantly overestimated with systolic gating relative to estimation without $(p=.030)$ or with diastolic $(p=.008)$ gating.

Conclusion: Three-dimensional, phase-contrast MR angiography has good image quality and enables assessment of renovascullar disease. Cardiac gating shows limited improvement of these results. 


\section{Introduction}

Renal artery stenosis is the most frequent cause of secondary hypertension, with an estimated prevalence of $3 \%-5 \%$ in the general population of people with hypertension (1-3). Detection of renovascular pathology in patients with hypertension andlor renal failure has become especially important, because correction of arterial stenoses by means of percutaneous transluminal angioplasty or surgery may cure hypertension (4-7).

To date, radiographic angiography is considered the most accurate method of assessing the presence and severity of renal artery stenosis. Because this examination is invasive, it is not suitable for screening a population of patients with a low prevalence of renal artery stenosis.

Several non-invasive imaging methods (e.g. intravenous pyelography intravenous digital subtraction angiography) have been proposed for such a population but were later discarded because of the insufficient results $(1,2,8)$. Duplex ultrasound (US) has been reported to have contradictory results (9-12). To our knowledge, the most widely used non-invasive test at the present time is renal scintigraphy performed after the administration of captopril; however, the results are problematic especially in patients with bilateral disease $(13-17)$.

In the last few years, several magnetic resonance (MR) angiographic techniques have been proposed for examination of patients suspected to have renovascular disease $(2,18-23)$. However, sensitivity and specificicy have been variable in these studies with respect to the detection of renall artery disease. Two-dimensional, time-of-flight (TOF) MR angiography has been reported to have a sensitivity of $53 \%-100 \%$ (specificity, $97 \%-78 \%$ ); two-dimensional, phase-contrast MR angiography has been noted to have a sensitivity of $80 \%$ (specificity, 91\%) (22,24-27). Publications concerning three-dimensional TOF MR angiography indicate a sensitivity and specificity of $100 \%$ and $76 \%$, respectively, whereas those concerning three-dimensional, phase-contrast MR angiography indicate a sensitivity and specificity of $84 \%$ and $97 \%$, respectively $(23,28)$. The benefit of gadolinium enhancement in three-dimensional, MR angiography has been mentioned in recent publications (sensitivity, 94\%; specificity, 98\%); however, these publications have had images of the distal arterial segments of inconsistent quality (29-32).

The variability of these results could be related to artefacts that hinder image interpretation; these artefacts may be due to the pulsatility of blood flow or to differences in $M R$ angiographic techniques, patient selection and/or interpretation criteria. We performed a prospective study to test the validity of three-dimensional, phase-contrast MR angiography and to evaluate the usefulness of cardiac synchronisation by comparing the image quality and validity of three different three-dimensional, phase contrast MR anglographic techniques: one sequence without cardiac synchronisation, one sequence with systolic gating, and one sequence with diastolic gating. Radiographic angiography was used as the standard of reference.

\section{Materials and methods}

\section{Patient Selection}

In the pillot phase of this study, the $M R$ angiography sequence used to depict the renal arteries was optimised. Imaging parameters were evaluated in ten healthy wolunteers 
without hypertension and in two patients with proved renowascular disease $(9$ men and 3 women, mean age 39.0 years).

In the second phase of this study, all patients with hypertension who were referred by the Department of Internal Medicine for radiographic angiographic evaluation of the renal vessels (38 consecutive patients; 24 men [mean age, 60 years; range, $37-78$ years]; 14 women [mean age, mean age 55 years; range, 24 - 74 years]) were prospectively enrolled over a period of six months (February - July 1994).

These patients had therapy-resistant hypertension (blood pressure $>160 / 100 \mathrm{~mm} \mathrm{Hg}$ during exterisive treatment), and most of them had undergone routine evaluation for renovascular hypertension. Evaluation included performance of laboratory tests, ultrasound of the kidneys, and renal scintigraphy.

Criterila for participation in the study included willingness to give informed consent, lack of standard contraindications to MR imaging (e.g. pacemaker, claustrophobia "or ocular metallic fragments) and our ability to perform the MR examination within 48 hours before to the radiographic angiographic procedure. The study was approved by the human investigation committee of our institute

\section{MR Angiography}

MR Angiography of the renal arteries was performed with a 1.5 Tesla whole-body MR. imager (ACS, Philips Medical Systems, Best, The Netherlands). The body coil was used for signal transmission and reception. No intravenous contrast material was administered. The patient breathed normally during data acquisition. No abdominal compression was used. To localize the renal arteries, a T1-weighted gradient echo multistack scout view was obtained at the level of the kidneys. The field of view (FOV) was $500 \mathrm{~mm}$, the matrix was $256 \times 256$, the section thickness was $15.0 \mathrm{~mm}$, the repetition time was $22.0 \mathrm{msec}$ and the echo time $7.0 \mathrm{msec}(22.0 / 7.0)$, and the flip angle was $20^{\circ}$. Images were obtained in the coronal and transverse planes.

Subsiequently, three separate three-dimensional, phase contrast $M R$ angiographic sequences were performed in each patient: a sequence without gating, a sequence with systolic gating, and a sequence with diastolic gating. T1-weighted, gradient-echo images were obtained in the transversal plane with the following parameters: $27.0 / 8.520^{\circ}$ flip angle, two signals.

Table 1. Summary of Imaging Parameters of the Three Three-dimensional Phase-contrast MR Alaglographic Pulse Sequerices.

$\begin{array}{lcrr}\text { Parameter } & \text { No gating } & \text { Systolic gating } & \text { Diastolic gating } \\ \text { Number of reconstructed sections } & 50 & 30 & 30 \\ \text { Flow-encoded velocity (cm/s) } & 45 & 45 & 35 \\ \text { Gate delay (msec) } & & 109-125 & 250-300 \\ \text { Gate widch (nsec) } & & 220 & 350 \\ \text { Examination time }(\text { min) } & 8 & 12-19 & 8-111\end{array}$

Note: Imaging wals performed with TH-weighted gradientecho with $27.0 / 8.5$ a $20^{\circ}$ flip angle, a $103 \times 128$ macrix and two signals acquired. A presaturacion slab below the lower pole of the kidneys was obtained. 
acquired, $75 \%$ partial echo sampling, $200 \times 140 \mathrm{~mm}$ FOV, $103 \times 128$ macrix, $12 \mathrm{~mm}^{3}$ acquired voxel size ( $5 \mathrm{~mm}^{3}$ reconstructed voxel size), and $45 \mathrm{~cm} / \mathrm{sec}$ flow-encoded velocity (Table 1).

Fourier interpolation was used to reconstruct sections thinner than those acquired. In the sequence performed without gating, 32 sections were acquired and reconstructed to 50 $2.0 \mathrm{~mm}$-thick sections. In the sequences performed with systolic or diastolic gating, 18 sections were acquired and reconstructed to $302.0 \mathrm{~mm}$-thick sections. The outer $10 \%$ on both sides was discarded.

To reduce the venous signal from the inferior vena cava, a transverse presaturation slab (60.0 mm thick) inferior to the lower pole of the kidneys was acquired. The maximum intensity projection (MIP) algorithm was used to create angiographic projections. To standardize our procedure as much as possible. MIPs were obtained in only the transverse, coronall and sagitcall planes.

Figure 1. Diagrams of cardiar gating "based on a two-dimensional velocity map of the blood flow in the arota just above the level of the kidneys. (a) Three-dimensional, phase-contrast MR angiography performed with systolic gating. The acquisition gate is set up at the upper 30-40\% of the systolic peak. (b) Thremedimensional, phase-contrast MR angiography performed with diastollc gating. The acquisition starts the hatfway point on the dowmward slope of the systolic peak.
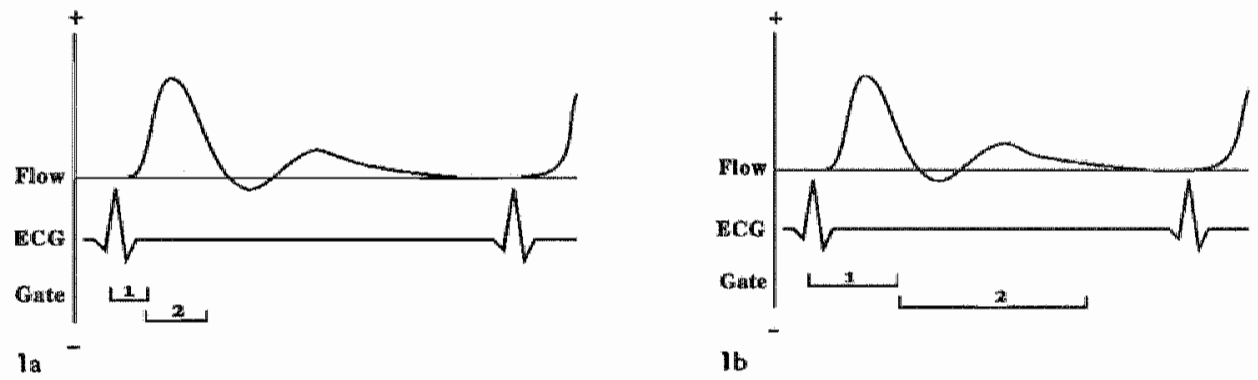

Note: $1=$ Gate delay: $2=$ Gate width; $E C G=$ electrowardiogram.

Before the three-dimensional sequences with cardiac gating were perfoimed, a two-dimensional (cardiac-triggered) velocity map of the blood flow in the aorta just above the level of the kidneys was obtained to determine the gate delay and gate width in relation to the R-wave peak on the electrocardiogram in each patient (Fig. 1). T1-welghted, gradient-echo, transwerse flow-velocity images were obtained with $20.0 / 8.5$, a $25^{\circ}$ flip angle, a $200 \mathrm{~mm}$ FOV, a $128 \times 128$ matrix, a single section, an $8 \mathrm{~mm}$ section thickness, a $120 \mathrm{~cm} / \mathrm{sec}$ flow-encoded velocity, 25 acquisition phases per R-R interwal, and retrospective cardiac symchronisation.

The imaging parameters in the sequences with cardiac gating were the same as those in the sequences performed without gating, except for the number of sections, flow-encoded velocity (with diastolic gating) and the implementation of gate delay and width (Table 1).

Cardiac gating in the three-dimensional imaging studies was performed in a steady state mode, in which the radio-frequency pulses and gradients continue throughout the entire heart cycle; however, data acquisition was limited to the selected gate. By adjusting the 
gate dellay and gate width relative to the patient's cardiac R-wave on the electrocardiogram, data acquisition could be performed in any desired portion of the velocity curve as was shown on the flow velocity map.

In the sequence performed with systolic gating, data were acquired in the upper $30-40 \%$ of the systolic peak on the velocity map (Fig la); this resulted in a gate delay of $109-125 \mathrm{msec}$ and gate width of 220 msec. Examination time for this pulse sequence ranged from 12 to 19 minutes, and flow-encoded velocity was $45 \mathrm{~cm} / \mathrm{sec}$.

In the three-dimensional MR angiographic sequence performed with diastolic gating, the acquisition gate scarted at the halfway point on the downward slope of the systolic peak flow on the welocity map. In most cases, this resulted in a gate delay of $250-300 \mathrm{msec}$ and a gate width of $350 \mathrm{msec}$. The flow-encoded velocity was $35 \mathrm{~cm} / \mathrm{sec}$, and the examination time for this pulse sequence was 8-11 minutes (Fig Ib).

In both sequences performed with cardiac gating, the gate delay and gate width had to be adjusted to the heart rate of the patient.

\section{Conventional Angiography}

Conventional angiography of the abdominal aorta and renal arteries was performed in the anteroposterior view with $45 \mathrm{ml}$ of iohexol (Omnipaque 140, Nycomed AS, Oslo, Norway) injected through a 5-French pigtail catheter (William Cook Europe AS, Bjaeverskow Denmark) positioned at the level of the renal arteries. If the renal arteries were not clearly depicted, additional intra-arterial digital subtraction angiography was performed in oblique projections, or selective renal angiography was performed with an end-hole catheter (William Cook Europe AS, Bjaeverskow "Denmark).

\section{Image Analysis}

Separate hard copies were made of each of the three-dimensional, phase-contrast MR angiographic image sets (sets obtained without gating, with systolic gating, or with diastolic gating), including the MIPs in three planes (sagittal, coronal and transverse) and original cross-sectional images; patient data and imaging parameters were not displayed. Two radiologists independently evaluated each set: one vascular radiologist (D.K.) and one MR radiologist (J.M.A.v.E). Neither had prior knowledge of the clinical patient data.

Each image set was assessed concerning image quality, venous vessel overlap, number of renal arteries per kidney, vessel segment depiction, and grading of renovascular disease. The overall image quality of each image set was scored on a three-point scalle (good, moderate, poor). The presence of venous vessel overlap, which hindered image interpretation, was scored on a two-point scale (yes, no). The worst result noted by either one of the obserwers in both these observations was accepted as the definitive score.

The number of renal arteries was assessed, and each artery was divided into three separate segments: proximal, middle and distal. Depiction of each segment in the three image sets was assessed and noted on a three-point scale (good, moderate or poor). The two radiologists reached consensus in a second round whenever there was disagreement between the individual interpretations of vessel segment depiction. Furthermore, the length of the renal artery depicted with each sequence was measured for the quantitative assessment of the image quality.

Four grades were used to categorize the severity of renovascular disease: Grades were based on the most severe reduction of arterial diameter compared with the diameter of 
the most normal-appearing segment proximal or distal to the stenosis. Grade I was mild disease (stenosis of $<50 \%$ ), defined as mere luminal narrowing grade 2 , moderate disease (stenosis of 50-74\%), defined as reduction in diameter with focal flow void ( $45 \mathrm{~mm}$ ): grade 3 , severe disease (stenosis of $75-99 \%$ ), defined as a longer region of signal intensity loss $(\geq 5 \mathrm{~mm}$ ) with distal recurrence of flow signal intensity; and grade 4 , occlusion (9).

The radiographic angiograms were blindly assessed with respect to the number of renal arteries and the presence of renowascular disease by a radiologist who had no prior knowledge of the clinical data of the patients or the results of the MR angiograms. Renal artery stenoses on radiographic angiograms were graded as they were on $M R$ angiograms.

\section{Statistical Analysis}

Pearson correlation coefficients were used to compare the results of both observers concerning the depiction of renal arteries in each three-dimensional, phase-contrast MR angiographic image set. The Fisher exact test was used to compare the depiction of the different vessel segments between the three three-dimensional, phase-contrast $M R$ angiographic image sets. The interobserver variability with respect to the presence and absence of renal artery stenosis was calculated for each imaging technique and expressed in $\kappa$ values. $\kappa$ is a measurement of agreement in excess of what is expected by chance and was calculated according to the formula $k=(\mathrm{Po}-\mathrm{Pe}) /(1-\mathrm{Pe})$, where $\mathrm{Po}$ is the observed and Pe the expected proportion of agreement (33). A paired Student t-test was used to differentiate between the depicted arterial lengths in the three pulse sequences.

To evaluate the differences in grading of renovascular disease, the McNemar test (exact distribution) was used. Only the arteries, which were seen by both observers in all three three-dimensional, phase-contrast MR pulse sequences were included in this test.

Sensitivity and specificity of each three-dimensional MR angiographic technique weire calculated. The standard of reference was negative when the radiographic angiogram showed no vascular disease. For clinically significant stenoses, the standard of reference was negative when the radiographic angiogram showed minor vascular disease with a reduction in lumen diameter of $50 \%$ or less.

\section{Results}

In $95 \%$ of the 38 patients $(n=36)$ all three three-dimensional, phase-contrast MR angiographic pulse sequences were pierformed. In two patients, only two pulse sequences were performed; this was due to logistic problems. During the 6-month interval of our study only three patients were excluded: Two patients had claustrophobia, and one patient had metal fragments in the back (probably from a grenade explosion during World War II). One of these three patients had significant renal artery stenosis at radiographic angiography.

Radiographic angiography revealed a total of 89 renal arteries in these 38 patients (seven patients had 3 or more arteries depicted). Sixty-five arteries (73\%) were considered normal. In a total number of 17 patients $(45 \%) 12$ arteries had mild stenosis $(<50 \%)$; nine, moderate stenosis $(50-74 \%)$ and one, severe stenosis $(75-99 \%)$. Two arteries were occluded. In 10 patients $(26 \%)$, at least one hemodynarnically significant stenosis could be demonstrated. No fibromuscular dysplasia-induced stenosis, lesion in an accessory renal artery, or branch vessel disease was demonstrated. 
Twbie 2: Overall Quality of Rend Artery Depiction on Images Obtained with Three Three-dimensional, Phase-comtrat MR Anglographic Pulse Sequences in 38 Patients.

\begin{tabular}{|c|c|c|c|}
\hline Image Qualicy & $\begin{array}{c}\text { No Gating } \\
(n-37)\end{array}$ & $\begin{array}{l}\text { Systolic Garing } \\
(n=38)\end{array}$ & $\begin{array}{l}\text { Diastolic Gating } \\
(\mathrm{n}=37)\end{array}$ \\
\hline Good & $22(59)$ & $27(71)$ & $27(73)$ \\
\hline Moderate & $11(30)$ & $9(24)$ & $6(16)$ \\
\hline Poor & $4(11)$ & $2(5)$ & $4(11)$ \\
\hline
\end{tabular}

Note: Quality of depiction was determined by the two observers. The worst result of the two was used. Data are numbers of patients. Numbers in parentheses are percentages.

Tabile 2 provides information concerning the overall image quality in the three image sets. Superposition of the renal arteries by adjacent vascular structures, particularly the renal veins and inferior vena cava was seen in the majority of the images obtained withour gating; however, this affected image interpretation in only four patients. The images obtained with systolic gating showed vessel overlap in six patients . impairing optimal image assessment in three. The images obtained with diastolic gating showed overlap in nine patients, affecting interpretation in two.

The interobserver agreement for the detection of renal arteries was very good in all three three-dimensional MR angiographic image sets (1.00,0.96 and 0.94 in the images obtained without gating, with systolic gating, and with diastolic gating, respectively). All accessory renal arteries $(n=13)$, whenever present, were included in the $M R$ imaging volume interest on images obtained with all three techniques. Of 87 renal arteries $82(94 \%)$ were seen by both observers on the images obtained without gating; $83(95 \%)$ were seen by both observers on images obtained with systolic gating, and $84(96 \%)$ were seen by one observer and $83(95 \%)$ by the other on image obtained with diastolic gating. Table 3 lists the number of overlooked renal arteries in the three series.

Table 3: Number of Renal Arteries Overlooked by Two Observers.

$\begin{array}{cccc}\text { Observer } & \begin{array}{c}\text { No Gating } \\ (n=87)\end{array} & \begin{array}{c}\text { Systolic Gating } \\ (n=89)\end{array} & \begin{array}{c}\text { Diastollc Gating } \\ (n=87)\end{array} \\ 1 & 5(6) & 4(4) & 3(3) \\ 2 & 5(6) & 4(4) & 4(4)\end{array}$

Note: Numbers in par entheses are percentiges.

Images with a poor overall image quality were excluded from further evaluation. The depicted vessel segments, the length of the artery depicted and the presence of renovascular disease could be assessed on images obtained in 33 patients without gating, on images obtained in 36 patients with systolic gating, and on images obtained in 33 patients with diastolic gating.

The results concerning separate vessel segment depiction are summarized in table 4 . Depiction of all proximal arterial segments was considered to be good in 32 patients on 
images obtained with cardiac gating (systolic and diastolic), but in only 13 patients on images abtained without gating ( $p<.0001$. Fisher's exact test). Likewise, the visualisation of the distal renal artery segment was noted as good on images obtained with diastolic gating in 11 patients, but on none of the images obtained with systolic gating or without gating $(\mathrm{p}<.0001$, Fisher's exact test).

Table 4: Depiction of Separate Vessel Segments of the Renal Arteries at Three Three-dimensional, Phase-contrast MR Angiographic Pulse Sequences according to Consensus of the Two Obseivers.

$$
\text { No Gating }(n=33)
$$

\section{Depiction}

\section{Good}

Moderate

Poor

\section{Proximal Middle Distal}

Segment Segment Segment

\section{Systolic Gating $(n=36)$}

Proximal Middle Pistal
Segment Segment Segment Segment Segment Segment

\section{Dastolic Gating $(n=33)$}

Proximal. Midde. Discal

Note: Data are numbers of patients

* Statistically significant according to Fisher exact test results( $p<.0001)$.

With exclusion of the images with poor overall image quality and the number of overlooked renal arteries (Table 2,3), the mean lengths of the renal artery depicted on the three separate three-dimensional, phase-contrast MR angiographic image sets were assessed by the $M R$ radiologist. On the images obtained without gating, the mean length of the arteries depicted $(n=74)$ was $3.4 \mathrm{~cm}$ (range, 0.3-7.0 cm), whereas the length of the arteries depicted on the images obtained with systolic gating $(n=81)$ was $3.5 \mathrm{~cm}$ (range, $0.2-6.8 \mathrm{~cm}$ ). On the images obtained with diastolic gating, the mean length of the arteries depicted $(n=76)$ was $4.6 \mathrm{~cm}$ (range, $1.7-8.2 \mathrm{~cm})$. These differences between the images obtained with diastolic gating and the images obtained with the other two sequences were statistically significant $(P<.0001$, paired t-test).

Results for the grading of nenowascular disease by both observers are summarized in Table 5 .

Table 5: Grading of Renovascular Disease with Three-dimensional Phase-contrast MR Angiography versus Radiographic Angiography in 66 Arteries.

\begin{tabular}{|c|c|c|c|c|c|c|}
\hline MR Angiogreplic grading & Nol & ating & Systoli & Gating & Diasto & ic gating \\
\hline relative oo conventional & $M R$ & Vascular & $M \mid \mathbb{R}$ & Vascular & $M R$ & Voscular \\
\hline angiographic grading & Radiologist & Radiologist & Radiologist & Radiologist & Radiologist & Radiologist \\
\hline Underestimation & 3 & 5 & 1 & 2 & 1 & 3 \\
\hline Concurrence & 58 & 56 & 54 & 57 & 62 & 61 \\
\hline Overestimation & 5 & 5 & 11 & 7 & 3 & 2 \\
\hline
\end{tabular}

Note: Only the arteries seen by both the MR radiologist and the wascular radiologist arg included 
Only the arteries that were seen by both observers in all three sequences were included. With findings of radiographic angiography as the standard of reference, the difference between overestimation by the $M R$ radiologist with three-dimensional, phase-contrast MR angiography performed with systolic gating and the overestimation with MR angiography performed witholt gating $(\mathrm{p}=0.030, \mathrm{McNemar}$ test $)$ or with diastolic gating $(\mathrm{p}=.008$, MeNemar test) was statistically significant. Although the trend to overestimate renovascular disease with systolic gating is also seen in the results of the vascular radiologist, the differences between pulse sequences were not statistically significant.

The interobserver agreement ( $K$ value) concerning the detection of renovascular disease (normal versus abnormal) by using the no gating, systolic gating, and diastolic gating was $.62,82$, and .86 respectively. The image interpretations of the MR radiologist were used to calculate the validity of each three-dimensional, phase-contrast MR angiographic image set concerning the presence of renowascular disease.

Table 6: Findings of Renal Artery Stenosis ( $50 \%)$.

\begin{tabular}{|c|c|c|c|}
\hline Results & $\begin{array}{c}\text { No Gating } \\
(n=33)\end{array}$ & $\begin{array}{c}\text { Systolic Gating } \\
(n=36)\end{array}$ & $\begin{array}{c}\text { Diastolic Gating } \\
(n=33)\end{array}$ \\
\hline \multicolumn{4}{|l|}{ Findings } \\
\hline Trueppositive & 10 & 14 & 11 \\
\hline False-negative & 3 & 1 & 1 \\
\hline False-positive: & 0 & 1 & 0 \\
\hline True-negative & 20 & 20 & 21 \\
\hline \multicolumn{4}{|l|}{ Statistics } \\
\hline Sensitivity $(\%)$ & 77 & 93 & 92 \\
\hline Specificity $(\%)$ & 100 & 95 & 100 \\
\hline
\end{tabular}

Table 6 summarizes the results of the three-dimensional MR angiographic pulse sequences concerning the detection of renovascular stenosis $(>0 \%)$. Findings of radiographic angiography were used as the standard of reference. In three patients, a stenotic lesion (stenosis of $<50 \%$ ) seen on radiographic angiography was not seen (false-negative finding) on images obtained without gating; in one patient, a stenotic lesion (stenosis of $<50 \%$ ) was not visible on images obtained with systolic or diastolic gating.

Retrospectively, these lesions remained non-visible. The overall sensitivity of the threedimensional, phase-contrast MR angiographic images obtained without gating for the diagnosis of renal artery disease (stenosis $>0 \%$ ) was $77 \%$, with a specificity of $100 \%$. The images obtained with systolic gating had an overall sensitivity of $93 \%$ (specificity, $95 \%$ ). With the images obtained with diastolic gating, overall sensitivity was $92 \%$ (specificity, $100 \%$ ).

The sensitivity of all three three-dimensional, phase-contrast MR angiographic images in the diagnosis of a haemodynamically significant stenosis (> 50\%) was $100 \%$, with a 
specificity of $96 \%$ (26 of 27 patients; no gating) to $82 \%$ (23 of 28 patients; systolic gating) to $96 \%$ (26 of 27 patients; diastolic gating).

\section{Discussion}

The results of this prospective study confirm the value of MR angiography of the renal arteries as a non-invasive screening modality in patients with clinically suspected renovascular hypertension $(2,8,34-38)$. We obtained diagnostic three-dimensional phase-contrast $M R$ angiograms of the renal arteries with highly accurate interpretation results in $95 \%$ of the patients. There was good interobserver correlation, and it was possible to reach a sensitivity and specifficity of $93 \%$ and $95 \%$, respectively, for diagnosing renal artery stenosis (>0\%) on images obtained with systolic gating and of $100 \%$ and $96 \%$ for dliagnosing hemodynamically significant stenosis $(>50 \%)$ on images obtained without gating or diastolic gating, respectively. Cardiac gating improved the image quality in some patients at the cost of a longer scan time but did not improve the test validity in the diagnosis of haemodynamically significant stenoses.

We have used a three-dimensional, phase-contrast MR angiographic technique, which combines the good spatial resolution and signal-to-noise ratio $(\mathrm{S} / \mathrm{N})$ of the three-dimensional acquisition and optimal background suppression of the phase contrast pulse sequence. This technique allows inspection of the vessels from any projection and overcomes the major drawback of two- and three-dimensional, TOF MR angiography: reduced sensitivity to in-plane flow because of saturation. This reduced sensitivity to in-plane flow may be particularly important because the renal arteries tend to run in the transverse plane. The three-dimensional "phase-contrast $M \mathbb{R}$ angiographic technique, on the other hand, is much more time-consuming and more sensitive to motion (respiration) than are two- and three-dimensional, TOF and two-dimensional, phase-contrast MR angiography.

Furthermore, phase-contrast $M R$ angiography has an increased sensitivity to signal loss from intravoxel spin-phase dispersion, which is due to disturbed or turbulent flow. This may lead to overestimation of renovascular disease and can pose problems, particularly in the assessment of the wessel origins. In addition, the pulsatility of blood flow may cause artefacts (ghosting) in MR anglography (in both phase-contrast and TOF) that can lead to false-positive image interpretations concerning the presence of renovascular stenosis. Cardiac gating may suppress these artefacts, as well as blurring, because of the movement of the vessel during the cardiac cycle (39-45). To investigate the usefulness of cardiac gating in three-dimensional, phase-contrast MR angiography of the renal arteries, we designed a prospective study to compare three-dimensional, phase-contrast $M R$ angiography performed with systolic gating, with diastolic gating, and without gating with radiographic angiography.

The overall image quality of the three image sets did not show a statistically significant difference, although cardiac gating improved the overall image quality in some patients (Table 2, Fig 2). In the small number of patients with images of poor overall quality, severe arterial disease in both the aorta and the renal arteries was proved at radiographic angiography. These poor results are probably related to signal intensity loss caused by turbulent andfor high-velocity flow. 


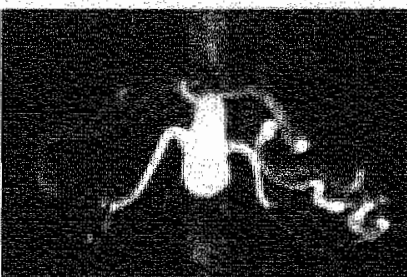

a

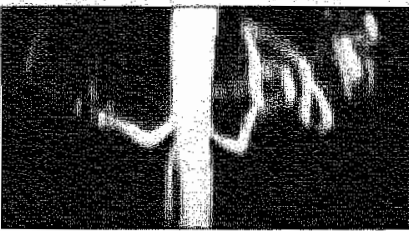

d

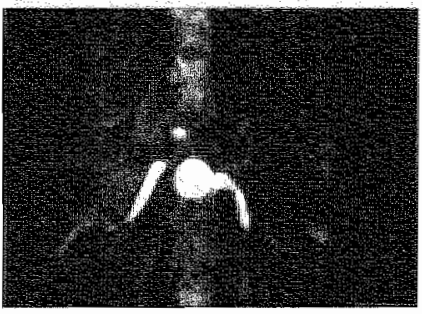

g

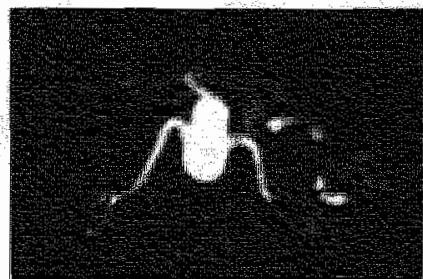

$b$

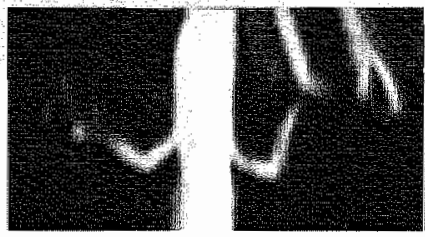

e

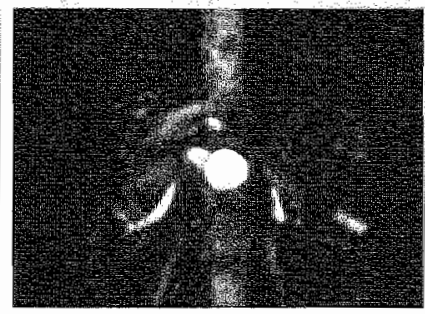

h

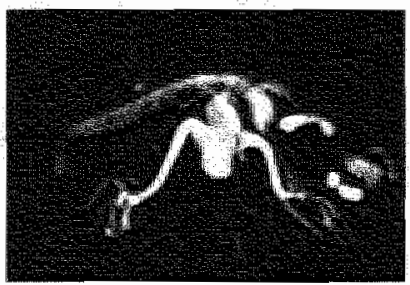

$c$

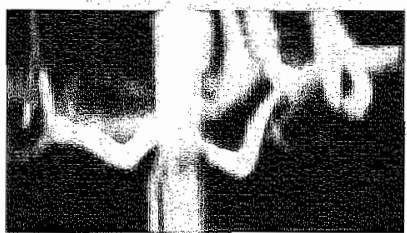

f

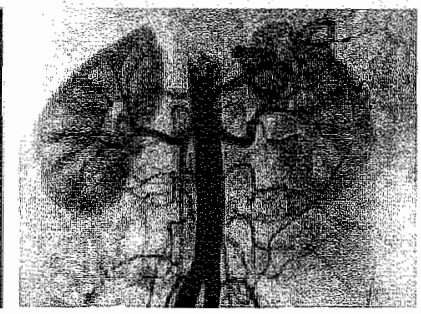

i

Figure 2. (a-f) Maximum intensity projections in transwerse and coronal planes of three separate threedimensional, phase-contrast MR angiographic pulse sequences ( $\mathrm{T} 1$-weighted gradient echo, 27.0/8.5, 20 flip angle) in a 48-year-old male patient. (a,d) Three-dimensional, phase-contrast MR angiograms obtained without cardiac gating show good signal intensity in the distal aorta and superposition of adjacent vessels (due to a higher number of sections). (b,e) Three-dimensional, phase-contrast MR angiograms obtained with systolic gating show excellent sigmal intensity in the distal ao ta, no superposition, and moderate contrast in the distal segment of the renal arceries. ( $c, 0$ Three-dimensional, phase-contrast MR angiograms with dlastolic gating show poor signal intensity in the distal aorta, no superposition, and good contrast in the distal segment of renal arteries. $(\mathrm{g}, \mathrm{h})$ Original cross-sectional images; they are essential for optimal assessment of the renal arteries. (i) Radiographic angiogram shows no renovascular disease. Because of the non-isotropic voxel size, the MIP image quality in the transverse plane is superior to the image quality in the coronal plane.

Superposition from overlapping vessels posed no statistically significant problem in this study. On images obtained with diastolic gating, as opposed to images obtained with the other two sequences, areas of signal intensity representative of the adjacent venous structures were present to some extent, because of the lower velocity-encoding values used; however, this affected image interpretation in only a limited number of patients. 


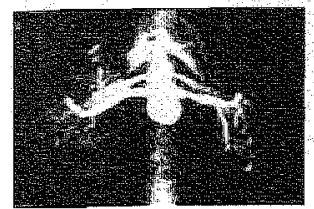

a

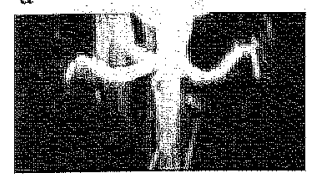

$\mathrm{e}$

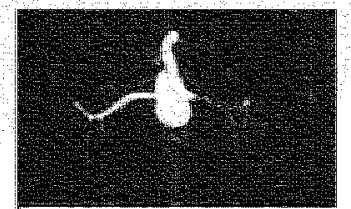

b

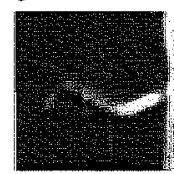

f

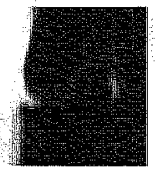

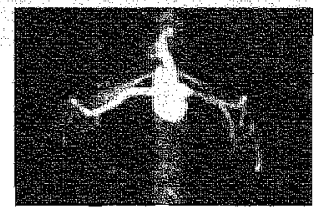

c

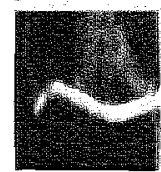

$\mathrm{g}$

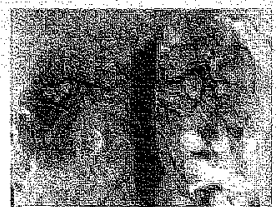

d.
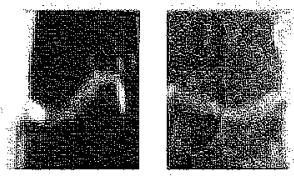

h.

Figure 3. Maximum intensity projections in transverse (a-c) and coronal (e-g) plane of three separate three-dimensional, phase-contrast MR angiographic pulse sequences (T1-weighted gradient echo, 27.0/8.5, $20^{\circ}$ flip angle) in a 65 -year-old male patient. (a,e) Three-dimensional. phase-contrast MR angiograns obtained without gating show a mormal right renal artery and minimal reduction of the vessel diameter (stenosis of $<50 \%$ grade 1 ) on the left side.. ( $b, n$ Three-dimensional, phase-contrast MR angiograms obtained with systolic gating show a grade I lesion near the orifice of the right renal artery and a grade 2 lesion (stenosis of $50-74 \%$ ) on the left side. $(c, g)$ Three-dimensional, phase-contrast MR angiogramis obtained with diastolic gating show a grade 1 lesion on both sides. (d,h) Radiographic angiograms show hemodynamically insignificant (stenosis of $<50 \%$ ) renovascular disease on both sides, which confirms the results obtained with diastolic gating.

Because the original cross-sectional images were particularly helpful and essential for optimall assessment of the renal arteries, interpretation was always based on both the MIPs and these transverse images (Fig. 2). Additional MIP images in planes other than the coronal, sagittal and transverse planes and/or image post processing might have been helpful but were not used in this study. A minority of the accessory renal arteries, although inside the imaging volume of interest, were not seen on the images obtained without gating or on the images obtained with cardiac gating (Table 3). This is probably due to the small diameter of these vessels. Nondepiction of these vessels poses a diagnostic dilemma, although the potential influence of stenoses in small accessory renal arteries on blood pressure is not completely understood.

Cardiac gating improved depiction of the proximal renal artery segment (Table 4), which is especially important because a large majority of the atherosclerotic lesions typically involve the proximal part of the vessel (46). The assessment of the distal renal artery segment with images obtained diastolic gating was significantly $(P<.0001)$ better (as was the mean length depicted significantly $[\mathrm{p}<.0001]$ longer) than it was with images obtained with either of the other techniques (Table 4). This was presumably due to the lower flow-encoded velocity in combination with the slower and less pulsatile flow during the gating period. The resolution was inadequate to evaluate the intrarenal vessels.

Discrepancies between $M R$ angiography and radiographic angiography in grading the severity of stenosis, as have been mentioned by others $(2,9,10,12)$, are caused by the presence of turbulent flow in the stenosis and the poststenotic vessel segment, which results in signal intensity loss on MR angiograms. Recent publications have shown that this signal intensity loss increases with increasing (systolic) flow velocity $(19,20)$, which results 


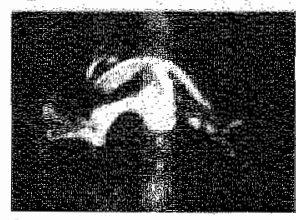

醉

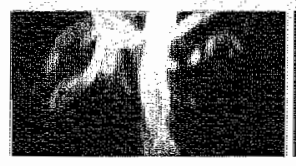

6

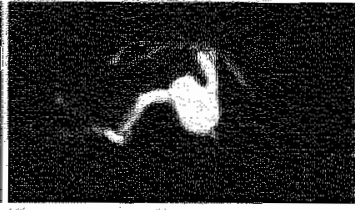

b:

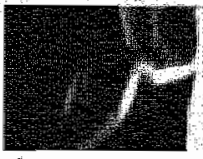

f

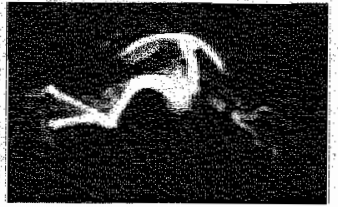

int:

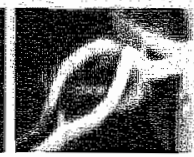

g

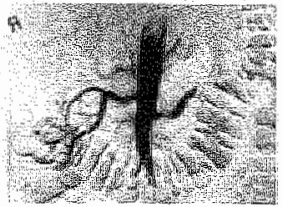

d
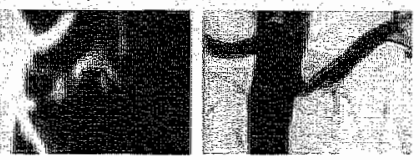

h

Figure 4. Maximum intensity piojections in transverse (a-c) and coronal (e-g) plane of three separate three-dmensional, phase-contrast MR angiographic pulse sequences (T1-weighted gradhent echo, $27.0 / 8.5$. $20^{\circ} \mathrm{flip}$ angle, trarsverse plane) ín a 49-year-old imale patient. (a,e) Three-dimensional, phase-contrast MR anglograms obtained without gating show superposition of adjacent vessels and mo wascular disease of the right renal artery. The left renal artery has two stenotic lesions (stenosis of 50-74\%). (b,f) Three-dimensional, phas -contrast MR angiograms obtained with systolic gating show no superpositjon of adjacent vessels and no disease on the right side. Poor image concrast of the left renal artery, caused by a severe stenösis (stenosis of $75-99 \%$ ) near the orifice. (c,g) Three-dimensional, phase-contrast MR angiograms obtained with diastolic gating show no superposition. a normal right renal artery, and two stenotic lesions on the left side $(50-74 \%)$. (d,h) Radiographic angiograms confirm findings in $c$ and $g$ off two stenotic lesions on the left side (arirow).

in a considerable overestimation of arterial stenoses. Data acquisition during diastole with slower flow velocities may reduce this signal loss and is considered more capable to accurately quantify the degree of vascular disease. However, in our study, neither flow compensation nor cardiac gating or the use of a very short echo time (8 msec) was sufficient to entirely compensate for this signal intensity loss, partly because of the relatively large voxel size. Therefore, overestimation of stenotic lesions remained a problem in this study (Table 5).

The need to predict the optimum velocity-encoding value in advance and the limited range around this optimum are additional problems of phase-contrast MR angiography of the renal arteries (44), because the flow rate in a stenotic artery is unpredictable and may be very different from the flow rate in the contralateral artery.

On the basis of the results of the MR radiologist only, there was a statistically significant difference between overestimation of renovascular disease on the images obtained with systolic gating and the overestimation with MR angiography performed without gating or with diastolic gating. Although the relatively small number of diseased arteries in this study does not allow any firm conclusion, three-dimensional, phase-contrast $M R$ angiography performed with diastolic gating does seem betrer for assessment of the severity of renovascular disease ( $\mathrm{Fig}, 3,4$ ). Assessment of the functional influence of stenoses with selective MR phase-contrast flow quantification in the renal arteries, which will be more feasible in the near future, will probably reduce the importance of visual grading of renal artery disease. 
The sensitivity of the detection of stenosis $(>0 \%)$ was high with images obtained with systolic $(93 \%)$ or diastolic $(92 \%)$ gating; however, for the images obtained whout gating: the overall sensitivity was only $77 \%$ (Table 6). These numbers yleld negative predictive values of $95 \%$ for images obtained with either systolic or diastolic gating and $78 \%$ for images obtained without gating. The differences are probably related to the poorer image quality, especially in the proximal vessel segment. All patients with images of poor overall quality were excluded from this ewaluation because we thought that these images would not justify any interpretacion of renovascular disease. In a clinical setting, radiographic angiography will be indicated in this group of patients. Postulating that every examination with poor overall image quality indicates (by definition) severe wascular disease at radiographic angiography and including these images in a retrospective statistical analysis would have improved the results of three-dimensional, phase-contrast $M \mathbb{R}$ angiography in general. On the other hand, we would have reduced the differences in sensitivity and specificity between the sequences performed without gating and those performed with gating.

The overall sensitivity for detection of significant stenoses ( $250 \%$ stenosis) in our study was $100 \%$ in all three phase-contrast. MR angiographic sequences, with a specificity of $96 \%$ (no gating) to $82 \%$ (diastolic gating). These sensitivity and specificity calculations were based on the independent interpretations of the MR radiologist only. If we had used the combined interpretations of both radiclogists, or of the vascular radiologist alone, the results, in terms of sensitivity and specificity, would have slightly decreased, in spite of the good interobserver agreement.

The results of this study indicate that three-dimensional, phase-contrast MR angiography is a highly sensitive technique for the detection of renowascular disease and, therefore, is suitable as a non-invasive screening modality. In a clinical setting we would have refrained correctly from more then $50 \%$ of the radiographic angiographic examinations of the patients in this study group on basis of their MR angiographic results alone.

Cardiac gating improved the results concerning (overall) image quality, sensitivity for diagnosing mild stenotic lesions $(<50 \%)$ and grading of vascular disease, at the cost of a substantially prolonged examination time. Because these improvements seem to be of relatively limited clinical impontance, we decided to refrain from cardiac synchronisation on a routine basis in our three-dimensional, phase-contrast $M \mathbb{R}$ anglographic screening procedure in patients suspected to have renovascular hypertension. Cardiac gating. particularly diastolic gating, may be helpful in some patients only. 


\section{References}

1. Hillmari B]. Imaging adwances in the diagnosis of renovascular fypertension. AJR 1989; 153:5-14.

2. Kim D. Edelman RR, Kent KC. Porter DH, Skillman Jj. Abdominal aorta and renal stenosis: evaluation with MR Aingiography, Radiology $1990,174727-731$.

3. Postma CT, van Oljen AHAM, Barentsz JO, de Boo T, Hoefnagels WH, Corstens FH. Thien T. The value of tests predicting renovascular hypertension in patients with renal artery stenosis treated by angioplasty. Arch htern Med 1991, 151:1511-1535

4. Working Group on Renowascular Hypertension. Detection, svaluation and treatment of renovascular Hypertension; Final report. Arch Intern Med 1987; 147: 820-829.

5. Klinge J. Mali WPTM, Puijlaert CBAJ, Geyskens GG, Becking WB, Feldberg MAM. Percutaneous transluminal renal angioplasty: hitial and long-term results. Radiology $1989 ; 171: 507-506$.

6. Losinno F, Zuccală A, Busato F Zucchelli P. Renal artery angioplasty for renovascular hypertension and preserwation of renal function: Long-term angiographic and clinical follow-up. AJR 199.4: 162:853-857.

7. Soulen MC. Renal angloplasty: Underutilized or overvalued? Radiology 1994; 193:19-21.

8. Yucel KE. Magnetic resonance angiography of the lower extremity and renal arteries. Sernin. Uitrasound CT MR 1992; 13:291-302.

9. Desberg A, Paushter D, Lammert G, Hale JC, Troy RB, Nowik AC, Nally JV jr. Welterreden AM. Renal artery stenosis: Evaluation with color Doppler flow imaging. Radiology 1990; 177:749; 753 .

10. Taylor D, Kettler M, Moneta G, Kohler TR, Kazmers A, Beach KW. Strandness DE jr. Duplex ultrasound scanning in diagnosis of renal artery stenosis: a prospective evaluation. Journal of Vascular Surgery 1988; 7:363-369.

11. Berland $L$, Koslin D, Routh W, Keller F. Renal artery stenosis: prospective evaluation of diagnosis with color duplex ultrasound compared with angiography. Radiology 1990; 174:421-423.

12. Schwerk $W$. Restrepo $G_{\text {s }}$ Stellwaag $M$, Klose $K_{n}$ Schade-Brittinger $C$. Renal artery stenosis: Grading with image-directed doppler ultrasound evaluation of renal resistive index. Radiology 1994; 190:785-790.

13. Mann S, Pickering T, Sos T, Uzzo RG, Sarkar S Friend K, Rackson ME, Laragh JH. Captoprill renography in diagnosis of renal artery stenosis: Accuracy and limitations. The American Journal of Medicine; 90:3040 .

14. Fommei E, Mezzasalma L, Ghione S, Volterrani D, Oei Y, Hilson A, Carrieri M. European captopril radionuclide test multicenter study: Preliminary resules. American Journall of Hypertension 1991: 4:690. 697 .

15. Shamlou KK, Drane WE, Hawkins IF, Fennell RS. Captopril renography and hyper-tensive renal transplantation patient: A predictive test of ther:apeutic outcome. Radialogy 1994; 190:153-159.

16. Schreil $G$, van Kroonenburgh $M$. Heidendal $G K$, van der Pol HA, de Leeuw PW. Interpretation of captopril menography by nuclear medicine physicians. Journal of Nuclear Medicine J Nud Med 1995; 36(12):2192-2195.

17. Mann SJ, Pickering TG. Detection af renovascular hypertension: State of the art: 1992.Annals of Internal Medicine 1992; $117: 845-853$.

18. Dumoulin $C_{L}$, Yucel KE, Wock $P$, Souza SP, Terrier $F$, Steinberg FL, Wegmüller H. Two- and threedimensional phase contrast MR angiography of the abdomen. Journal of Computer Assisted Tomography $1990 ; 14: 779.784$

19. Edelman RR. MR Anglography: Present and furture, AJR 1993; 161:1-11.

20. Vock $P$, Terrier $F$, Wegmüller $H$, Mahler F, Geptsch P. Sousa SP, Dumoulin CL. Magnetic resonanice angiography of abdominal vessels: early experience using the three-dimensional phase contrast technique. Br ) Radiol 1991: 64:110-16. 
21. Grist TM. Magnetic resonance angiography of renal artery stenosis. American Journal of Kidney Disease 1994: $24: 700-712$

22. Debatin JF, Spritzer CE, Grist TM. Beam C, Swetkey LP, Newman GE, Sostman HD. Imaging of the renall arteries: Value of MR Angiography. AJR 1991: 157:981-990.

23. Loubeyre P, Revel D, Garcia P, Delignette A, Camet E. Chirossel P, Genin G. Amial M. Sereening patients. for renal artery stenosis: Value of three-dimensional Time-of-Flight MR Angiography. AJR 1994; 162:847852.

24. Hertz SM, Holland A, Baum A, Haskal Z] "Carpenter JP. Evalluation of renal artery stemosis by magnetic resonance angiography. The Americam Journal of surgery 1994: 168; 40-143.

25. Yucel KE, Kaufnan JA, Prince M. Bazari H, Fang LS, Waltman AC. Time of flight renal MR anglography: Utility in patients with renal insufficiency. Magnetic Resonance Imaging 1993; 11:925-930.

26. Servois V. Laissy JP, Feger C, Sibert A, Delahousse M, Balleynaud S, Mery JP Menu Y. Two-dimensional time-of-flight magnetic resonance anglography of renal arteries without maximum intensity projections: A. prospective comparison with angiography in 21 patients screened for renovascular hypertension. Cardio Vascular and Interventional Radiology 1994: 17:138-142.

27. Arlart IP, Guhl L, Hausmann R. Evaluation of 2D- and 3D-time-of-flight MRA in renal artery stenosis. Fortschritte Röntgenstr. 1991: 157:59-64.

28. Whadyslaw GM. Magnetic resonance angiography of renal arteries. Urologic Clinics of North America. 1994:21:201-214.

29. Vogl T], Hoffmann Y', Mühler A, Felix. R. Contrast-enhanced magnetic resonance angiography. Radiologe: 1994; 34:423-429.

30. Prince MR, Narasimham DI, Stanley JC, Chenevert TL, Williams DM, Marx MV, Cho KJ. Gadoliniumenhanced magnetic resonance angiography of the abdominal aortic aneurysms. Journal of Vascular Surgery 1995; 21:656-669.

31. Carriero A, Magarelli N, D'Ettorre $L$, Severini $S$, Tartaro A, Bonomo $L$. Renal arteries: angiography with TOF 3D magnetic resonance with and without contrast media (Gd-DTPA). Radiol. Med. Torino 1994" 87:254-259.

32. Prince MR, Yucel KE, Kaufman JA, Harrisam DC, Geller SC. Dynamic gadolinium-enhanced threedimensional abdominal MR angiography. JMRI 1993; 3:877-881.

33. Cohen JA. A coefficient of agreement for nominal scales. Education and Psychological Measurement $1960 ; 20: 37 \times 46$.

34. Edellman RR. Wentz KU, Mattle $H$, Zhao B, Lin C. Kim D. Laub G. Projection arteriography and venography: initial clinical results with MR. Radiology 1989; 172:351-357.

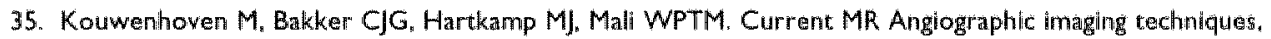
A survey. In: Lanzen P. Rosch J, ed. Vascular Diagnostics. 1st ed. Heldelberg. Germany, Pa: SpringerVerlag.

36. Keller PJ, Drayer BP, Fram EK, Williams KD, Dumoulin CL, Souza SP. MR Anglography with twodimensional acquisition and three dimensional display; Work in progress. Radiology 1989; 173:527.532.

37. Edelman RR, Mattle HP. Atkinson DJ. Hoogewoud HM. MR Angiography. AJR 1990"154: 937.946.

38. Arlart IP. Guhl L. Edelman RR. Magnetic Resonance Angiography of the abdominal aorta. Cardiovasc Intervent Radiol 1992; 15:43-50.

39. De Graaf RG, Groen JP. MR. Angiography with pulsatile flow. Magn Res Imaging 1992; 10:25-34.

40. Selby $K$, Saloner D. Anderson CM. MR Imaging of vessels origins using cardiac-phase-specific data acquisition (abstr). In: Book of abstracts: Society of Magnetic Resonance in Medicine 1993. Berkeley, Carlif: Society of Magnetic Resonance in Medicine, 1993:378 
41. Saloneir D, Selby K, Anderson CM. MRA studies of arterial stenosis: Improwements by diastolic acquitition. Magnetic Resonance in Medicine 1994; 31.196-203.

42. Evans AJ Blinder RA, Herflcens R), Herflkens R. Sprizzer CE, Kullhe DO. Fram EK, Hedlund LW. Effects of turbulence on signal intensty in gratient echo images. Inwest Radiol 1988; 23:512-518.

43. Podolak M), Hedind LW. Evaris Al, Herntens R.j: Evaluation of flow through simulated vascular stenoses whth gradient echo Magnetic Resonance Hmaging. Inwest Radiol 1989; 24:184-189.

44. Meyers SP, Talagal SL, Totverman S, Azodo MW. Kwok E, Shapiro L Shapiro R, Pabico RC. Applegate GR. Ewalluation of renal arteries in kidney donors: Value of three-dimensional phase-contrast MR anglography with maximum iritensity projection or surface rendering. A.R 1994; 164:117-121.

45. Kouwenhoven M, Wasser M, de Grat RG, Groen JP. Cardiac-gated phase-contrast angiography (abstr). In: Book of abstracts: Society of Magmetic Resonance in Medicine 1994. Berkeley. Carlif: Society of Magnetic Resonance in Medicine, 1994:118.

46. Pohl MA, Nowik AC. Natural history of atherosclerotic and fibrous renal artery pathology: Clinical complications. Am. J. Kidney Dis. 1985: 5:A120-A130. 


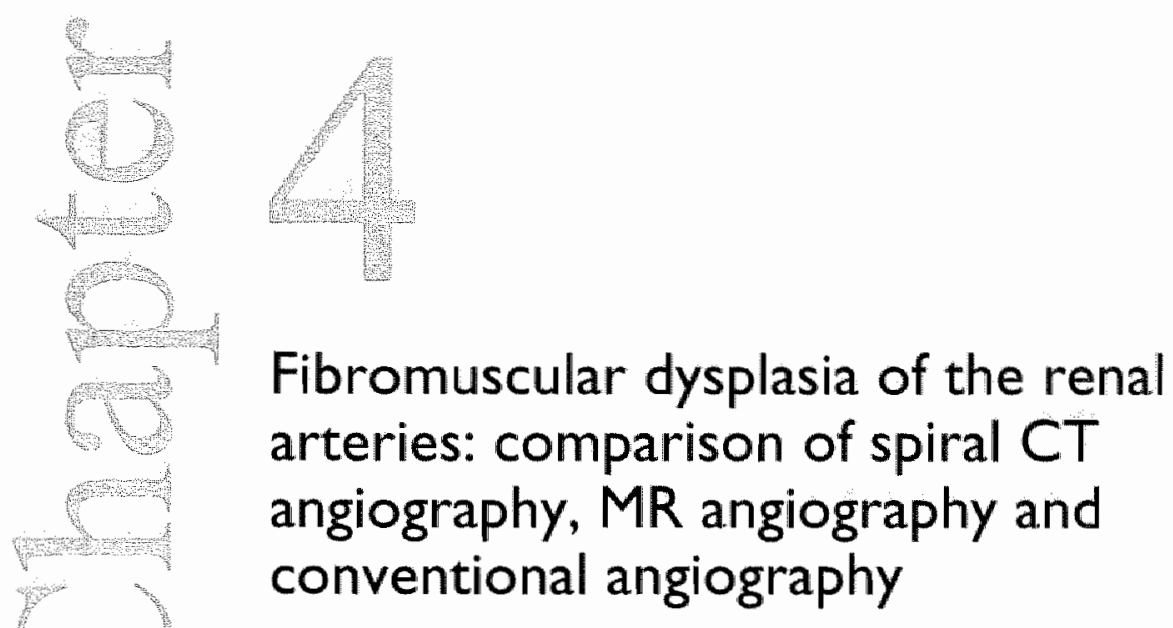

de Haan MW, Kessels AGH, Vasbinder GBC, Beek FJA, Korst MBJM, Leiner $T$, Maki JH, van Zwam WH, de Leeuw PW, van Engelshoven JMA.

Submitted for publication 


\section{Abstract}

Objective: To test the feasibility of MR angiography (MRA) and CT angiography (CTA) techniques in the assesment of renal artery fibromuscular dysplasia with the objective to identify possible sources of error in depiction of this renall artery disorder.

Materials and methods: Image data of the phase-contrast MRA (PC-MRA), gadolinium enhanced MRA (CEMRA) and CTA examinations of 29 consecutive patients with angiographically proven renal artery fibromuscular dysplasia were analyzed by two observers. Detection rate, location and extent of fibrodysplastic lesions $(n=40)$ were recorded, supplemented with a lesion-to-lesion analysis by comparing the PC-MRA, CEMRA and CTA images with intra-arterial digital subtraction anglography (ia-DSA).

Results: A total number of 26 PC.MRA's, 27 CE-MRA's, and 29 CTA's were available for evaluation. In terms of detection rate CTA (81.6\%) performed significantly better than CE-MRA (42.9\%), and PC-MRA (26.5\%). The detection rate of renal artery abnormalities decireased with the increase of its distance from the aortic ostium in all three imaging techniques. Likewise, the extent of the fibromuscular dysplastic lesions influenced the detection rate considerably in all three imaging modalities: mild manifestations were seen in only 10\%, 29\% and $60 \%$ of cases with respectively PC-MRA, CE-MRA and CTA, whereas sewere lesions were detected in respectively 60,91 and $100 \%$.

Conclusion: The present study shows that neither PC-MRA, neitherr CE-MRA, nor CTA can relliably diagnose renal artery fibromuscular dysplasia. 


\section{Introduction}

Systemic hypertension is an important risk factor for both myocardial infarction and cerebral stroke. Identification of an underlying treatable cause of hypertension poses a major challenge in the management of a hypertensive patient. Renovascular disease, albeit rare, is the most common cause of secondary hypertension with an estimated prevalence of $3.5 \%$ in the overall population with hypertension. Renal artery stenosis can be treated by means of percutaneous endovascular interventions such as balloon angioplasty and/or stent implantation, or surgical techniques in order to facilitate blood pressure control and preservation of the renal function. Seventy percent of the renal artery stenoses are atheromateous in origin (1), whereas the next most common cause is fibromuscular dysplasia. This noninflammatory dysplastic process is characterized by abnormalities in the fibromuscular lining of the renal artery. The classic angiographic presentation of the most common form of fibromuscular dysplasia, medial fibroplasia, is characterized by multiple aneurysms separated by focal narrowing: string-of-beads-sign, involving the mid and distal renal artery. These abnormalities are predominantly present in persons aged $25-50$ years and are more common in females. The excellent long-term results of percutaneous or surgical intervention of fibrodyspllastic lesions make early identification of these patients an important clinical challenge (2).

Conventional angiography still is considered the standard of reference in the diagnosis of renovascular pathology. More recently, dedicated CT and MR protocols were introduced for volumetric data acquisition with high contrast-enhancement of the renal vessels yilelding high sensitivities and specificities for the detection of main renal artery stenosis (3-6).

However, in most studies that reported sensitivities up to $100 \%$ for MRA and CTA to detect renal artery stenosis, either the prevalence of fibromuscular dysplasia was quite low or patients with fibromuscular dysplasia were excluded from the analysis. Some authors have indicated that the results of CTA and MRA to diagnose fibromuscular dlysplasia in the renal arteries is less favourable $(7,8)$, buc, with the exception of Bergri et al (9), no separate assessment of the test performance in this subgroup of patients is reported.

Recently published results of a prospective multicenter study (RADISH-study) concerning the validity of CE-MRA and CTA to diagnose renal artery stenosis in hypertensive patients show an overall poor performance of both tests with sensitivities ranging from $57 \%-67 \%$ for MRA and from $61 \%-69 \%$ for CTA. Specificity ranged from $77 \%-90 \%$ for MRA and from $89 \%-97 \%$ for CTA (10). A striking difference with other studies was the relatively thigh proportion in this series of patients with fibromuscular dysplasia: $38 \%$ of all patients with renal artery stenosis.

The purpose of the present study was to scrutinize the MRA and CTA data of all patients from the RADISH-study with renal fibromuscular dysplasia as detected on ia-DSA in order to identify possible sources of error in the depiction of this renal artery disorder that may have contributed to the overall poor test performances and to give suggestions for further improvement. 


\section{Materials and methods}

\section{Patients}

This study is part of the afore mentioned Dutch multicenter study (RADISH=study" "Renal Artery Diagnostic Imaging Study in Hypertension") in which the results of PC-MRA, CE-MRA and CTA of the renal arterles in patients suispected of renovascular hypertension were compared with the results of Ia-DSA as the standard of reference, in order to establish the validity of MRA and CTA to diagnose renal artery stenosis. Details about the RADISH-study are comprehensively described elsewhere (10, Appendix). In brief, over a 3-year period 402 hypertensive patients between 18 and 75 years of age and with a diastolic blood pressure of $\geq 95 \mathrm{~mm} \mathrm{Hg}$ were included in the study. These subjects were prospectively recruited from the outpatients' clinics of the Internal Medicine departments of three large teaching hospitals and three universicy hospitals in the Netherlands. In order to raise the pre-test probability of the presence of renal artery stenosis, patients had to exhibit at least one of the commonly accepted clinical clues for the presence of renal artery stenosis (10). All included patients were scheduled to have their MRA, CTA and ia-DSA examination within a three-month window.

Twenty-nine of the 402 patients $(7 \%$ ) proved to have fibromuscular dysplasia on ia-DSA as assessed in consensus by three vascular radiologists. These 29 patients were included in the present study. In the 29 patients studied, 57 main renal arteries and 11 supernumerary renal arteries ( 9 patients) were identified on ia-DSA; one renal artery was occluded. Intraarterial DSA showed unilateral fibromulscular dysplasia in 17 patients (58\%); bilateral fibromuscular dysplasia in 11 patients $(38 \%)$, and 1 patient had fibromuscular dysplasia in one renal artery and a hemodynamically significant atherosclerotic stenosis of $\geq 50 \%$ in the contralateral artery. Thus a total number of 40 fibromuscular dysplastic lesions in 29 patients were available for analysis.

The institutional review board of each participating hospital had approved the study protocol, including this subgroup analysis, and patients were required to sign an informed consent form prior to inclusion in the study.

\section{Imaging techniques}

Each participating hospital was equipped with state-of-the art MR scanners $(1.0$ or 1.5 Tasta), helical CT scanners (single or multiple detector-row systems), and DSA systems. Due to the variety of manufacturers and models of imaging equipment, each hospitall was allowed to use the scan protocol which was considered optimal for its setting. Also, the hospitals were allowed to change the scan protocols during the study when new insights emerged or in case upgrades on the machinery were installed. Information about manufacturers, scan protocols, and used contrast agents is shown in table 1. Intra-arterial DSA was performed by means of catherization of the suprarenal aorta through the right or left femoral artery by using a $4-\mathrm{Fr}^{*}$ or $5-\mathrm{Fr}$ pigtail or other non-selective catheter. Images were obtained in anteroposterior view. When visualization of the renal vasculature was considered inadequate, additional oblique projections and/or" selective renal angiograms were obtained. Intra-arterial DSA was the standard of reference. 


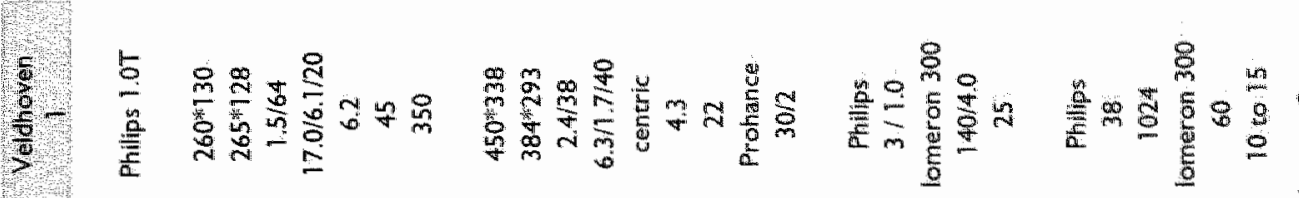

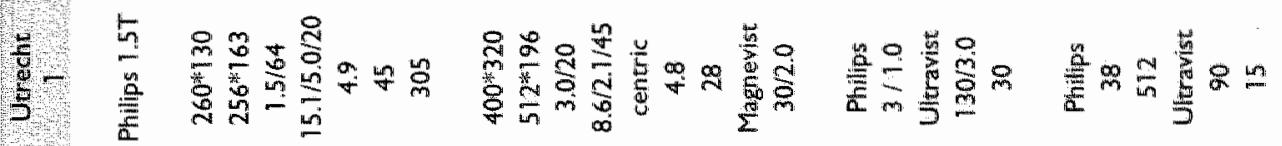

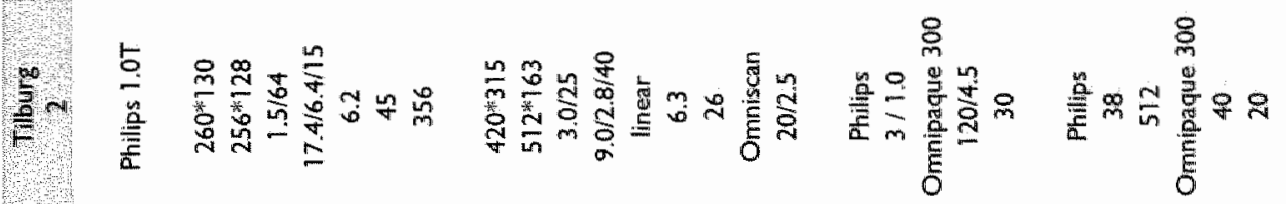

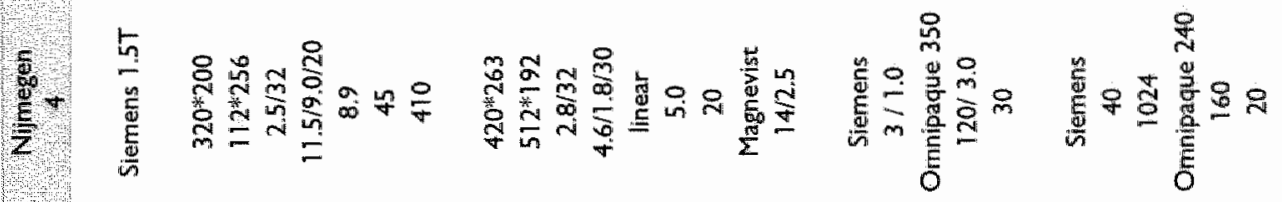

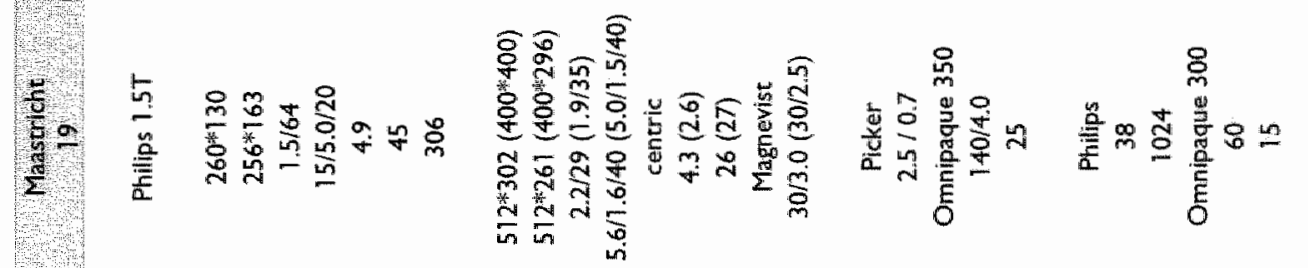

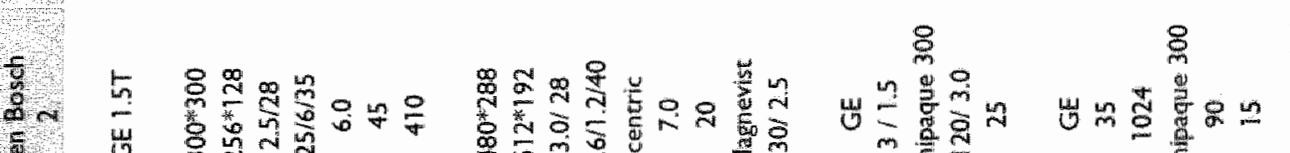
$z$ 


\section{mage evaluation}

As part of the RADISH-study, two, respectively three and three experienced observers retrospectively ewaluated the PC-MRA, CE-MRA and CTA image data. Assessment was performed independently and the observers were blinded for all other diagnostic data and clinical results. Digital image data of all MRA and CTA exams were read on a workstation (Easy Vision, release 4.2.1. Philips Medical Systems, Best. The Netherlands), which was equipped with all common post-processing facilities including maximum intensity projection, shaded surface display and multi planar reformatting. The observers were allowed to use any of these post-processing techniques additional to the source images.

Additionally, analysis of all PC-MRA, CE-MRA and CTA data of the patients with angiographically proven fibromuscular dysplasia was performed in consensus by two observers, using the same workstation and post-processing techniques. Both observers were informed about the purpose of the study and of the presence of fibromuscular dysplasia in one of the renal arteries but not of its location. The number of normal arteries and of arteries with evidence of dysplasia and/or significant stenotic disease was recorded. These interpretations were compared with the corresponding data of the RADISH-study. The location of the fibromuscular dysplastic lesions on la-DSA was expressed in centimeters from the aortic ostium. The extent of fibromuscular dysplasia was indicated on a three-point scale (severe, moderate, mild). Subsequently, a lesion-to-lesion analysis was performed in order to assess possible specific pitfalls in the depiction of fibromuscular dysplasia of the renal arteries. For this assessment two observers compared in consensus the PC-MRA, CE-MRA and CTA data with the corresponding ia-DSA images of all arteries with angliographically proved fibromuscular dysplasia. A standard form was used to collect all relevant data.

\section{Statistical analysis}

Since we selected only patients with fibromuscular dysplasia, no realistic account of the total number of the false-positive results of PC-MRA, CE-MRA and/or CTA could be derived. Therefore, apart from detection rate, no information on the test validity of any of the three tests could be obtained.

The influence of severity and location on the detection of fibromuscular dysplasia was assessed using the Chi-square test or, if appropriate, the Fisher exact test, after dichotomisation of the results.

\section{Results}

The clinical characteristics of the 29 patients with angiographically proven fibromuscular dysplasia are shown in Table 2.

Except for the distribution of gender, no statistically significant differences were found for the characteristics of the 29 subjects included in this analysis as compared to the total group of 402 patients included in the RADISH-study (10).

In 26 patients (90\%; 52 kidneys), all three imaging studies, i.e. PC-MRA, CE-MRA and CTA were performed. As a consequence of their claustrophobia two patients were not submitted to the MR examination; in one patient the MR examination was limited to only a CE-MRA for the same reason. Thus, a total number of 26 PC-MRA's, 27 CE-MRA's, and 29 CTA's were available for evaluation. Due to problems with digital data transfer with 
Table 2. Demographic and clinical characteristics of the 29 patients with anglographically proven fibromuscular dysplasia.

Male female

\begin{tabular}{|c|c|}
\hline $\mathrm{Age}-\mathrm{y}$ & median mean \pm SD (range) \\
\hline $\begin{array}{l}\text { Systolic blood pressure at } \\
\text { baselinet - mm/lg }\end{array}$ & mean 1 SD (range) \\
\hline $\begin{array}{l}\text { Diastolic blood pressure } \\
\text { at baselinet }-\mathrm{mm} H \mathrm{~g}\end{array}$ & mearl \pm SD (range) \\
\hline $\begin{array}{l}\text { Years with known } \\
\text { hypertension }\end{array}$ & mean $+\mathrm{SD}$ (range) \\
\hline Smoking habit & smokers - no. $(\%)$ \\
\hline
\end{tabular}

4.25

$53,50,9+92$

$183 \pm 17.7,(140-228)$

$111 \pm 11.4$

$6,3 \pm 8,4$

12

Note: * All patients were included on the basis of a diastolic blood pressure of $\geq 95 \mathrm{mmH}$. Blood pressures presented here were either measured at the time of inclusion or in the time period between inclusion and thospital admission for ia-DSA.

one of the participating hospitals however, the imaging studies of two patients could not be analysed. Both patients had mild unilateral fibromuscular dysplasia on ia-DSA.

All PC-MRA, CE-MRA, and CTA images were considered to be of enough of diagnostic quality by the eight independent observers of the RADISH-study. However, during subsequent analysis in the present study two PC-MRA and five CE-MRA studies were considered of non-diagnostic quality, including 2, respectively 7 kidneys with fibromuscular dysplasia. The performance of the three imaging tests in terms of their potential to detect fibromuscular lesions as executed within the framework of the RADISH-study and the present study are tabulated in table 3 .

Table 3: Number of detected and missed fibromuscular lesions with all thee imaging techniques by independent, blinded observers from the RADISH-study (Obs. 1-8) compared to the results of two observers in consensus with prior knowledge of the presence of fibromuscular dysplasia in the present study (Consensus).

\begin{tabular}{|c|c|c|c|c|c|c|c|c|c|c|c|}
\hline & \multicolumn{3}{|c|}{ PCMRA } & \multicolumn{4}{|c|}{ CEMRA } & \multicolumn{4}{|c|}{ CTA } \\
\hline & Obs & $\begin{array}{c}\text { Obs. } \\
2\end{array}$ & Consensus & Obs: & Obs. & $\begin{array}{c}\text { Obs. } \\
5\end{array}$ & Consensus & Obs: & Obs & $\begin{array}{c}\text { Obs } \\
8\end{array}$ & Consensus \\
\hline Detected & 7 & 5 & $9(26 \%)$ & 10 & 8 & 10 & $15(43 \%)$ & 17 & 110 & 16 & $31(82 \%)$ \\
\hline $\begin{array}{l}\text { Nor } \\
\text { detected } \\
\text { Nont } \\
\text { diagnostic }\end{array}$ & 29 & 31 & $\begin{array}{l}23 \\
2\end{array}$ & 27 & 29 & 27 & $\begin{array}{l}13 \\
7\end{array}$ & 23 & 30 & 24 & 7 \\
\hline Total & 36 & 36 & $34 *$ & 37 & 37 & 37 & $35^{\text {唡 }}$ & 40 & 40 & 40 & $38^{*}$ \\
\hline
\end{tabular}

Note: * Due to problems with digital data transfer wich one of the participating hospitals, the imaging studies of two patients were not available for this analysis. Both patients had mild unilateral fibromuscular dysplasia on ilar-DSA. 


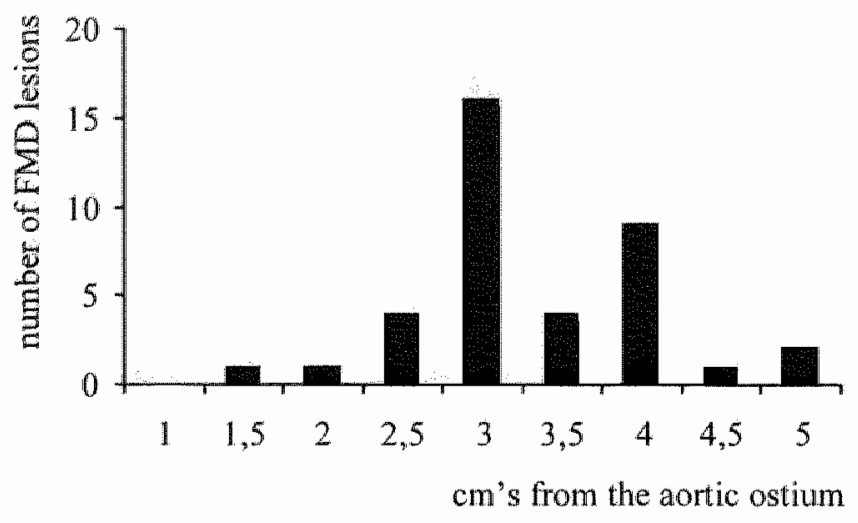

Figure 1: Distribution of distances of the fifbro-muscular dysplastic in the remal arceries in centimeters from the aortic astium.

The location of the fibromuscular dysplastic lesions on ia-DSA expressed in centimeters from the aortic ostium is shown in figure 1 .

In table 4 the relation between the extent and location of fibromuscular dysplasia and the number of detected lesions as obtained with all three imaging techniques are indicated.

Table 4: Extent and location of fibromuscular dysplasia in relation to the number of detected and missed fibromuscular dysplastic lesions obtained with all three imaging techniques by two observers in consensus with prior knowledge of the presence of fibromuscular dysplasia.

\begin{tabular}{|c|c|c|c|c|c|c|c|}
\hline & \multicolumn{3}{|c|}{ on tent IMD } & \multicolumn{3}{|c|}{$\begin{array}{l}\text { Distance of } \mathrm{TMD} \text { from the aroric } \\
\text { ostium on } 1 \mathrm{a} \text { DSA }\end{array}$} \\
\hline & & Mide & Moderate & Severe & $42,5 \mathrm{~cm}$ & $2.5-3 \mathrm{~cm}$ & $33 \mathrm{~cm}$ \\
\hline & Detected & 1 & 2 & 6 & 1 & 7 & 1 \\
\hline \multirow{3}{*}{$P C \times M R A$} & Not detected & 9 & $10(2)$ & 4 & $3(1)$ & 8 & $12(1)$ \\
\hline & pralue & \multicolumn{3}{|c|}{0.009} & & \multicolumn{2}{|c|}{0.05} \\
\hline & Detected & 4 & 1 & 10 & 2 & 8 & 5 \\
\hline \multirow[t]{3}{*}{ GIMAR } & Not detected & $3(3)$ & $9(4)$ & 1 & 3 & $5(2)$ & $5(5)$ \\
\hline & p vallue & \multicolumn{4}{|c|}{0.0001} & \multicolumn{2}{|c|}{0.5} \\
\hline & Detected & 6 & 13 & 12 & 4 & 16 & 11 \\
\hline eta & Not detected & 4 & 3 & 0 & 2 & 0 & 5 \\
\hline & p value & \multicolumn{3}{|c|}{0.07} & & \multicolumn{2}{|c|}{0.11} \\
\hline
\end{tabular}

Note: The presented p values are calculated afrer dichotomisation of the test results by combining the mild and moderate resultes, respectively the $\leq 2.5 \mathrm{~cm}$ and $2.5-3 \mathrm{~cm}$ results. Numbers in parentheses are not detrected llesions as a result of mon-diagmostic examinations. 
Severe fibromuscular dysplastic lesions on ia-DSA were seen on PC-MRA in only 6 cases $(60 \%)$, whereas $10(91 \%)$ respectively $12(100 \%)$ were noted with CE-MRA and CTA.

The lesion-to-lesion analysis demonstrated that the characteristic string-ot-beads sign. considered pathognomonic for (medial) fibromuscular dysplasia, could be seen on the CE-MRA and CTA images in $80 \%$, respectively $95 \%$ of cases, although in some vessels only discrete irregularities were noted. Relatively large, hilar aneurysms were seen in two cases. On the PC-MRA the presence of fibromuscular dysplasia in the renal arteries was suggested by an abrupt drop in signal intensity with or without a distal recurrence of flow silgnall in $50 \%$ of cases (Figure 2).

Figure 2: Bilateral renal artery FMD on DSA (a); suggested by an brupt drop iri signal intensity in the renal arteries with (right renal artery) and without (left renal artery) distal recurrence of flow signal on PC-MRA (b); and presented as (discreet) vessel wall irregularities in both renal arteries on CE CTA (c) and CTA (d).
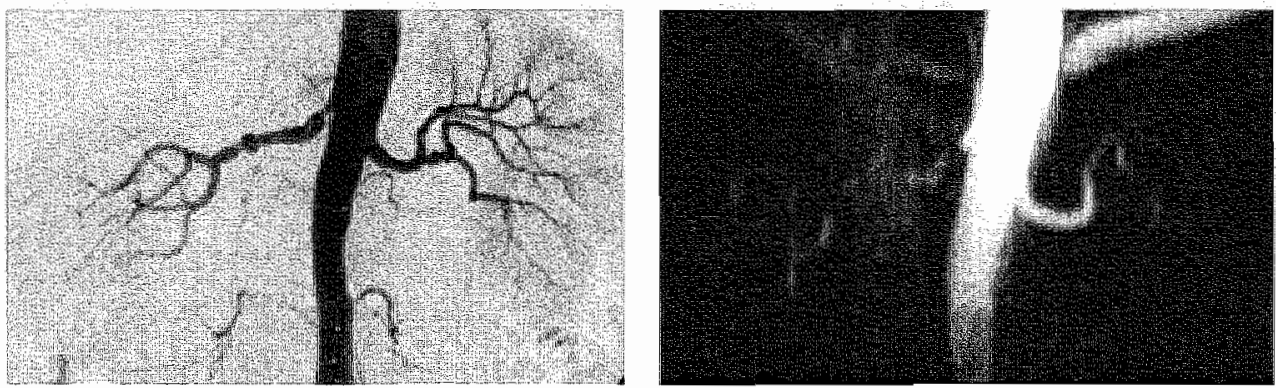

a

b
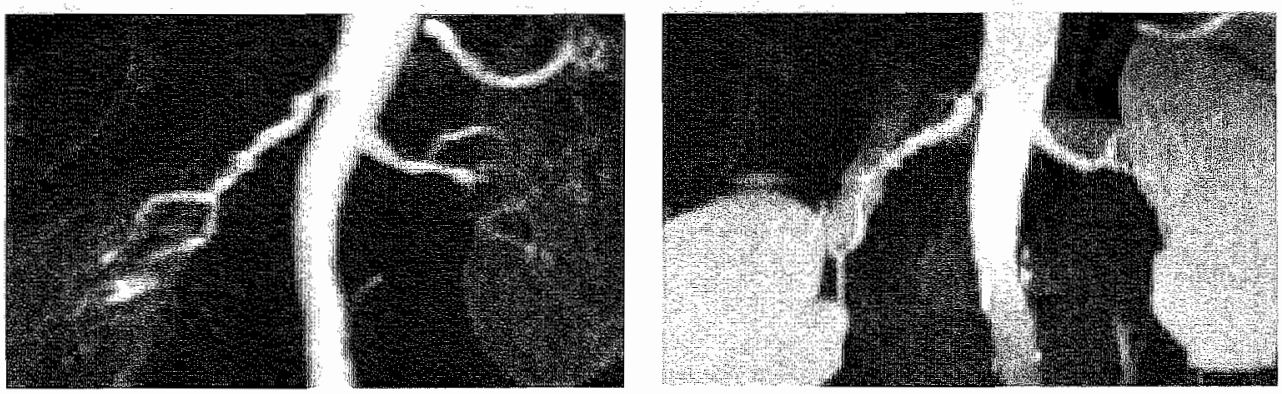

$\mathrm{c}$

d

\section{Discussion}

The major finding of this study is that neither MR angiography nor $C T$ angiography can reliably identify renal artery fibromuscular dysplasia in patients suspected of renovascular hypertension. Even in this artificially composed population with a very high prevalence of fibromuscular dysplasia the observers frequently failed to identify this renal artery abnormality despite prior knowledge of the presence of this disease in one of the renal arteries. The results of CTA were better than CE-MRA, which in turn performed better 
than PC.MRA, but with none of the three techniques a detection rate of $\geq 82 \%$ for the presence of fibromuscular dysplasia could be reached.

These results, though disappointing, confirm the assumption that MRA and CTA techniques are, to date, inadequate for non-invasive ewaluation of renal artery fibromuscular dysplasia $(7,8)$. As a result of the inclusion criteria the pre-test likelihood for renal artery stenosis in the initial group of patients from the RADISH-study was high compared to the general population. Further increase of the pre-test likelihood by identifying factors which are thought to be associated with fibromuscular dysplasia might be difficult, since, apart from gender, no discriminating clinical features were found in this sub-group of patients relative to the initial group of patients from the RADISH-study. There was a significant female predominance in our group of patients $(0: 9=4: 25$ ), whereas the age of these patients was relatively high as compared to international literature: mean $51 \pm 9$ years (range 30-66), median 53 years. This is not in accordance with the internationally accepted, young adult profile of patients with fibromuscular dysplasia (Table 2).

The limited spatial resolution in relation to the relatively small calibre of the segmental arteries is likely to be one of the limiting factors $(7,8)$. Also, motion artefacts can influence the image quality of the more distal part of the renal arteries, typically the segment of presentation of fibromuscular dysplasia. A recent MR study demonstrated the presence of significant renal motion in caudo-cranial direction during sustained breath-hold at end inspiration, ranging from -5.2 to $23.1 \mathrm{~mm}$ and -16.6 to $32.5 \mathrm{~mm}$, respectively (for a scan duration of 26 seconds). The observed average displacement of the kidney during breath-hold CE-MRA was greater than the typically employed voxel size, jeopardizing the reliability of CE-MRA interpretation of the distal renal artery segments (11). This phenomenon may result in incorrect diagnoses, and is likely to affect image quality on CTA as well. These limitations seem to apply also to our data since PC-MRA, being the technique with the longest acquisition time, produced the worst results as opposed to CE-MRA and, more distinctly to CTA. Furthermore, the probable presence of a peripherally located renal artery disease like fibromuscular dysplasia in combination with a relatively poor depiction of the peripheral renal artery segment on MRA resulted in a number of non diagnostic (examinations in this study.

The detection rate of renal artery abnormalities fell with the increase in their distance from the aortic ostium in all three imaging techniques: of all abnormalities lacated more than $3.0 \mathrm{~cm}$ from the aortic ostium only $8 \%$ were detected with PC-MRA, whereas with CE-MRA and CTA $33 \%$, respectively $68 \%$ of the lesions were noted, as opposed to $40 \%$, respectively $55 \%$ and $91 \%$ for the more proximally located lesions (Table 4).

Likewise, the extent of the fibromuscular dysplastic lesions influenced the detection rate considerably in all three imaging modalities. Mill manifestations of renall artery fibromuscular dysplasia were seen in only $10 \%, 29 \%$ and $60 \%$ of cases with respectively PC-MRA, CE-MRA and CTA, whereas severe lesions were detected in 60, 91 respectively $100 \%$ of cases resulting in a statistically significant difference between the combined grades 1 and 2 compared to grade 3 with both MR techniques (Table 4).

A lesion-to-llesion analysis was performed in order to get a better understanding of the potential pitfalls and/or limitations of PC-MRA, CE-MRA and CTA in the detection of fibromuscular dysplasia in the renal arteries. Four frequently encountered sources of error could be identified; 1) Superpositioning from overlapping vessels, caused by a suboptimal 
Figure 3: Distal manifestation of fibromuscular dysplasia in the right renal artery on DSA (a)! suggested by discreet outpouchings on the PC-MRA source images (b): and on the mult planar reformatted images on CE-MRA (c) and CTA (d)
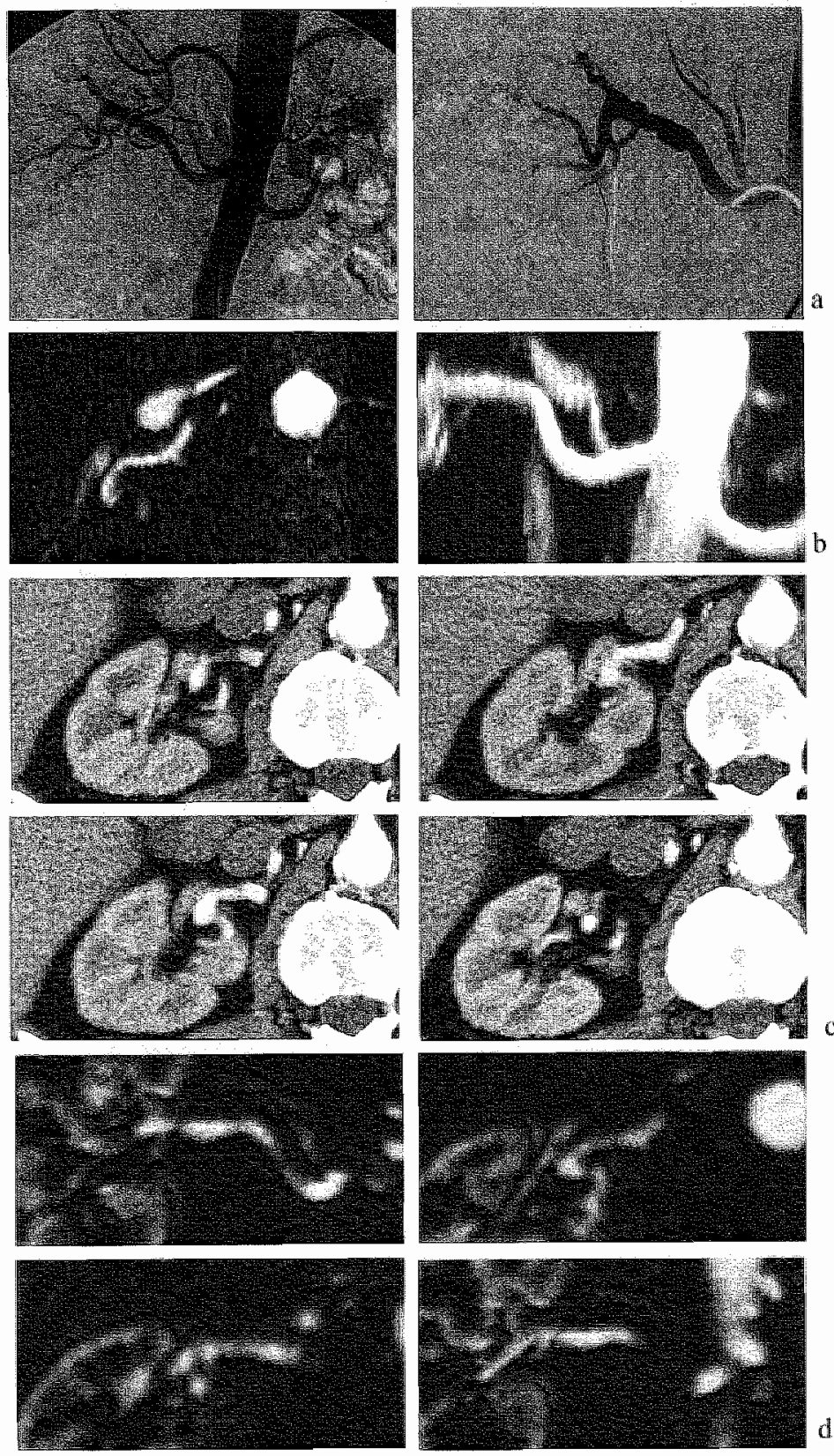
timing of data acquilition relatiwe to the arrival of the contrast bolus; 2) A downward andfor tortuous course of the renal artery making interpretation of the source images alone virtually impossible and necessitating advanced (free-curved) multi-planar reformatting; 3) The distal manffestation of fibromuscular dysplasia, together with the multiple (perihilar) branching and 4) Relatively long fibromuscular dysplastic lesions with only discreet aneurysmal outpouchings (figure 3).

In conclusion, the present study shows that neither PC-MRA, neither CE-MRA nor CTA can reliably diagnose renal artery fibromuscular dysplasia. Future technologic developments, particularly focusing on a more rapid data acquisition and improvement of spatial Iresolution seem necessary before these techniques can be fully implemented in daily practice. Pending these improvements, ia-DSA remains the gold standard for the detection of renal artery fibromuscular dysplasia. 


\section{References}

1. Pickering TG. Renovascular hypertension: etiology and pathophysiology, Seminars in Nuclear Medicine. 1989: 19:79-88:

2. Van Bockell $J H_{n}$ Weibull $H$. Fibrodysplastic disease of the renal arteries. Eur / Vasc Surg. 1994; 8:655-657.

3. Snidow Jl, Johnson MS, Harris VJ, Margosian PM, Aisen AM, Lalka SG Cilkrit DF. Trerotola SO. Threedimensional Gadolinium-enhanced MR angiography for aotroiliac inflow assessment plus renal artery screening in a single breath-hold. Radiology 1996; $198.725-732$.

4. De Cobelli F, Venturini M, Vanzulli A, Sironi S, Salvioni M, Angeli E, Scifo P, Garancini MP, Quartagno R, Bianchi G, Del Maschio A. Renal artery stenosis: prospective comparison of color-Doppler US and breath-hold, three-dimensional, dynamic, Gadolinium-enhanced MR angiography. Radiology. 1997; 214:373-380.

5. Kaatee R., Beek FJA, de Lange EE, van Leeuwen MS, Smits. HFM, van der Ven PJG, Beutler JJ. Mali WPTM. Renal artery stenosis: detection and quantification with spiral CT anglography versus optimised digital subtraction angiography. Radiology. 1997; 205:121-127.

6. Bakker J, Beek. FJA, Beutler J. Hené R], de Kort GAP, de Lange EE, Moons KGM, Mali WPTM. Renal artery stenosis and accessory renal arteries: accuracy of detection and visualization with Gadoliniumenhanced breath-hold MR angiography. Radiology. 1998; 207:497-504.

7. Rieumont My. Kaufman JA, Güller SC, Yucel EK "Cambria RP. Fang LST, Bazari H, Waltman AC. Evaluation of renall artery stenosis with dynamic Gadolinium-enhanced MR angiography. AJR. 1997; 169:39-44.

8. Dong Q, Schoenberg SO, Carlos RC, Neimatallah M, Cho KJ. Williams DM. Kazanjian SN, Prince MR. Diagnosis of renal vascular disease with MR angiography. Radiographics. 1999; 19:1535-1554.

9. Beregi J-P, Louvegny S, Gautier C. Mounier-Vehier C, Desmoucelle F, Wattinne L, McFadden E. Fibromuscular dysplasia of the renal arteries: comparison of helical CT angiography and arteriography. A.JR. 1999: 172:27-34.

10. Vasbinder GBC, Nelemans PJ, Beek FJA, Flobbe K, de Haan MW, Kessels AGH, Korst MBJM, Kroon AA, Leiner T, Maki JH, Postma CT, van Zwam WH, de Leeuw PW, van Engellshoven JMA. Computed Tomographic Angiography and Magnetic Resonance Angiography for the Diagnosis of Renal-Artery Stenosis: a Comparative Study with Digital Subtraction Angiography. Results of the Renal Artery Diagnostic Imaging Study In Hypertension (RADISH). Submitted

11. Vasbinder GBC. Maki JH, Nijenhuis Rj, Leiner T, Wilson GJ, Kessels AGH, Kaandorp DW, Ho KJAM, and van Engelshowen JMA. Motion of the distal renal artery during $3 D$ Contrast-enhanced breath-hold MRA. J Magn Reson Imaging: 2002:16(6):685-96. 


\section{Renal artery blood flow: quantification with breath-hold or respiratory triggered phase-contrast MR imaging.}

de Haan MW, Kouwenhoven $M_{n}$ Kessels AGH, van Engelshoven JMA.

European Radiology 2000; 10:1133-1137. 


\section{Abstract}

The aim of this study was to evaluate the validity and reproducibility of breath-hold and respiratory triggered phase-contrast (PC) MR imaging techniques in the measurement of renal artery blood flow. In twelve healthy subjects cardiac-gated PC flow measurements were obtained in the renal arteries using a breath-hold and a respiratory triggered technique. The flow measurements were repeated in each separate renal artery. Comparison between the sum of flow measurements in the renal arteries and the difference in aortic flow measurements above and below the renal arteries served as an internal control. The flow measurements showed a good reproducibility both with the breath-hold $(r=0.92, p<0.0001)$ and with the respiratory triggered $(r=0.91, p<0.0001)$ technique. The validity of both methods was good and did not differ statistical significantly. Reproducible quantitative measurements of renal artery blood flow are possible with respiratory controlled, cardiac-gated "PC MR imaging. 


\section{Introduction}

Renal artery stenosis is the most frequent cause of secondary hypertension, with an estimated prevalence of $3-5 \%$ in the general population of people with hypertension $(1,2)$. Identifying hypertensive patients with renovascular disease could allow for potential curative therapy. Correction of arterial stenoses by means of percutaneous transluminal angioplasty (PTRA) or surgical techniques shows normalisation or improvement of the hypertension in the majority of these patients (3-5). However, in $10-30 \%$ there is no response to these therapeutic regimens $(5,6)$ and it seems unpredictable who will respond and who will not. Moreover, many aortograms obtained for other reasons demonstrate renal artery stenosis in normo-tensive patients.

Up to now the decision to correct renal artery stenosis in hypertensive pacients is predominantly based upon morphologic information (stenosis $>50 \%$ ) provided by current imaging techniques, including intra-arterial digital subtraction angiography (ia-DSA), computed tomographic angiography, and magnetic resonance (MR) angiography $(7,8)$. Doppler sonography is used for non-invasive detection of renal artery stenosis with warying results concerning diagnostic accuracy because quantification of renal artery blood flow is influenced by a variety of errors inherent in the indirect calculation of Doppler parameters $(9,10,11)$. Various functional tests, for example para-aminohippuric acid (PAH) clearance, venous renin sampling and radionuclide renography are either indirect measures of disease or yield only total renall flow, rather than unilateral flow to each kidney $(12,13,14)$.

Knowledge of blood flow in the individual renal artery in patients with hypertension would provide a better understanding about the pathophysiology of renovascular hypertension and this information might be important in the therapeutic management of these patients. Furthermore, measurements of renal artery blood flow could serve as a non-invasive test for follow-up after PTRA or surgical reconstruction and for evaluation of various vasoactive agents.

Recent publications indicate that high-resolution 3D gadolinium-enhanced $M R$ angiography is the preferred $M R$ angiography technique for morphologic assessment of the renal arteries. Other $M R$ angiographic techniques (i.e. phase-contrast and time-of-flight) show limitations in depicting small-calibre vessels and distal renal artery segments (15). However, phase-contrast MR imaging (PC MR), which goes beyond morphologic imaging by allowing quantitative evaluation of flow dynamics, may be used to determine the hemodynamic significance of renovascular disease. Flow quantification with PC MR uses the velocity-dependent phase shifts of flowing spins (16). In combination with cardiac triggering, flow rates can be determined at specified phases of the cardiac cycle. This enables the flow rates to be studied as a function of time. The accuracy of PC flow measurement has been validated in vitro and in vivo $(17,18)$

In the past few years, several phase-contrast MR techniques have been proposed for quantification of blood flow in the renall arteries $(19,20)$. However, the reported results show varying success in renal blood flow measurement compared to results obtained by means of para-aminohippurate (PAH) clearance. Respiratory motion, which causes the renal arteries to move during data acquisition, appears to be a considerable source of error in these measurements $(20,21,22)$. Symchronisation with respect to respiratory motion, along with cardiac triggering, seems to be necessary to obtain accurate, reproducible flow data $(22,23)$. 
The aim of this study was to determine the feasibility and reproducibility of two respiration controlled PC MR techniques: a breath-hold sequence, and a respiratory triggered sequence, to measure blood flow in the individual renal arteries.

\section{Materials and Methods}

\section{Subjects}

Twelve subjects ( 8 male, 4 female, mean age 35 years, range $23-48$ year) were recruited. All voluriteers were normotensive and without known underlying renal disease. Criteria for participation in the study included willingness to give informed consent, and lack of standard contra-indications to MR imaging (e.g. pacemaker, claustrophobia, or ocular metallic fragments). The ethical review board of our institute approved the study.

\section{MR imaging technique}

All images were acquired on a 1.5 Tesla whole-body MR system (ACS II, Philips Medical Systems, Best, The Netherlands), using the quadrature bady coil for signal transmission and reception. No abdominal compression was used.

To localize the renal arteries, a T1-welghted gradient echo multistack scout view was obtained at the level of the kidneys (TR/TE: 22.0/7.0, 20 flip angle, $15.0 \mathrm{~mm}$ slice-thickness, FOV: $500 \mathrm{~mm}, 256 \times 256$ matrix). Images were obtained in the coronal and transwerse planes.

Subsequently, a non-gated three-dimensional phase-contrast MR angiographic (3D PC-MRA) sequence was performed for morphological assessment of the renal arteries (8).

T1-weighted, gradient-echo images were obtained in the transverse plane with the following parameters: TR/TE: $27.0 / 8.5,20^{\circ}$ flip angle, two signalls averaged, $75 \%$ partial echo sampling, $200 \times 140 \mathrm{~mm}$ FOV, $128 \times 103$ acquisition matrix, using a 256 reconstruction matrix and $45 \mathrm{~cm} / \mathrm{sec}$ flow-encoded velocity. Fourier interpolation was used to reconstruct sections thinner than those acquired. In the sequence performed without gating, 32 sections of $4 \mathrm{~mm}$ were acquired, reconstructed to 64 slices of $2.0 \mathrm{~mm}$. The outer $10 \%$ on both sides was discarded resulting in 50 slices of $2 \mathrm{~mm}$.

To reduce the venous signal from the inferior vena cava, a transwerse presaturation slab (60.0 $\mathrm{mm}$ thick) was placed inferior to the lower pole of the kidneys. The maximum intensity projection (MIP) algorithm was used to create angiographic projections in the transverse, coronal and sagittal plane. Both the MIPs and the original transwerse images were used to select an image plane perpendicular to the studied artery for flow quantification.

A flow compensated turbo gradient-echo phase-contrast MR (PC MR) technique was used for flow data acquisition with the following parameters: FOV $180 \times 90$. TR/TE 12.0/7.0, $25^{\circ}$ flip angle, $7.0 \mathrm{~mm}$ slice-thickness, two signals averaged allowing fold-over suppression in the phase-encoding direction (anterior-posterior), $128 \times 96$ acquisition matrix, using a 128 reconstruction matrix, in-plane voxel size $1.4 \times 1.9 \mathrm{~mm}$, cardiac triggering, 8 phases per cardiac cycle, linear profile order, 10 profiles per heart phase, flow-encoded velocity $120 \mathrm{~cm} / \mathrm{sec}$. Electrocardiography was used for cardiac synchronisation.

Flow quantification was performed both with a breath-hold (acquisition time 30 seconds), and a respiratory triggered technique (acquisition time 2 minutes). Images were obtained perpendicular to the right and left renal artery $8-15 \mathrm{~mm}$ from their aortic origin. 
In order to acquire information about the reproducibility of the flow measurements, flow quantification in each separate renal artery was repeated within 5 minutes in each subject without changing the scan-parameters and/or off-centres.

As an internal validation of the measurements, flow data were obtained in each renal artery separately and in the abdominal aorta superior and inferior to the origins of the renal arteries. To avoid inclusion of the superior mesenteric artery, the position of the slices was carefully planned on the MIP's of the non-gated 3D PC-MRA sequence. Postulating that no other (major) vessel originates from the involved aortal segment contains that, with accurate flow measurements, the sum of flow volumes in the renal arteries and inferior aorta is the same as in flow volume measured in the aorta superior to the renal artery origins.

Consequently, 12 separate flow measurements were performed in each individual.

\section{Evaluation and Statistics}

To ensure optimal vessel demarcation and measurement reproducibility, all phase-contrast flow data were analysed in a contour detection program, on an off-line workstation (Sun Microsystems, Mountain View, California, U.S.A.). The employed automated region of interest ( $R O$ I) definition algorithm defined the region on the phase-contrast MR images bounded by an operator-defined ellipse drawn generously around the vessel on the modulus images. Instantaneous flow (millilitres per second) was calculated from the individual velocity images by integrating velocity (centimeters per second) across the area (square centimeters) of the vessel. Mean flow in each vessel was calculated as the average of instantaneous flows across the cardiac cycle.

The interobserver agreement was determined by calculating the Pearson correlation coefficients for both the breath-hold and the respiratory triggered flow measurements.

Validity assessment of both techniques was based on differences between the in- and outgoing flows.

\section{Results}

Non-gated three-dimensional phase-contrast MR angiography (3D PC-MRA) revealed a total of 26 renal arteries in the 12 subjects. Two subjects showed an accessory renal artery. None of the visualized arteries showed renovascular disease on the non-gated 3D PC-MRA images. The waveforms in the renal arteries showed a continuous forward flow characteristic of an arterial system with llow peripheral resistance. The aortic waveforms showed a more pulsatile flow pattern with a phase of retrograde flow during diastole.

The flow measurements in the renal arteries showed a good reproducibility with Pearson correlation coefficients of 0.92 and $0.91 \quad(p<0.0001)$ for the bireath-hold and respiratory triggered technique respectively (Fig la and $1 \mathrm{~b}$ ).

The residual flow, i.e. the difference between flow measured in the superior aorta (inflow) and the sum of measurements of both renal arteries and inferior aorta (outflow), should be equal to zero. The standard deviations of this residual flow with the mean set to zero are for the breath-hold and respiratory triggered 11.4 and 9.3 respectively. These values do not differ significantly (F-test: $\mathrm{p}=0.23$ ). 
Figure 1 a, b: Scattior pllor of the firt and second flow measurement with orthogonal regression line

\section{Breath-hold}

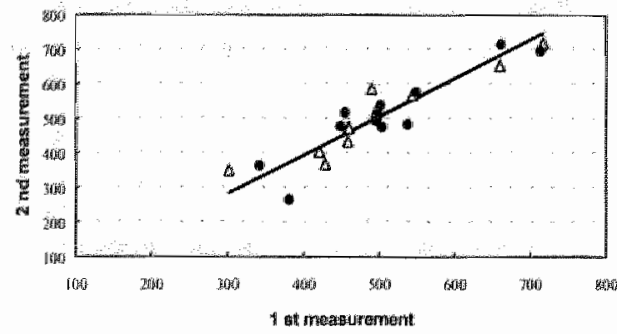

$1 \pi$
Respiratory triggered

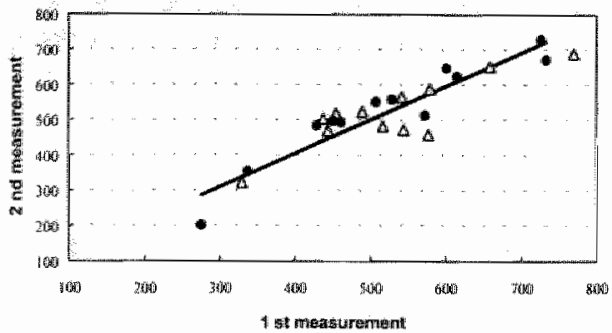

la

Note: $\Delta$ right renal artery - left renal artery

In one subject a relatively large residual flow was noted: $680.6 \mathrm{~m} / / \mathrm{min}$ using the breath-hold technique, respectively $434.0 \mathrm{~m} / \mathrm{min}$ with the respiratory triggered technique, probably caused by poor positioning of the flow-acquisition slices. If these deviating results would have been omitted, the difference in standard deviations for the breath-hold and the respiratory triggered technique, namely 4.2 . and 8.6 respectively, becomes statistically significant $(p=0.01)$, thus favouring the breath-hold technique.

Likewise, the independent MRA measurements of the total renal blood flow (RBF) calculated from the sum of renal artery flows concurred well with the RBF calculated from the aortic difference (Fig $2 \mathrm{a}$ and $2 \mathrm{~b}$ ).

Figure 2 a, b: Scatter plot of the total renal blood flow calculated from the sum of renal flows and from the aortic difference.

Breath-hold

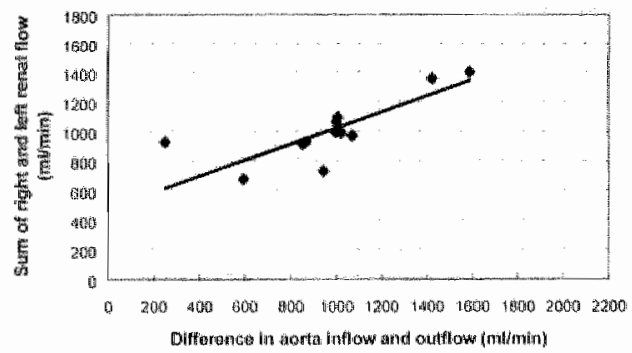

$2 a$
Respiratory triggered

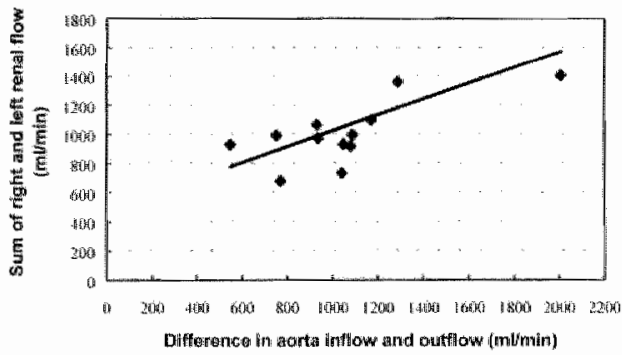

$2 b$ 


\section{Discussion}

Respiration controlled MR phase imaging promises to be a reliable technique for non-invasive measurement of blood flow in the renal arteries. The obtained absolute flow measurements in the renal arteries and abdominal aorta correspond well with results of other published studies (20-24).

Comparison between the in - and outgoing flows, i.e. flow in the superior abdominal aorta vs. flows in the renal arteries and inferior abdominal aorta, served as an internal control from which information was derived about the accuracy of the MR technique. The degree of reproducibility, which to our knowledge has not been addressed in recent literature. was evaluated by repeating the separate flow measurements in the renal arteries without changing scan-parameters and/or off-centres. Thus 12 separate flow measurements, i.e. 6 with the breath-hold and 6 with the respiratory triggered technique, were performed in each individual. In this study these independent measurements yielded overall concurring and reproducible results with both the breath-hold and the respiratory triggered technique.

The optimal method for flow data acquisition and evaluation in the renal arteries is not yet certain. Several published reports show reliable flow measurements using MR techniques without respiratory synchronisation $(19,21,24,25)$, whereas others identify respiratory motion as a significant potential source of error in quantitative flow assessment in the renal arteries $(20,22,23)$. This contrast could be related to differences in the location of the parasagittal imaging plane with respect to the aorta, since respiration is likely to have a more significant unfluence on motion of the renal vessels in the periphery than in their central segment.

Misalignment between slice direction and vessel axis and partial volume effects due to the limited in-plane resolution are other potential sources of error. Great care was taken to localize the renal arteries on MR angiography, using both MIP's in three different planes and the original transverse images, and (double-) angulating the slice perpendicular to the flow axis.

With a typical R-R interval of $850 \mathrm{msec}$ ( $70 \mathrm{bpm})$, respiratory synchronisation, along with cardiac triggering, permitted a temporal resolution of only about 107 msec, allowing reproducible assessment of the mean renal artery blood flow. However, the relative low temporall resolution of this technique does not allow qualitative analysis of flow profiles, which might be necessary in patients with more complex flow patterns. In a recent publication Schoenberg et al (26) described a cardiac-gated cine phase-contrast $M R$ technique, without respiratory symchronisation, with a temporal resolution from 32 to $16 \mathrm{msec}$. This technique enabled him to analyse the pulsatile properties of the renal artery waveform and to identify different segments of the flow profile. However, reduction of the mimean renal blood flow proved to be the only statistically significant parameter in accurate differentiation between hemodynamically relevant high-grade $(\geq 50 \%)$ stenosis and low-grade ( $<50 \%)$ stenosis. Maximum velocity and time to systolic maximum were more sensitive to changes at lower degrees $(<50 \%$ ) of stenosis.

Published reports indicate that differences from right to left in excess of $15 \%$ (calculated by dividing the difference from right to left by the average of the two) are abnormal (18). Measurements in this study showed asymmetry in all subjects to some extent: mean difference $8.6 \%$ and $13.0 \%$ for the breath-hold and respiratory triggered technique 
respectively. In two subjects a mean right-to-left difference greater than $15 \%$ was noted with the breath-hold technique, as opposed to three subjects with the respiratory triggered technique.

In summary, quantitative assessment of renal artery blood flow may prove to be important in the clinical evaluation of patients with renal artery pathology. Furthermore, measurement of renal blood flow could serve as a non-invasive test for follow-up after PTRA or surgical reconstruction and for evaluation of various vasoactive agents.

This preliminary study shows that reproducible quantitative measurements of renal artery blood flow are possible with respiratory controlled, cardiac-gated, phase-contrast MR imaging. Our data show a slight preference for the breath-hold technique compared to the respiratory triggered technique. However, the study is limited by the small sample size $(n=12)$ and the composition of the subject-group (i.e. healthy, relatively young volunteers). which makes extrapolation of the results to the daily practice difficult. Further and larger studies in (hypertensive) patients comparing different MRA techniques mutually and with other methods, and studies that address the reproducibility of the various techniques would be worthwhile. 


\section{References}

1. Hillman BJ. Imaging advances in the diagnosis of renovascular hypertension. AJR 1989; 153:5-14.

2. Kim D, Edelman RR, Kent KC, Porter DH, Skifilman Jj. Abdominal aorta and renal stenosis: evaluation with MR Angiography. Radiology 1990; 174:727-731.

3. Working Group on Renowascular Hypertension. Detection evaluation and treatment of renovascular hypertension; Final report. Arch intern Med 1987; 147:820-829.

4. Losinno F, Zuccalà A, Busato F, Zucchelli P. Renal artery angioplasty for renovascular hypertension and preserwation of renal function: Long-term angiographic and clinical follow-sp. AJR 1994: 162:853-857.

5. Klinge J. Mali WPTM, Puijlaert CBA., Geyskens GG. Becking WB, Feldberg MAM. Percutaneous transluminal renal angioplasty: Initial and Long-term Results. Radiology 198\%: 171:501-506.

6. Ramsay LE, Waller PC. Blood pressure response to percutaneous transluminal angioplasty for renovascular hypertension: an overview of published series. BMJ 1990; 300: 569.72.

7. Olbright CJ, Paul K. Prokop M. Chavan A, Schaefer-Prokop CM, Jandeleit K, Koch KM, Galanski M. Minimally invasive diagnosis of renal artery stenasis by spiral computed tomography angiography. Kidney int 1995; 48:1332-7.

8. de Haan MW. Kouwenhowen M. Thelissen GRP, Koster D, Kessels AGH, de Leeuw PW, van Engelshoven JMA. Renovascular disease in patients with thypertension: Detection with systolic and diastolic gating in three-dimensional Phase-contrast MR Angiography. Radiology 1996; 198:449-456.

9. Desberg AL, Paushter DM, Lammert GK, Hale JC, Troy RB, Novick AC, Nally JR, Weltewreden AM. Renal artery stenosis: Evaluation with color Doppler flow imaging. Radiology 1990; 177:749-753.

10. Patriquin HB, Lafortune M, Jequier JC, O'Regan S, Garel L, Landriault J, Fontaine A، Filiatrault D. Stenosis of renal artery: assessment of slowed systole in the downstream circulation with Doppler sonography. Radiology 1992; 184:479-485.

11. Bude RO, Rubin JM. Detection of renal artery stenosis with Doppler sonography: It is more complicated than originaily thought. Radiology 1995; 196:612-613.

12. Aukland K. Methods for measuring renal blood now: Total flow and regional distribution. Ann. Rev. Physiol.1989: 42:543-555.

13. Chen CC, Hoffner PB, Vahjen G, Gattschalk A, Koster K, Zabal IG, Setaro IF, Roer DA, Black HR. Patients at high risk for renal artery stenosis: a simple method of renal scintigraphic analysis with $T \mathrm{c} 99 \mathrm{~m}$ DTPA and captopril. Radiology 1990; 176:365-370.

14. Dunnick NR, Sfakianakis GNV. Screening for renovascular hypertension. Radiol Clin North Am 1991; 29:497-510.

15. Dong Q. Schoenberg SO, Carlos RC, Neimatallah M, Cho KJ, Williams DM, Kazanjian SN, Prince MR. Diagnosis of Renal Artery Disease with MR. Angiography. Radiographics 1999; 19:1535-1554.

16. Kouwenhoven M, Bakker $C_{j} G_{1}$ Hartkamp M]. Mali WPTM. Current MR angiographic imaging techniques: a survey. In Lanzer P. Rosch J, eds. Vascular diagnostics. 1 st ed. Heidelberg, Germany: Springer-Verlag.

17. Evans A. J. Iwai F, Grist TA, Sostman HD. Hedlund LW, Spriczer $C T$ " Negro-Vilar $R$, Beam CA, Pelc NJ. Magnetic resonance imaging of blood flow with a phase subtraction technique investigative Radiclogy 1993; 28:109-115.

18. Pelc LR, Pelc NJ, Rayhill SC, Castro LJ, Glover GH. Herfkens RJ, Miller DC, Jeffrey RB. Arterial and venous blood flow: non-invasive quantitation with MR imaging. Radiology 1992; 185:809.812.

19. Wolf RL. King BF, Torres VE, Wilson DM, Ehrman RL. Measurement of normal renal artery blood flow: Cine Phase-Contrast MR Imaging vs. clearance of p-aminohippurate. AJR 1993; 161:995-1002 
20. Sommer G. Noorbehesht B. Pelc N, Jamison R, Pinevich A), Newton L, Myers B. Normal renal blood flow measurement using Phase-Contrast Cine Magnetic resonance Imaging Investigative Radiology 1992; 27:465-470.

21. Maler SE, Scheidegger MB, Luil K, Schneider E, Bolliger A, Boesinger P. Renal artery velocity mapping with MR imaging Journal of Magnetic Resonance lmaging 1995; 5:669-676.

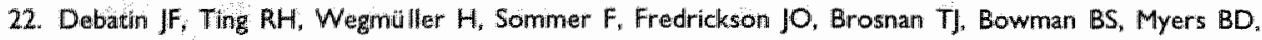
Herfkens RJ, Pelc N]. Renal artery blood flow: Quantification with Phase-Contrast MR imaging with and without breath holding Radiology 1994;190:371-378.

23. Thomsen $C$, Corsten M, Sondergaard L. Hendriksen O. Stähiberg F. A segmented K-space Velocity mapping protocol for quantification of renal artery blood flow during breath-holding. Journal of Magnetic Resonance Imaging 1995; 5:393-401.

24. Lundin B, Cooper TG, Meyer RA, Potchen EJ. Measurement of total and unilateral renal blood flow by oblique-angle welocity-encoded 2D-cine Magnetic Resonance Angiography. Magnetic Resonance Imaging 1993: 11:51-59.

25. Cortsen M. Pexersen LJ, Stahlberg F. Thomsen $C$, Sondergaard L., Petersen JR, Laidefoged SD, Hendriksen 0 . MR velocity mapping measurement of the renal artery blood flow in patients with impaired kidney function. Acta Radiologica 1996; 37:79-84.

26. Schoenberg SO. Knopp MV, Bock M, Kallinowski $F$, Just A, Essig M, Hawighorst $H$, Schad L, van Kaick $G$. Renal artery stenosis: Grading of hemo-dynamic changes with cine phase-contrast MR blood flow measurements. Radiology 1997; 203:45-53. 

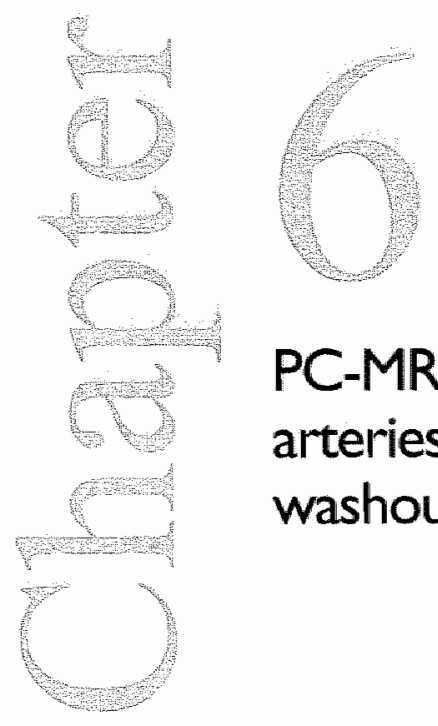

\section{PC-MR flow quantification in renal arteries; comparison with ${ }^{133}$ Xenon washout measurements.}

de Haan MW, van Engelshoven JMA, Houben AJHM, Kaandorp DW, Kessels AGH, Kroon AA, de Leeuw PW.

Hypertension 2003; 41:114-118. 


\section{Abstract}

To assess the accuracy of $2 D$ phase-contrast MR (2D PC MR) renal artery flow measurements, data obtained with this technique were compared to those acquired with the ${ }^{13 y}$ Xenon washout procedure. In addition, the 2D PC MR flow data were related to functional renal information as derived from selective arterial and venous renin sampling. In 53 patients suspected of having renovascular hypertension MR angiography of the renal arteries was performed, followed by a three-step angiographic procedure: 1) selective venous and arterial renin sampling; 2 ) assessment of the renal blood flow by means of the ${ }^{133}$ Xenon washout technique and 3) conventional renal angiography. After initial assessment, 71 kidneys were left for analysis. The overall prevalence of renovascular disease $\geq 50 \%$ stenosis was $18 \%$. Mean renal blood flow as assessed with the 2D PC MR technique showed a significant correlation with the ${ }^{133}$ Xenon washout flow measurements, with a Pearson correlation coefficient of 0.69 (two-tailed; $p<0.01$ ). Phase-contrast MR blood flow measurements correlated poorly with the presence and/or severity of renovascular disease on conventional angiography $(r=0.1, p=0.36)$. Likewise, no statistically significant correlation with either venous renin levels or the renin ratio could be identified. In conclusion, measurement of renal artery blood flow using a 2D phase-contrast MR technique is technically feasible. However, the mean renal artery blood flow correlates poorly with either the presence of renovascular disease on angiography or with renin levels. Further improvement of this technique is necessary before it can be applied on a larger scale. 
Comporison of PC-MR flow quantification and ${ }^{133}$ Xenon washout

\section{Introduction}

Magnetic resonance angiography (MRA) is a promising non-inwasive imaging modality for the screening of renovascular disease (1-3). Recent publications indicate that highresolution 3D gadolinium-enhanced $M R$ angiography is the preferred MR angiographic technique for assessment of the renal arteries (4-7). However, similar to other imaging methods employed in the diagnosis of renal artery stenosis, most MRA techniques solely rely on the morphologic assessment of the vasculature. To assess the hemodynamic consequences of a particular arterial lesion, additional functional tests are still required.

Published reports concerning several non-invasive techniques (eg, duplex ultrasound and/or nuclear clearance techniques) show a great variety in diagnostic accuracy as well as various specific limitations of these tests in the assessment of renal artery blood flow (8-10). Therefore, the demand for a reliable, non-invasive screening method remains valid (11). Magnetic resonance phase-contrast (PC MR) protocols have been proposed to provide the desired functional information through direct, non-invasive 2D PC MR renal artery flow quantification. The accuracy of this technique was verified, both in vivo and in vitro, by comparison with other non-invasive (e.g. duplex ultrasound and/or nuclear clearance techniques) and invasive techniques (implantation of ultrasound probes) or by internal validation by comparing aortic flow measurements above the renal arteries with the total flow through the renal arteries and aorta distal of these arteries (12-14).

In the current study the ${ }^{133}$ Xenon washout technique was used as an independent test for comparative evaluation of the acquired 2D PC MR renal artery flow data in hypertensive patients. The ${ }^{133}$ Xenon washout technique requires selective arterial catheterisation to allow local disposition of the tracer and therefore has the potential to provide information about blood flow of both kidneys separately.

The primary objective of this investigation was to assess the accuracy of the $2 D P C M R$ flow measurements in patients suspected of having renovascular hypertension by comparing the results of these measurements with those obtained by ${ }^{133}$ Xenon washout. In addition, the 2D PC MR flow data were related to functional renal information as obtained by selective arterial and venous renin sampling to assess the presence of renal artery stenosis. In this respect, conventional renal angiography was used as the standard of reference for the diagnosis of renal artery disease.

\section{Materials and methods}

\section{Patients}

Over an 11 -months period, all patients who were referred by the Department of Internal Medicine for angiographic evaluation of the renal arteries were prospectively enrolled in the present study. Selection criteria included malignant, accelerated and/or treatmentresistant hypertension, hypertensive retinopathy grade III or IV, loss of renal function after ACE inhibition, unilateral loss of kidney volume or unexplained deterioration of renal function (change in serum creatinine $>20 \mu \mathrm{mol} / /$ within 12 months).

Three weeks before angiography all antihypertensive medication was discontinued. In addition, patients were asked to use a salt-restricted diet containing $55 \mathrm{mmol}$ of sodium per day during the last week prior to admission. The rationale for the latter is that data on renal blood flow or renin secretion should always be interpreted in relation to sodium 
intake and that standardisation, therefore, is mandatory. Adherence to this diet was checked by measuring 24-hour sodium output at the time of admission to the hospital.

The institutional review board had approved the study protocol, and patients were required to sign an informed consent form before they were included in the study.

\section{Diagnostic protocol}

The protocol of this study was fitted with a strict sequence of diagnostic modalities in order to avoid mutual influences; therefore the MRA examination was always performed one day before the conventional angiography was planned.

During the angiographic procedure, three separate, successive steps were taken: 1) selective renal venous and arterial renin sampling; 2) assessment of renal blood flow by means of the ${ }^{133}$ Xenon washout technique and finally 3 ) conventional, intra-arterial renal angiography. Onily after completion of the first two steps, contrast material was administered.

\section{MR imaging technique}

All images were acquired on a 1.5 Tesla whole-body MIR system (Gyroscan NT, release 6; Philips Medical Systems, Best, the Netherlands), using the quadrature body coil for signall transmission and reception. No abdominal compression was used.

After localizing the renal arteries, a non-gated 3D phase-contrast MR angiographic (3D PC-MRA) sequence was performed to visualize the renal arteries (12). T1-weighted gradient-echo images were obtained in the transverse plane with the following parameters: TRJTE 27.018.5, flip angle $20^{\circ}$, two signals averaged, $75 \%$ echo sampling, $200 \times 140 \mathrm{~mm}$ FOV, $103 \times 128 \mathrm{~mm}$, acquisition matrix, using a 256 reconstruction matrix, and flow-encoded velocity range (Venc) of $45 \mathrm{~cm} / \mathrm{s}$. Fourier interpolation was used to reconstruct sections thinner than those acquired.

To reduce the venous signal from the inferior caval vein, a transverse presaturation slab $(60.0 \mathrm{~mm}$ thick) was placed inferior to the lower pole of the kidneys. The maximum intensity projection (MIP) algorithm was used to create angiographic projections in the transverse, coronal and sagittal planes. Both the MIP's and the original transverse images were used to select an acquisition plane to the artery studied for flow quantification.

A $2 D$ PC MR technique was used for flow data acquisition during normal breathing with the following parameters: TR/TE: 14/6; flip angle $20^{\circ}$. FOV: $300 \times 210 \mathrm{~mm}$, slice thickness: $6 \mathrm{~mm}$; acquisition matrix: $256 \times 108$, and Venc: $120 \mathrm{~cm} / \mathrm{s}$. The scan was retrospectively triggered using a peripheral pulse unit (PPU), yielding 25 heart phases at a frequency of 65 heartbeats/min. within a scan time of $\approx 2$ minutes. The flow data were obtained in a plane perpendicular to the right and left renal artery, 8 to $15 \mathrm{~mm}$ from the origin.

To ensure optimal vessel demarcation and measurement reproducibility, all quanticative $2 D$ PC MR flow measurements were analysed using a contour detection program on an off-line workstation (Sun Microsystems, Mountain View, California, U.S.A.). The automated region of interest definition algorithm selected the region on the $2 D$ PC. MR images within an operator-defined ellipsis drawn generously around the vessel on the modulus images. Instantaneous flow ( $\mathrm{m} / \mathrm{sec}$ ) was calculated from the individual velocity images by integrating velocity $(\mathrm{cm} / \mathrm{sec})$ across the area $\left(\mathrm{cm}^{2}\right)$ of the vessel. Mean flow in each vessell was calculated as the average of instantaneous flows across the cardiac cycle. 


\section{Angiographic procedure}

The procedure was carried out in the angiosuite of the department of radiology, which is equipped with both an X-ray system and Nal (TI) gamma spectroscopy systen. After selective catheterisation of the renall wessels and before any intra-arterial contrast material was given, blood samples for determination of active plasma renin concentration (APRC) were drawn simultaneously from aorta and both renal veins.

Subsequently, mean renal blood flow (MRBF) for each kidney was assessed by means of the ${ }^{133}$ Xenon washout technique (15). Only after completion of these measurements, diagnostic intra-arterial renal angiography was performed with a commercially available digital subtraction system (Integris 5000; Philips Medical Systems; Best, The Netherlands). Angiographic images of the abdominal aorta and renal arteries were obtained in anteroposterior and left and right oblique views with injection of $30 \mathrm{mll}$ iohexol (Omnipaque 300; Nycomed, Oslo, Norway) through a 4-F Universal Flush catheter (Cordis Europe, Roden, The Netherlands) positioned at the level of the renal arteries. Selective renal angiography was performed in the majority of cases with injection of $12 \mathrm{ml}$ iohexol through a 5-F end-hole Cobra-2 or Simmons-2 catheter (Cordis Europe, Roden, the Netherlands).

Three experienced interventional radiologists, who were blinded to the $M R$ angiographic results independently read and interpreted the conventional angiograms. For cases in which the three observers had conflicting interpretations of the angiograms $>10 \%$ difference in degree of stenosis), a fourth interventional radiologist was asked to establish a definite diagnosis, based on his review of all three separate interpletations as well as on the anglographic irmages.

\section{Intra-arterial ${ }^{133}$ Xenon washout technique}

The principles of the inert gas washout technique are based on the work of Kety (16). For any substance carried to an organ by the blood, it is evident that the amount which enters the organ within a specified time interval must equal the amount of that substance, which, during the same time interval, leaves the organ, plus the amount which is accumulated and metabolised in that organ. In the case of an inert unmetabolized substance such as xenon, no conversion takes place. Thus, derived from several equations, monitoring the disappearance of ${ }^{133}$ Xenon from the organ will allow calculation of flow per unit volume of tissue (15).

The Xenon washout curves were analyzed as described earlier (15-18). In brinef, after subtraction of background radiation, the disappearance of ${ }^{133}$ Xenon from the kidney, measured by an extra-corporal gamma-probe, is analyzed mathematically using a twomphase exponential decay. Occasionally, a monophasic decline in activity is observed and the curve analyzed accordingly. The mean renal blood flow (MRBF) is calculated as the weighted average of the fast and the slow component (18). All analyses were performed using Prism 3.0 software.

To convert the relative blood flow per kidney as determined from ${ }^{133}$ Xenon washout technique to absolute blood flow per kidney it is necessary to know the total tissue vollume of the separate kidneys. For this purpose computer tomography (CT) was introduced as an independent imaging modality, since the MR scout images were thought to be insufficient for adequate assessment of the kidney volume. Spiral CT was performed with a commercially available double-helix scanner (Elscint Ltd, Haifa, Israel). After 
localizing the level of the kidneys, a volume acquisition was performed with the following protocol: $120 \mathrm{kV}$ at $350 \mathrm{~mA}, 30$ seconds continuous exposure, 2.5-mm collimation, and $1.3 \mathrm{~mm} / \mathrm{sec}$ table speed. The axial source images were postprocessed on an off-line workstation (Sun Microsystems, Mountain View, California, U.S.A.). The volumes of the kidneys were calculated by multiplying the renal surface area on every individual slice ( $\mathrm{mm} 2$ ) by the slice thickness ( $\mathrm{mm}$ ) and adding up all sllice volumes.

When performed this way, the ${ }^{13}$ Xenon washout study provides an accurate estimate of renal blood flow and in our hands has a variability of $8 \%$ for repeated measurements (19).

\section{Statistical Analysis}

Conventional anglography was regarded as the standard of reference for detection of renal artery stenosis. A significant stenosis was defined as luminal narrowing exceeding $50 \%$ of the vessel diameter. Renal arteries with evidence of fibromuscular dysplasia were graded as significantly stenosed $(\geq 50 \%)$.

Statistical differences were assessed using the two-sample Student's t-test. Associations between the renal artery blood flow quantification techniques, or active plasma renin ratio

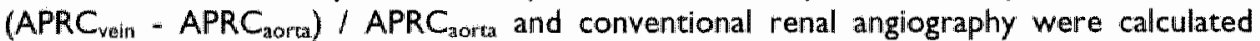
using the Pearson correlation coefficient and orthogonal regression analysis.

\section{Results}

Fifty-three patients with 106 kidneys were prospectively enrolled in this study: The mean age was 55 years (range, 30 to 79), and 60\% were men. Mean systolic blood pressure measured at three separate, consecutive occasions was $188 \mathrm{mmHg}$; mean diastolic blood pressure was $109 \mathrm{mmHg}$. Serum creatinine averaged $109 \mu \mathrm{mol} / \mathrm{l}$. Conventional renal angiography showed supernumerary arteries in 16 kidneys $(15 \%)$, with one kidney that showed three separate renal arteries. Total occlusion of the renal artery was found in three kidneys.

Kidneys with supernumerary renal arteries were excluded from analysis because a mismatch between the ipsilateral individual renal arteries in these cases could occur during the blinded first two steps of the angiographic procedure: sampling and ${ }^{133} X$ enon washout studies. Also, the kidneys with a total occlusion of the renal artery were discarded.

In 14 of the remaining 87 kidneys (16\%), the 2D PC MR quantitative flow images showed insufficient quality for automatic contour detection due to improper slice positioning and/or to flow voids during systole caused by proximal stenoses. In another two (unilateral) cases it was not possible to obtain ${ }^{133}$ Xenon washout information, probably due to poor positioning of the intra-arterial catheter, thus leaving 71 corresponding 2D PC MR and ${ }^{133}$ Xenon washout flow measurements for further analysis.

In this group of 71 kidneys, conventional angiography showed four arteries with mild renovascular disease $(20 \%-50 \%$ stenosis) and significant renal artery stenosis $\geq 50 \%)$ in 13 arteries (overall prevalence 18\%). Significant bilateral disease was seen in three patients.

\section{D PC MR versus ${ }^{133}$ Xenon washout flow measurements}

Assessment of MRBF with the 2D PC MR technique correlated significantly with the ${ }^{133}$ Xenon washout flow measurements (Figure 1), with a Pearson correlation coefficient of 0.69 (two-tailed; $p<0.01$ ). 
Figure 1: Scatter plot of the corresponding renal artery flow measurements obtained by $2 \mathrm{D} \mathrm{PC} \mathrm{MR}$ technique and ${ }^{133}$ Xenon washout technique.

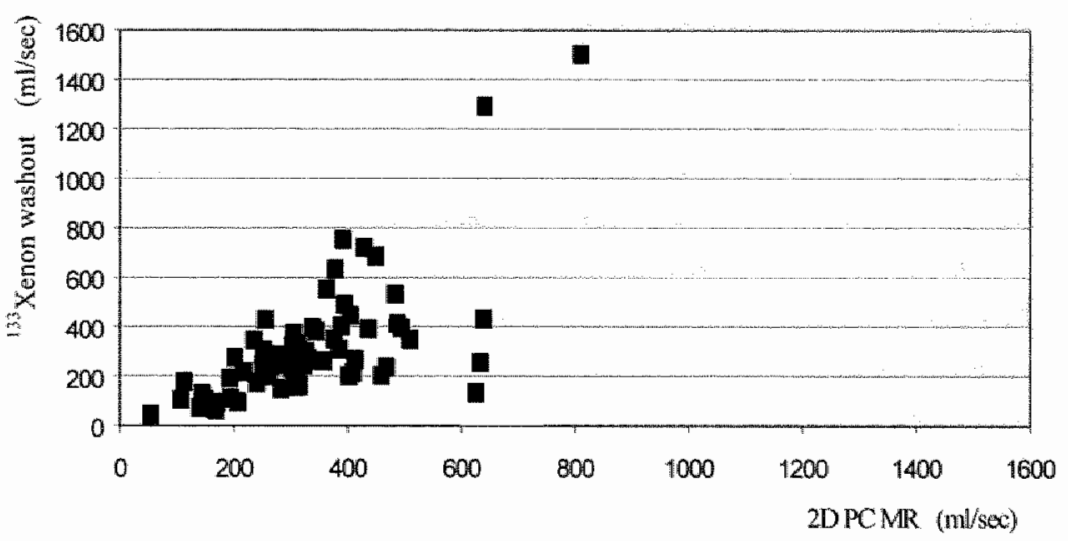

Note: $y=2.2 x-420 ; r=0.69 ; p<0.01$

Excluding two outlying results with relatively high renal artery blood flow measurements obtained with both techniques would have resulted in a correlation coefficient of 0.51 . The MRBF to the right kidney was $322 \mathrm{ml} / \mathrm{sec}$. and to the left kidney $347 \mathrm{ml} / \mathrm{sec}$. (overall mean flow per kidney $334 \mathrm{ml} / \mathrm{sec}$ ) using the 2D PC MR technique for flow quantification. Using ${ }^{133}$ Xenon washout for flow quantification these respective flow data were $323 \mathrm{ml} / \mathrm{sec}$, $318 \mathrm{ml} / \mathrm{sec}$. and $321 \mathrm{ml} / \mathrm{sec}$.

\section{Flow measurements in relation to the presence of renal artery stenosis}

The 2D PC MR renal artery blood flow measurements correlated poorly with the presence and/or severity of renovascular disease (\% of stenosis) on conventional renal angiography $(r=0.1, p=0.36)$ (Figure 2). Furthermore, in patients with unilateral renovascular disease on angiography no significant difference in $2 D$ PC MR blood flow measurements between both kidneys could be detected.

Adjusting the 2D PC MR flow measurements to the renal volume by calculating the renal flow index: Flow $(\mathrm{ml} / \mathrm{min}) / \mathrm{kidney}$ volume $\left(\mathrm{cm}^{3}\right)$ and relating these to the presence andlor severity of renovascular pathology on conventional angiography falled to show a statistically significant relation. Similar observations in relation to the presence of renovascular disease were noted using the ${ }^{133}$ Xenon washout technique for renal artery flow quantification, further acknowledging the good correlation between the two independent techniques.

Active plasma renin concentration (APRC) in the aorta averaged $24 \mathrm{mU} / \mathrm{l}$. In both the right and left renal veins, mean renin concentrations were $27 \mathrm{mU} / \mathrm{l}$. No statistically significant correlation between the renal artery flow measurements using 2D PC MR or ${ }^{133}$ Xenon washout and the active plasma renin ratio $\left(A P R C_{\text {vein }}-A_{P R C}\right.$ aorta $) / A P R C_{\text {aorta }}$ could be identified ( $r=0.4, p=0.1$; and $r=0.3, p=0.26$, respectively). 
Figure 2: Scatter plot of the renal artery flow measurements obtained by 2 D PC MR (4) technique and

13. Xenor washout technique (O) yersus degree of scenosis.

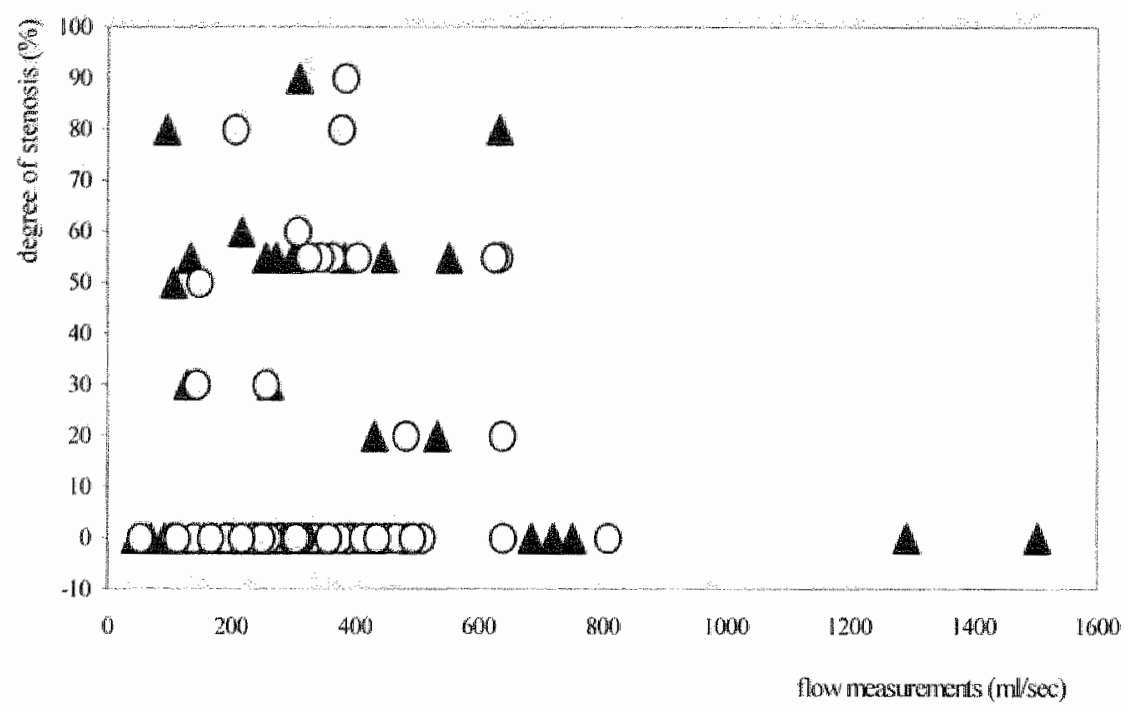

\section{Discussion}

The present data show that the use of 2D phase-contrast MR (2D PC MR) blood flow measurements enables hemodynamic evaluation of the renal arteries in a cohort of hypertensive patients with clinical suspicion of renovascular disease. The absolute flow measurements in the renal arteries are comparable with results of other published series $(14,20)$. As demonstrated in Figure 1, the 2D PC MR renall artery flow measurements correlated significantly with the corresponding renal artery flow data as obtained independently by the ${ }^{13}$ Xenon washout technique, with a Pearson correlation coefficient of 0.69 (two-tailed; $p<0.01$ ). This is $a$ promising level of correlation, especially considering that these flow measurements are not completely identical; that is $2 \mathrm{D}$ PC MR relates directly to the renal artery flow whereas "Xenon washout represents the flow through the renal microcirculation.

The calculated correllation is influenced to some extent by the two outliers shown in Figure 1, with relatively high renal artery blood flow measurements obtained with both techniques. Analysis without these two values would have resulted in a correlation coefficient of 0.51 . The dispersion in the scatter plot in Figure 1 rises with the increase in measured MRBF, indicating a stronger correlation between the two methods at flow levels that are particularly relevant for the distinction between hemodynamically significant and non-significant renovascular disease.

Despite this correlation, we failed to identify a statistically convincing relationship between the presence and/or severity of renovascular pathology on conventional, intra-arterial renal angiography, and either 2D PC MR or ${ }^{133}$ Xenon washout data technique for flow quantification. Moreover, in patients with unilateral renovascular disease we could not find a significant difference in blood flow between the two kidneys with either technique. 
Likewise, no statistically significant correlation could be identified between active plasma renin ratio as a measure of functional hemodynamic abnormalities and the renal flow data with the use of either 2D PC MR or the ${ }^{133}$ Xenon washout technique.

Given the correlation between the two independent flow quantification techniques, the lack of discriminating power of 2D PC MR flow quantification for assessing the presence of renovascular disease cannot, a priori, be attributed to inaccuracies of the applied $M \mathbb{R}$ technique.

Our observations contrast with those from several publications in international literature on this topic $(13,21)$. This seems, at least partially, related to methodological differences. For instance, as opposed to Binkert et al. (21) we did not inject paramagnetic contrast prior to the phase-contrast flow acquisition, which might have allowed for a better dellineation of the renal arteries and thereby a more accurate detection of the transverse vessel area (22). Moreover, we did not include a qualitative analysis of the flow velocity curve, since a reduction of MRBF is considered to be the most important parameter for differentiating between significant and non-significant renal artery stenosis (13). Finally, the differences in prevalence of renovascular disease between the respective studies make dissimilarities in inclusion criteria and patient selection probable, which will affect the result. of these examinations and make mutual comparisons cumbersome.

Apart from the procedural differences, more fundamental explanations of physiological nature must be considered. Data in literature indicate that the degree of stenosis does not correlate well with flow measurements (23). Therefore, relating a single deviating renal artery flow measurement to the presence and/or severity of renal artery stenosis may prove to be unjustified. Serial, sellective renal artery flow measurements under controlled circumstances may be necessary in order to detect changes of mean renal artery flow volume over time. Furthermore, a chronic and slowly progressive disorder like renovascular disease triggers various compensatory mechanisms in one or both kidneys to maintain a normal renal artery blood flow, possibly even up to a very late stage of the disease. Thus, adaptation of endothelial function may take place at a much earlier stage of renovascular disease than what is now considered as significant stenosis (19). Moreover, the negligible difference in flow measurements between normal and abnormal kidneys can also be explained by either adaptation of the abnormal kidney or by underlying disease, for example, nefrosiclerosis, in the "normal" kidney.

Even with serial renal artery flow measurements the adaptation of a kidney to a stenotic lesion might not be fully appreciated. Serial quantitative studies of renoparenchymal perfusion with pharmacological challenges such as captspril may be necessary to obtain the essential functional information that allows to define the therapeutic options for a particular patient.

A major shortcoming of this study relates to the lace of a sufficient number of patients with significant renovascular disease on conventional angiography. This limits statistical assessment of the measurements in relation to the degree of stenosis and makes additional research imperative. A second limitation is relatively high number of excluded original examinations, particularly reflecting the delicacy of the 2D PC MR flow quantification technique in patients. Furthermore, we did not repeat the $2 D$ PC MR flow renal artery flow measurements in order to assess the reproducibility of these flow measurements. However, in a previously published study we have shown that quantitative measurement of renal artery blood flow with 2D PC MR is highly reproducible $(12)$. Still, the spread of MR 
results in the present study calls for further improvements before wide spread clinical application of this technique can be advocated.

In conclusion, the good correlation between two independent flow quantification techniques, that is $2 \mathrm{DPC} \mathrm{MR}$ and ${ }^{133}$ Xenon washout, indicates that mean renal artery blood flow assessment using a 2D PC MR technique is feasible. However, the poor correlation of both techniques with either the presence of renovascular disease on conventional angiography or the active plasma renin ratio demonstrates a lack of discriminating power of our study protocol for the functional evaluation of the renal arteries.

\section{Perspective}

Despite the good correlation of 2D PC MR flow with another independent, method $\left({ }^{133}\right.$ Xenon washout) to measure renal blood flow, many more studies are necessary to establish the place of MR flow quantification for the detection of the presence and degree of renal artery stenosis. Also, more work is needed to evaluate whether MR flow data obcained either under basal conditions or after, for instance, captopril challenge, are able to detect whether a stenosis leads to abnormal physiology and ultimately true renovascular hypertension. 


\section{References}

1. Grist TM. Magnetic resonance angiography of renal artery stenosis. American Jourthal of Kidney Disease. 1994: $24: 700-712$.

2. Debatin FJ. Sprizzer CE Grist TM. Beam C. Swetsky LP, Newman GE, Sostman HD. Imaging of the renal arteries: Value of MR angiography. AJR. 1991:157:981-990.

3. de Haan MW. Kouwenthowen M, Thelissen GRP, Koster D, Kessels AGH, de Leeuw PW, van Engelshoven JMA. Renovascular disease in patients with hypertension: Detection with systolic and diastolic gating in threemdimensional, phase-contrast MR angiography. Radiology. 1996:198:449-456.

4. Snidow IJ, Johnson MS, Harris VJ, Margosian PM, Aisern AM, Lalka SG, Cikrit DF, Trerotola SO. Treedimmensional gadolinium-enhanced MR angiography for aortoiliac inflow assessment plus renal artery screening in a single breath-hold. Radiology. 1996; 198:725-732.

5. Hahn U, Miller S, Nagele T, Schick F, Erdtmann B, Duda S, Claussen CD. Renal MR angiography at 1.0 T: three-dimensional (3D) phase-contrast techniques versiss gadolnium-enhanced 3D fast low-angle shot breath-hold imaging. AJR. 1999:172: 1501-1508.

6. Schoenberg SO, Bock M, Knopp MV. Essig M, Laub G, Hawighorse H, Zuna I. Kallinowski F, van Kaick G. Renal arteries: optimisation of three-dlimensional gadolinium-enhanced MR anglography with bolustiming-independent fast multiphase acquisition in a single breath-hold. Radiology. 1999;211:667 679.

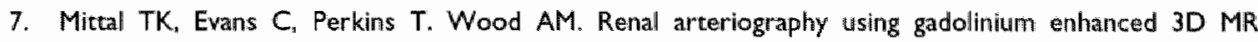
anglography: clinical experience with the technique, its limitations and pitfalls. BNR. 2001;74:495-502.

8. Breitenseher von M. Kainberger F, Hübsch $P_{n}$, Trattnig $S_{n}$ Baldt M, Barton $P_{n}$ Karnel $F$. Screening of renal artery stenosis: early results of colour Dopplen sonography. Fortschr. Röntgenstr. 1992;156,3:228-231.

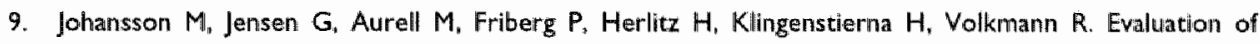
duplex ultrasound and captopril renography for detection of renovascular hypertension. Kidney international. 2000;58:774-782.

10. Dunnick NR, Sfakianakis GN. Screening for renovascular hypertension. Radiol. Clin. North. Am. $1991 ; 29: 497-510$.

11. King BF Jr. Diagnoscic imaging evaluation of renovascular hypertension. Abdom. Imaging. 1995;20:395. 405.

12. de Haan MW, Kouwrenhoven M, Kessels AGH, van Engelshoven JMA. Renal artery blood flow: quantification with breath-hold or respiratory triggered phase-contrast MR imaging. European Radiology. 2000:10:1133-11137.

13. Schoenberg SO. Knopp MV. Bock M, Kallinowski F, Just A, Essig M. Hawighorst H. Schad L. wan Haick G. Renal artery stenosis: grading of hemodymamic changes with che phase-contrast MR blood flow measurements. Radiology. 1997:203:45-53.

14. Wolf RL. King BF, Torres VE, Wilson DM, Ehrman RL. Measurement of normal renal artery blood flow: Cine phase-contrast MR imaging vs. clearance of [-aminohippurate. AJR. 1993;161:995-1002.

15. Ladefoged J. Measurement of renal blood flow in man with the ${ }^{133}$ Xenom washout technique. Scandinawian J. din. \& lab. Investigation. 1966:18:299-315.

16. Kety S.S. The theory and applications of the exchange of inert gas at the lung and tissue. Pharmacol. Review. 1951;3:1.

17. De Leeww PW. Birkenhäger WH: Use of the xemon-133 washout technique in diagnosing renovascular disease in hypertension. Nephron. 19:86:44:5;7.

18. Hollenberg NK, Mangel R. Fung HY: Assesstment of intrarenal perfusion with radio xenon: a critical review of analytical factors and their implications in man. Semin Nucl Med. 1976:6:193-216. 
19. Viderma TKA, Houben AJH, Kroon AA, Koster D, van der Zander wan Engelshoven JMA, de Leeww PW. Nitric oxide dependency of renal blood flow in thypertension with and without renal artery stenosis. I Am Soc Wephrol. 2001:12(9):1836-43.

20. Dobatin IF, Ting RH, Wegmüler $H$, Sommer, FG, Fredrickson JO, Brosnan T], Bowman BS, Myers BD, Herfketis R. Pelc N). Renal artery blood flow: quantitation with phase-contrast MR imaging with and without bireath holding Radiology. 1994:790371-378.

21. Binkert CA, Hoffmian U. Leung DA, Matter H.G. Schmidt M, Debatin JF. Characterization of renal artery stenoses based on magnetic resonance renall flow and volume measurements. Kidney International. $1999,56: 11046-1954$

22. Bass JC. Prince MR, Londy F. Chenewert TL. Effects on $3 \mathrm{D}$ phase-contrast MR angiography of the renal arteries: $A / R$ : $1997,1682261-266$.

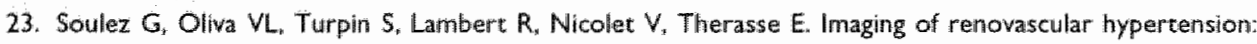
respective values of renal scintigraphy, renal Doppler US, and MR angiography. Radiographics. $2000,20 \% 355-168$ 

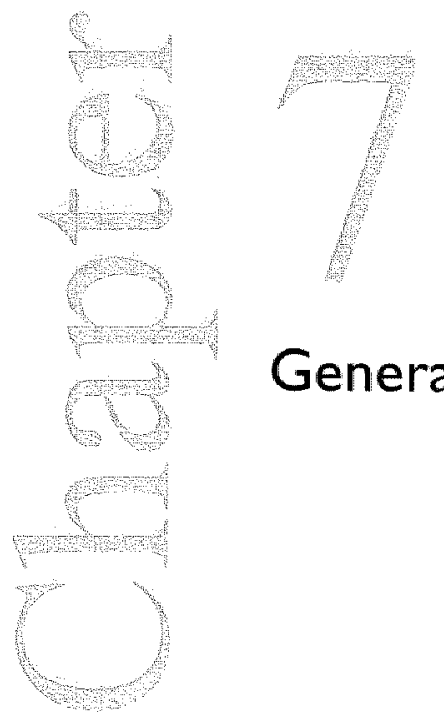

General discussion 


\section{General discussion}

Hypertension is probably one of the more important health problems in the developed countries. The prevalence of hypertension depends on both the (racial) composition of the population and the criteria used to define the condition. In a population of Dutch adults, approximately $14 \%$ of both males and females have a diastolic blood pressure greater than $95 \mathrm{~mm} \mathrm{Hg}$ (1). Even in its mild forms, hypertension is a progressive disease with severe atherosclerotic complications and end ofgan damage, eg. cardiomegaly, congestive heart failure, retinopathy, a cerebrovascular accident, and/or renal insufficiency, if left untreated. Although the understanding of the pathophysiology of an elevated arterial pressure has increased, in majority of cases its etiology is still unknown.

Renal artery stenosis (RAS) is the most frequent cause of secondary hypertension, with an estimated prevalence of $3 \%-5 \%$ in the general population of people with hypertension $(2-4)$. The clinical presentation of RAS varies significantly between patients, ranging from incidental findings of renal artery stenosis on angiography in normotensive persons to severe hypertension and progressive loss of renal function. Therefore, the diagnosis of renovascular hypertension ( $\mathrm{RVH}$ ), which suggests a causal relationship between RAS and hypertension, cannot be made in most patients.

Possibly as a consequence of these contingencies, it is still unknown if percutaneous renal artery angloplasty or stent placement is superior to medical therapy or surgical revascularisation in reducing cardiovascular mobidity and mortality or in preserwing renal size and function (5). Nevertheless, identification of RAS, preferably in combination with assessment of its hemodynamic effect on the renal prerfusion, in parients with hypertension and/or renal failure remains important, because correction of arterial stenoses may improve blood pressure control and/or stabilize renal function in a certain number of these patients (6-10).

Various imaging techniques can be applied for the detection of RAS. These can be divided in functional tests: (captopril) renography and duplex ultrasound; and morphological methods including MR angiography (MRA), CT angiography (CTA) and intra-arterial digital subtraction angiography (ia-DSA). The latter test is still regarded the most accurate method to assess the presence and severity of renal artery stenosis. However, its invasive nature and high costs make this procedure unsuitable as a screening modality in a population of patients with a low prevalence of tenal artery stenosis.

Captopril renography measures the physiological effects of angiotensin II on renal autoregulation of glomerular filtration rate (GFR). Supposedly a fall in GFR after administration of captopril indicates hemodynamically significant RAS. This non-invasive test has been reported to be highly sensitive $(91 \%-94 \%)$ and highly specific $(84 \%-95 \%)$ in detecting RAS. However, recent studies have demonstrated less impressive results with considerable wariation in inter- and intra-observer interpretations especially in patients with small kidneys and/or bilateral disease (11-16).

Likewise, duplex ultrasound thas been advocated as the optimal non-invasive screening test, because it has the potential to combine direct visualization of the renal arteries with acquisition of flow velocity profiles, thus providing both anatomical and functional information. Yet, the relatively large number of incomplete examinations in combination with the wide range of results published in international literature does not seem to support the general application of duplex ultrasound as a screening procedure for 
detection and assessment of renovascular disease. The results of our study on duplex ultrasound of the renal arteries (chapter 2) show an overall sensitivity of only $50 \%$ (specificity: 91\%; PPV: $88 \%$; NPV: 59\%) for detecting hemodynamically signilicant renovascular disease when commonly applied parameters were used at internationally accepted thresholds: i.e. PSV $>180 \mathrm{~cm} / \mathrm{sec}$ and RAR $>3.5$. Obtaining these parameters requires evaluation of the entire length of the renal artery. which, even in experienced hands is cumbersome. Therefore, waveform analysis of the intrarenal vasculature with several criteria, i.e. mean resistive index, tardus-parwus phenomena and acceleration time, thas been proposed as an alternative to detect upstream stenosis (17). This was further accentuated in a recent study where duplex ultrasound was suggested to be the most valuable non-inwasive test, not only in screening for renal artery disease but allso to estimate its functional significance by means of determination of the resistive index (18). However, the intrarenal parameters are influenced by several complex faccors including pulserate and diastolic blood pressure, which seems reflected by the wide range of reported sensitivities and specificities for detection of significant renovascular disease: $57 \%-100 \%$ and $69 \%-99 \%$ respectively, despite the theoretical advantages of this approach. In the last decade, several magnetic resonance (MR) angiographic techniques have been proposed for examination of patients suspected to thave renovascular disease. The two more basic techniques used in MRA: time-of-flight (TOF) and phase-contrast (PC), display the anatomic details of vasculature without using intravenous contrast material. TOF-MRA is based on contrast formation by the inflow of unsaturated spins (blood) into surrounding saturated spins (perivascular tissue). This technique has a reduced sensitivity to inmplane flow because of rapid saturation of inflowing spins, that may hamper depiction of the renal arteries. Furthermore, TOF-MRA has the tendency to overestimate (the presence of) renovascular disease, which is also reflected by the wide range of reported results.

In the phase-contrast technique (PC-MRA) the phase shift of the signals from the protons is recorded. Because moving spins have different phase shifts, the protons in the fllowing blood may be discriminated from the stationary ones (perivascullar tissue). Phase-contrast MRA has the tendency to overestimate (the presence of) renovascular disease as a result of artefacts caused by the pulsatility of blood flow and by its increased sensitivity to signal loss from intravoxel spin-phase dispersion, due to disturbed or turbulent flow. Since cardiac gating may suppress these artefacts, we designed a prospective study in a limited number of patients to evaluate the usefulness of three-dimensional (3D) PCMRA performed with cardiac synchronisation in the assessment of renal arteries (chapter 3). In accordance with data reported in the international literature, the results of this study indicate that 3D PC.MRA is a highly sensitive and specific technique for the detection of renovascular disease.

Yet, these promising results could not be reproduced in the subsequent prospective, multicenter study (RADISH-study) in which the overall sensitivity of PC-MRA for detection of significant renovascular disease ranged from $51 \%$ to $56 \%$ with specificities ranging from $86 \%$ to $91 \%$ (19. Appendix). Interestingly, in the same study comparable results for gadolinium enhanced MRA (CE-MRA) and CTA were noted, even though recent publications indicate that these techniques may be preferred for non-invasive assessment of the renal arteries (20-22). Methodological differences between our study and the RADISH-study, including dissimilarities in patient selection, study design and image evaluation, may, at least partially, account for this contrast in outcome. Furthermore, 
similar to most other studles that reported high sensitivities, the 3D PC-MRA study (chapter 3) did not contain patients with fibromuscular dysplasia as opposed to the RADISH-study which included a relatively high proportion of patients with fibromuscular dysplasia ( $38 \%$ of all patients with significant renovascular disease).

The presence of fibromuscular dysplasia in the renal arteries seems especially rellevant and is possibly a qualifying parameter in the presentation of test results because, as shown in chapter 4, neither PC-MRA, neither CE-MRA nor CTA can reliably dliagnose this disorder. This is particularly relevant because we also found that there are no clinical features that can identify patients with fibromuscular dysplasia, except perhaps that the condition occurs more commonly in females than in males. A meta-analysis by Martin et al (23) showed a mean cure tate of renovascular hypertension (i.e. restoration of blood pressure to less than $140 / 90 \mathrm{~mm} \mathrm{Hg}$ without antihypertensive medication) of $44 \%$ for renal revascularisation of stenoses related to fibromuscular dysplasia, as opposed to almost no cure when the renall artery stenosis was caused by atherosclerosis. Therefore, the cure rate of for (medial) fibromuscular dysplasia is sufficiently high to recommend revascularisation and underlines that early identification of these patients is important (10). Technologic developments, particularly focusing on more rapid data acquisition and improvement of spatial resolution, seem essential before either MRA or CTA can be fully implemented in daily practice. Eventually, CTA may prove to be the preferred non-invasive imaging modality of the renal arteries because of its significantly shorter acquisition time compared to MRA, thanks to the recently introduced multi-detector, helical CT technique. Pending these improvements, ia-DSA remains the gold standard for the detection of renovascular pathology.

Nevertheless, the challenge of diagnosing renovascular disease does not only rest in purely morphological identification of renal artery pathology, but also, and this is probably more important, in the determination of its effect on renal blood flow and kidney perfusion. In two studies, we have shown that non-invasive flow quantification in the renal arteries by means of $2 D$ phase-contrast MR (2D PC MR) is technically feasible. In a relatively small group of healthy volunteers reproducible measurements could be obtained (chapter 5), whereas in hypertensive patients the 2D PC MR blood flow measurements corresponded reasonably well with renal artery flow data as obtained independently by the ${ }^{133}$ Xenon washout technique (chapter 6).

However, a statistically convincing relationship between these $2 D$ PC MR flow measurements and both the presence and/or severity of renovascular pathology on ia-DSA and the degree of renin stimulation could not be identified. Similar to data published by Wierema et al, no significant difference in blood flow between the two kidneys could be demonstrated in patients with unilateral renovascular disease (24).

This could mean that adaptation of renal endothelial function may take place at a much earlier stage of renovascular disease than what is now considered as significant stenosis. Consequently a normal renal artery bllood flow could be maintained, possibly even up to a very late stage of the disease. Therefore, serial, selective renal artery flow measurements under controlled circumstances seem necessary to detect changes of mean renal artery flow volume over time. Additional quantitative studies of renoparenchymal perfusion with pharmacological challenges such as captopril may be necessary to obtain the essential functional information that allows to define the therapeutic options for a particular patient. Given the present status of MR flow quantification in the renal arteries and the expected 
mprovements of the technique in the near future, we believe that MR flow quantification will become indispensable for the non-invasive functional assessment of renovascular pathology: 


\section{References}

1. Hofman A, Valkenburg HA. Een epidemiologisch onderzoek naar tisico-indicatoren voor hart-en vaatziekten (EPOZ). Il. Voorkomen, opsporing en behandeling wan hypertensie in een open bevolking. Nad. Tijdschr Geneeskunde 1980, 124:189-195.

2. Hilman B]. Imaging advances in the diagnosis of renovascular hypertension. AJR 1989, 153:5-14.

3. Kim D. Edelman RR, Kent KC. Porter DH. Skillman Jj. Abdominal aorta and renal stenosis: evaluation with MR Angiography. Radiology 1990, 174:727-731.

4. Positma CT, van Oifen AHAM, Barentsz JO, de Boo T, Hoefnagels WH, Corstens FH, Thien $T$. The value of terts predicting renovascular hypertension in patients with renal artery stenosis treated by angloplasty. Arch Intern Med 1991, 151:1531-1535.

5. Guidelines for the reporting of renal artery revascularisation in clinical trials. Rundback JH, Sacks D, Kent C. Cooper C, Jones D. Murphy T, Rosenfield K, White C, Bettmann M, Cortell S. Puschett J, Clair

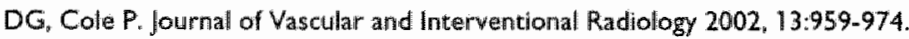

6. Working Group on Renovascular Hypertension. Detection, evaluation and treatment of renovascular hypertension; Finall report. Arch Intern Med 1987, 147:820-829.

7. Klinge J. Mali WPTM, Puijlaert CBAJ. Geyskens GG, Becking WB, Feldberg MAM. Percutaneous transluminal renal angioplasty: Initial and Long-term Results. Radiology 1989, 171:501-506.

8. Losinno $F$, Zuccala $A$, Busato $F$, Zuechelli $P$. Renal artery angioplasty for renovascular hypertension and preservation of renal function: Long-term angiographic and clinical follow-Lp. AJR 1994, 162:853-857.

9. Soulen MC. Renal angioplasty: Underutilized or overvalued? Radiology 1994, 193 (1):19-21.

10. Martin LG, Rundback JH, Sacks D. Cardella JF, Rees CR, Matsumoto AH, Meranze SG, Schwartzberg MS, Silverstein MI, Lewis CA, for the SIR. standards of practice committee. Quality improvement guidelines for angiography, angioplasty, and stent placement in the diagnosis and treatment of renal artery stenosis in adults. J. Vasc. Interv. Radiol. 2002, 13:1069-1083.

11. Mann S, Pickering T, Sos T, Uzzo RG, Sarkar S, Friend K, Rackson ME, Laragh JH. Captopril renography in diagnosis of renal artery stenosis: Accuracy and limitations. The American Journal of Medicine; 90: 30-40.

12. Fommei E. Mezzasalma L, Ghione S, Volterrani D. Oei Y, Hilson A, Carrieri M. European captopril radionuclide test multicenter study: Preliminary results. American Journal of Hypertension 1991: 4:6906975 .

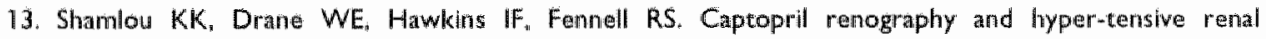
transplantation patient: A predictive test of therapeutic outcome. Radiology 1994; 190:153-159.

14. Schreij $G$, van Kroönenburgh $M$, Heidendal GK, van der Pol HA, de Leeuw PW. Interpretation of captopril renography by nuclear medicine physicians. I Nucl Med. 1996,37:1652-5.

15. Mann S』. Pickering TG. Detection of renovascular hypertension: State of the art: 1992.Amnals of Internal Medictne 1992; 117:845 -853.

16. Huot Sf, Hansson JH, Dey H, Conato f. Utility of captopril renal scans for detecting renal artery stenosis. Arch Intern Med. 2002; 162;1981-1984.

17. Baxter GM, Aitchison F, Sheppard D. Moss JG. McLeod MJ. Hardem PN, Love JG, Robertson M. Taylor G. Colour Doppler ultrasound in renal artery stenosis: intrarenal waveform analysis. British Journal of Radiology 1996; 69:810-815.

18. Radermacher J. Chavan A, Bleck J. Vitzthum A, Stroess B, Gebel MJ, Galanski M, Koch KM, Maller H. Use of Doppler Ultrasonography to predict the outcome of therapy for renal-artery stenosis. New England Journal of Medicine 2001; 344:410-417. 
19. Vasbinder GBC, Nelemans PJ, Beek FJA, Flobbe K, de Haan MW. Kessels AGH, Korst MBjM, Kroon AA, Leiner T, Maki JH, Positma CT, wan Zwam WH, de Leeuw PW, wan Emgelshoven JMA. Conputed Tomographic Angiography and Magnetic Resonance Anglograpliny for the Diagnosis of Renal-Artery Stenosils: a Comparative Study with Digital Subtraction Angiography. Results of the Renall Artery Diagnostic Imaging Study in Hypertension (RADISH) Sudy. Submitted.

20. Beregi J.P. Elkohen M, Deklunder G, Artaud D. Coullet JM. Wattïne L. Helical CT angiography compared with arteriography in the detection of renal artery stenosis. AJR 1996: 167:495-501.

21. Hahn U, Miller S, Nagele T, Schick F, Erdtmann B, Duda S, Claussen CD. Renal MR angiography at 1.0 T: three-dimensilonal (3D) phase-contrast techniques versus gadolinium-enhanced 3D fast low-angle shot breath-hold imaging. AJR 1999; 172:1501-1508.

22. Schoenberg SO, Bock M, Knopp MV, Essig M, Laub G, Hawighorst H, Zuna I, Kallinowski F, van Kaick G. Renal arteries: optimisation of three-dimensional gadolinium-enhanced MR anglography with bolusm timing-independent fast multiphase acquisition un a single breath-hold. Radlology 1999; 21 1:667-679.

23. Martin LG, Rees CR, O'Bryant T. Percutaneous angioplasty of the renal arteries. In. Strandness DE Ir, van Breda A eds. Vascular diseases. Surgical and Interventional therapy. $1^{\text {s* }}$ ed. Niew York. NY: Cluturchill Liwingston, 1994,721-742.

24. Nitric oxide dependence of renal blood flow in patients with renal artery stenosis. Wierma TKA. Houben AlHM, Kroon AA, Koster D, van der Zander K, van Engelshoven JMA de leeuw PW. I Am Soc Nephrol 2001: 12:1836-1843. 


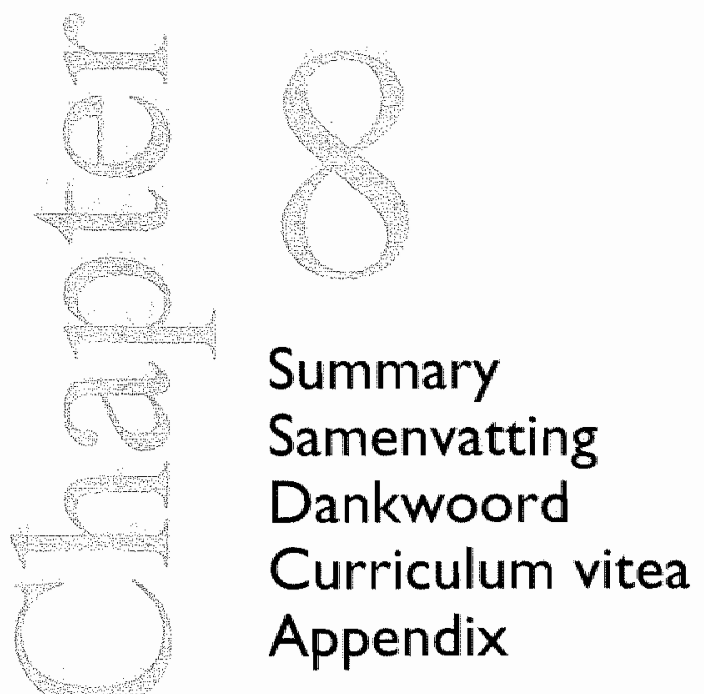




\section{Summary}

Hypertension is probably one of the more important health problems in the developed countries. Depending on the racial composition of the study and the criteria used to define this condition, the prevalence of hypertension may reach $15 \%$ in the adult population. Even in its mild forms, hypertension is a progressive disease with severe atherosclerotic complications and end organ damage if left untreated. In the majorty of cases "the etiology of hypertension is uniknown.

Renal artery stenosis (RAS) is the most frequent cause of secondary hypertension, with an estimated prevalence of $3 \%-5 \%$ in the general population of hypertensive patients. Identification of RAS in patients with hypertension and/or renal failure, preferably in combination with assessment of its themodynamic effect on renal perfusion "poses an important clinical challenge, since surgical or percutaneous treatment of these lesions may improve blood pressure control and/or stabilise renal function in a certain number of these patients.

To date, conventional $\mathrm{x}$-ray angiography still is considered as the most accurate method to assess the presence and severity of renal artery stenosis. However, its invasive nature and high costs, in addition to the requirement to use nefrotoxic contrast medium and radiation, make thils procedure less appropriate as a screening modality. The ideal screening procedure to select patients for renal angiography should be simple, non- (or minimally) invasive and highly accurate both for the detection of renovascular disease and for assessment of its clinical significance. This thesis focuses on the diagnostic performance of several non-invasive radiological techniques for detection and evaluation of renovascular disease.

Chapter 2 discusses a study that evaluated the accuracy of duplex ultrasound for the diagnosis of renal artery stenosis in a cohort of seventy-eight hypertensive patients with clinical suspicion of renovascular disease. Based on the combination of the peak systolic velocity ( $P S V_{\text {max }}$ ) and peak renal to aortic velocity ratio (RAR) at thresholds commonly applied in current literature: i.e. PSV max $>180 \mathrm{~cm} / \mathrm{sec}$ and RAR $>3.5$, the results of the duplex ultrasound examination showed an overall sensitivity of $50 \%$, a specificity of $91 \%$ and positive (PPV) and negative (NPV) predictive values of $59 \%$ and $88 \%$ respectively. These results, although disappointing, fall well within the wide range of internationally reported data in terms of specificity, sensitivity as well as in number of inadequate examinations and do not seem to support general application of duplex ultrasound as a screening procedure for detection and assessment of renovascular disease.

In the last decade several magnetic resonance (MR) angiographic techniques have been proposed for examination of the renal vasculature. Phase-contrast magnetic resonance anglography (PC MRAj has shown variable results with respect to detection of renal artery disease. Artefacts caused by the pulsatility of blood flow, that hinder image interpretation could, at least partially, be responsible for this variation in test accuracy. In chapter 3 , the value of cardiac synchronisation on image quality and validity of three-dimensional PC-MRA (3D PC MRA) of the renal arteries is explored in a cohort of 38 consecutive patients. The main results of this study indicate that $3 D$ PC MRA is a highly sensitive technique for the detection of renovascular disease, whereas implementation of cardiac gating on a routine basis is not supported by its limited improvement of these results. 
Following, in chapter 4 the performance of MR and CT anglography the detection of the second most common form of renal artery stenosis: fibromuscular dysplasia was analyzed. Thils noninflammatory dysplastic process is characterized by abnormalities in the fibromuscular lining of the renal artery, seen as multiple aneurysms separated by focal narrowing: string-of-beads-sign on angiography. In 40 kidneys (29 patients) with angiographically proven fibromuscular dysplasia in the renal arteries, neither PC.MRA, neither contrast enhanced MRA (CE-MRA), nor CTA showed reliable results in diagnosing this renal artery disorder. Even in this artificially composed population wh thery high prevalence of fibromuscular dyspiasia the observers frequently failed to identify fibromuscular dysplasia despite prior knowledge of the presence of this disease in one of the renal arteries. The results of CTA were better than CE-MRA, which in turn performed better than PC-MRA, but with none of the three techniques a detection rate of $\geq 82 \%$ for the presence of fibromuscular dysplasia could be reached. Further analysis showed that both extend of fibromuscular dysplasia as well as the distance of these lesions from the aortic ostium influenced the results in all three techniques. The limited spatial resolution in relation to the relatively small caliber of the segmental arteries, together with motion artifacts influencing the image quality of the more distal part of the renal arteries were identified as possible causes for the poor performance of the three non-invasive imaging modalities.

The challenge of diagnosing renovascular disease does not only rest in purely morphological identification of renal artery pathology, but also, and this is probably more important, in the determination of its effect on renal blood flow and kidney perfusion. In chapter 5, a technique that goes beyond purely morphologic imaging of arteries is evaluated for non-invasive quantitative assessment of renal artery flow dynamics: 2D phase-contrast MR flow quantification. The aim of the presented study was to determine the feasibility and reproducibility of two respiration controlled PC MR techniques: a breath-hold sequence, and a respiratory-triggered sequence, to measure blood fllow in the individual renal arteries. In twelve healthy subjects reproducible quantitative measurements of renal artery blood flow with both respiratory controlled, cardiac-gated, phase-contrast MR techniques was possible. However, the limited sample size of this study together with the composition of the subject-group (i.e. heallthy, relatively young volunteers) made extrapolation of the results to the daily practice premature and called for larger, comparative studies in patients.

Therefore, the study described in the chapter 6 was a logical continuation of this line of investigation. In this study the ${ }^{133}$ Xenon washout technique was used as an indeprendent test for comparative evaluation of the accuracy of the 2D PC MR renal artery flow measurements obtained in patients suspected of having renowascular hypertension. In addition, the 2D PC MR flow data were related to functionall renal information as acquired by selective arterial and venous renin sampling in order to assess the presence of renal artery stenosis. The results showed a good correlation of 2D PC MR flow quantification with the ${ }^{133}$ Xenon washout technique to measure renal artery blood flow. However, a poor correlation of both techniques with both the presence of renovascular disease on conventional angiography, and the degree of renin stimulation, was also noted. This lack of discriminating power of $2 \mathrm{D}$ PC MR flow quantification for functional assessment of the renal arteries calls for futher improvement before it can be applied on a larger scale. 
In conclusion, the detection of renovascular disease with either MR or CT angiography is. far from perfecti. In view of the recently introduced multi-detector helical technique, CTA may eventually prowe to be the preferred non-inwasiwe imaging modality of the renal arteries because of its significantly shorter acquisition time compared to MRA. The quantitative studies on the other hand, indicate that 2D PC MR flow quantification may well become a key instrument in the non-invasive functional assessment of renovascular pathology 


\section{Samenvatting}

Hypertensie of hoge bloeddruk is een relatief veel voorkomend gezondheidsproblemen in de Westerse wereld. Afhankelijk van de raciale samenstelling van de bestudeerde patiënten groep en de gehanteerde definities voor deze aandoening kan de prevalentie van hypertensie in een groep van volwassen personen oplopen tot $15 \%$. Hypertensie is een progressieve ziekte en heeft, als de ziekte niet wordt behandeld, zelfs in milde vorm ernstige complicaties tot gevolg: hartaanval, beroerte (een herseninfarct of -bloeding) of hartfalen. In de meerderheid van de gevallen blijft oorzaak van hypertensie onbekend waardoor de mogelijkheid van gerichte prewentie en/of behandeling wordt beperkt.

Nierarterie stenosen (vernauwingen van de nierslagader) zijn, hoewel schaars, de meest voorkomende vorm van secundaire hypertensie met een geschatte prevalentie van $3.5 \%$ in een algemene populatie van hypertensieve personen. Het aantonen vah nierarterie stenosen bij patienten met hypertensie en/of progressief nierfunctie verlies is een belangrijke klinische uitdaging, omdat percutane dan wel chirurgische correctie van de stenosen in een bepaald aantal van hen kan leiden tot een betere bloeddruk controle en/of behoud van nierfunctie. Tot op heden wordt conventionele röntgen angiografie nog steeds beschouwd als de meest betrouwbare methode om de aanwezigheid en de ernst van nierarterie stenosen te bepalen. De hoge kosten, het invasieve karakter en de noodzakelijke toepassing van straling en nefrotoxisch contrast, maken deze procedure evenwel minder geschikt alls screeningstest.

Om patiënten te kunnen selecteren voor een dergelijk angiografisch onderzoek zou men in het ideale geval de beschikking hebben over een eenvoudige en niet- (of minimaal) invasieve test met een hoge betrouwbaarheid voor het aantonen van nierarterie stenosen. In dit proefschrift wordt het vermogen van enkele niet-inwasieve, radiologische technieken om nierarterie afwijkingen op te sporen en functioneell te evalueren nader onderzocht.

In hoofdstuk 2 wordt een studie gepresenteerd waarin de nauwkeurigheid van duplex echografie voor het opsporen van nierarterie stenosen wordt geevalueerd in een coliort van 78 hypertensieve patiënten met klinische verdenking op nierarterie afwijkingen. Met name is een de combinatie van een tweetal erkende Doppler parameters onderzocht: piek systolische snelheid (PSV max $_{\text {) }}$ en de ratio tussen de piek snelheden in nierarterie en aorta (RAR), hierbij gebruikmakend van internationaal geaccepteerde drempelwatrden voor hemodynamisch significante stenosen (PSV max $>180 \mathrm{~cm} / \mathrm{sec}_{\text {; }}$ RAR $<3,5$ ).

In de onderzochte groep patiënten is een sensitiviteit bereikt van slechts $50 \%$ voor het aantonen van ernstige nierarterie stenosen met een specificiteit van $91 \%$ en een positief (PPV), en negatief (NPV) voorspellende waarde van 59\%, respectievelijk $88 \%$. Hoewel teleurstellend vallen deze resultaten, wat betreft sensitiviteit en specificiteit en aantal onvolledige onderzoeken binnen het (brede) bereik van de internationaal gepubliceerde resultaten. Uitgaande van deze gegevens kan worden geconstateerd dat algemene toepassing van duplex echografie als screeningstest voor detectie en evaluatie van nierarterie afwijkingen onvoldoende onderbouwd is.

Gedurende de afgellopen jaren zijn als alternatief voor duplex echografie verschillende magnetische resonantie (MR) technieken ontwikkeld om de nierarteriën af te beelden. Met één van deze MR technieken: phase-contrast magnetische resonantie angiografie (PC-MRA) zijn met betrekking tot het vaststellen van nierarterie stenosen zeer wisselende resultaten geboekt. Hinderlijke artefacten veroorzaakt door de pulsatiliteit van de bloedstroom 
zouden, ten minste deels verantwoordelijk kunnen zijn voor deze variatie in testresultaten. Als mogelijke oplossing van dit probleem is de waarde van cardiale synchronisatie op de beeidkwalliteit van drie dimensionale PC-MRA (3D PC-MRA) nader bekeken in een groep van 38 patiënten. De resultaten van deze studie, zoals beschreven in hoofdstuk 3, laten zien dat 3D PC-MRA een zeer gevoelige test is voor het aantonen van nierarterie stenosen, waarbiij de toegewoegde waarde van cardiale synchronisatie echter zodanig beperkt blijkt dat routinematige toepassing er van niet zinvol is.

Zeventig procent wan de nierarterie stenosen zijn van atherosclerotische origine, terwijl de volgende meest voorkomende oorzaak fibromusculaire dypsplasie is. Deze noninflammatoire dysplastische aandoening wordt gekarakteriseerd door afwijkingen in de fibromusculaire wandlaag van de nierarteriën en manifesteert zich angiografisch als multiple focale verwijdingen afgewisseld met korte vernauwingen: het "kralensnoer" teken.

In hoofdstuk 4 wordt de nauwkeurigheid bestudeerd van zowel MR als CT angiografie om dergelijke fibromusculaire dysplastische afwijkingen in de nierarteriën aan te tonen. In 40 nieren (29 patiënten) met angiografisch aangetoonde fibromusculaire dysplasie waren zowel PC-MRA, contrast versterkte MRA (CE-MRA), als CTA niet in staat om de afwijkingen betrouwbaar af te beelden. Zelfs in deze kunstmatig samengestelde groep van patiënten met een zeer hoge prevalentie van fibromusculaire dysplasie blijken de waarnemers veelvuldig niet in staat de aandoening te identificeren, ondanks voorkennis over de aanwezigheid er van.

De resultaten van CTA zijn beter dan CE-MRA en PC-MRA, maar met geen van de drie technieken kan een detectiegraad van meer dan $82 \%$ worden bereikt. Additionele analyse wijst uit dat de zowel ernst van fibromusculaire dysplasie als de afstand van de afwijkingen ten opzichte van de nierarterie oorsprong van invloed zijn op de testresultaten van alle drie de technieken. Als mogelijke verklaring voor de slechte resultaten van de drie technieken wordt de beperkte spatiële resolutie in relatie tot het kleine kaliber van de bloedvaten geïdentificeerd. Voorts blijken bewegingsartefacten, met name optredend in het meer perifere deel van de nierarteriën een belangrijke verstoring te geven van beeldkwaliteit en beeldinterpretatie.

De uitdaging om afwijkingen aan de nierarteriën te diagnostiseren is niet beperkt tot de puur morfologische weorgavo van doze bloedvaten, maar omvat ook het vaststellen van de functionele invloed van deze afwijkingen op de bloedstroom naar, en doorstroming van, de nieren. In hoofdstulk 5 wordt een techniek geëvalueerd die in staat is om zowel de nierarteriën af te beelden als de bloedstroom naar de nieren kwantitatief te bepalen: 2D phase-contrast MR flow quantitification. Het belangrijkste doel van deze studie was de toepasbaarheid en reproduceerbaarheid vast te stellen van twee werschillende, ademhaling gecontroleerde 2D PC MR technieken (breath-hold; respiration triggered) voor bepalen van de bloedstroom in de afzonderlijke nierarteriën. In twaalf gezonde vrijwilligers blijken met beide ademhaling gecontroleerde, cardiac-gated 2D PC MR technieken reproduceerbare kwantitatieve analyses van de nierarterie doorstroming mogelijk. Echter, de geringe omvang van deze studie alsmede de samenstelling van de bestudeerde populatie (gezonde, relatief jonge vrijwilligers) beperkte de mogelijkheid om de behaalde resultaten naar de dagelijkse praktijk te extrapoleren en vroeg om aanvullende, vergelijkend studies in patienten.

De in hoofdstuk 6 beschreven studie vormt derhalve een logische voortzetting van bovenbeschreven onderzoekslijn. In deze studie wordt wederom de bloedstroom door de 
individuele nierarterièn berekend, echter ditmaal in hypertensiewe patiënten met klinische verdenking op nierarterie afwijkingen en met de ${ }^{133}$ Xenon washout techniek als onafhankelijke vergelijkende test. Om ook de invloed van de nierarterie afwijkingen te kunnen evalueren worden de 2D PC MR bloedstroom berekeningen vergeleken met functionele informatie van de nieren, zoals deze wordt verkregen door selectieve arteriele en veneuze renine sampling. De aldus verkregen bloedstroom bepalingen laten een goede correlatie zien tussen de 2D PC MR methode en de ${ }^{133}$ Xenon washout techniek.

Helaas wordt ook een slechte correllatie gesignaleerd van beide technieken met zowel de aanwezigheid van nierarterie afwijkingen op de conventionele angiografie als met de renine ratio. Het discriminerend vermogen van het toegepaste studie protocol om nherarteriën en/of nierarterie afwijkingen functioneel te evalueren blijkt derhalve van slechts beperkte waarde en maakt verder onderzoek noodzakelijk.

Geconcludeerd kan worden dat het vermogen van MR en CT angiografie om nierarterie afwijkingen op te sporen verre van volmaakt is. Dankzy de recent geintroduceerde multidetector techniek, is het mogelijk dat het CT angiografisch onderzoek op termijn de imodaliteit van eerste keuze wordt voor het in beeld brengen van nierarterièn. Anderzijds geven de kwantitatieve analyses in dit proefschrift aan dat 2D PC MR flow quantification een belangrijk instrument kan worden bij de non-invasive functionele evaluatie van nierarterie pathologie 


\section{Dankwoord}

Het schrijwen van een proefschrift naast het dagelijks beoefenen van de radiologie in een academisch ziekenhuis vereist gedurende een aantal jaren veel inzet en doorzettingsvermogen. Dit geldt niet alleen woor de auteur maar ook voor de wele mensen die, ieder op zijn/haar gebied een rol hebben gespeeld bij het tot stand komen.

In willigkeurige volgorde wil ik met name bedanken:

Henk Speelman, Simon Robben, Con de Haan, Tim Leiner, Guillaume Thelissen, Maaike Evers, Catharien Romijn, Chris Ras, Willem de Haan, Monique Willems, Frits Bär, Patty Nelemans, Dave Kaandorp, Jos van Engelshoven, Jacques Pleumeekers, Mark Geerlings,

Derk, Geert Wijnhoven "Christianne Schiffer, Peter de Leeuw, Henk Schoenmakers, Ingrid Danklof, Peter Kitslaar, Annemieke Oomen, Henriette Beeksma, Karin Flobbe, Ellen Bouchoms, Marc Kouwenhoven, Jan Offermans, René Pluymakers, Dick Romijn,

Ine Kengen, Hugo Meijer, Fons Kessels, Paul Hofman, Karel Leunissen, Dick Koster, Kristell Vranken, Marlou Mommers, Jan Wilmink, Shala Azizi, Kai Yiu Ho, Boudewijn

Vasbinder, Dorke Warnier, Koo de Priester, Dave Douwes, Brigitte Custers, Dirk Geurts, Eveline Peeters, Jim Reekers, Charles Gemmeke, Hanneke de Jonge, Blagoja Janevski, Roy Vliegen, Margriet den Hartog, Jan op den Oord, Hans Smeets, Jan-Willem Gratama, Gijs, Pim Versluis, Jeroen Kroll, Jan Tordoir, Riël Snoep, Olaf Kurwers, Ralf Eschweiler, Etienne Lemaire, Astrid Muermans, Dave Sanders, Gerrit Kemerink, Ann van der Goten, Thea Sevriens, Otsie Verhaar, Bram Kroon, Jenny Amory, Erik Beek, Peter Verkoeyen. Edith Köhler, Wim van Zwam, Regina Beets, Mike Korst, Audrey Quaedvlieg, Ellen Nijssen, Ria Gulpers, Sonia Tattipatta, Khiam Oei, Marcel van Florop, Maria Pisters,

Bas, Frans van der Zande, Irene Schilder, René Weijers, Paul van Es, Marianne de Vries, Ed van der Linden, Boy Houben, Rob Lamers, Esther Peeters, Jef Willigers wacqueline Neven, Roland Kersemakers, Arie Lawrijssen, Jeff Maki en Sigrid van Hoof. 
Chapter 8 


\section{Curriculum vitae}

De auteur van dit proefschrift werd geboren op 9 maarc 1959 in 's Gravenhage geboren. In 1978 behaalde hij zijn WWO diploma aan het Haags Montessori Lyceum in 's Gravenhage. In datzelfde jaar begon hij met de studie geneeskunde aan de Rijksuniversiteit te Leiden, alwaar in 1986 het artsexamen werd afgelegd. Na zijn afstuderen werkte hij gedurende ruim 2 jaar als arts-assistent niet in opleiding (AGNIO) op de afdeling heelkunde van het Rode Kruis Ziekenhuis (hoofd dr. J.J. Hamming) 's Gravenhage, gevolgd door een veel kortere periode wederom als AGNIO ditmaal op dee afdeling heelkunde van het Westeinde Zlekenhuis (hoofd dr. R.K.J. Kounans) in dezelfde stad. In 1989 werd met de opleiding tot radioloog gestart in het academisch ziekenhuis Maastricht (opleiders: prof. dr. B.K. Janewski en prof. dr. J.M.A. van Engelshoven). Na zijn registratie tot radioloog op 1 april 1995 werd hij aangesteld als staflid aan de afdeling radiologie van het academisch ziekenhuis Maastricht.

In 1990 is hij gehuwd met Catharien Romijn. Samen thebben ze drie zonen: Gijs (1992), Derk (1994) en Bas (1995). 
Chapter 8 


\section{Appendix}

\section{The RADISH-study}

As a sequel to the initial pilot study on three-dimensional phase-contrast MR Angiography (3D PC-MRA) of the renal arteries (chapter 3) a prospective multicenter study was desilgned to evaluate the validity of MRA and computed tomographic angiography (CTA) in a large group of patients: the RADISH-study. This study was designed as a comparative study of PC-MRA gadolinium enhanced MRA (CE-MRA), CTA and the gold standard ia-DSA to detect the presence of renal artery stenosis.

Over a three-years period, subjects were prospectively recruited from the outpatients' clinics of the Internal Medicine departments of three large teaching hospitals and three university hospitals in the Netherlands. All hypertensive patients between 18 and 75 years of age with diastolic blood pressure of $>95 \mathrm{~mm} \mathrm{Hg}$ were eligible for participation. In order to raise the pre-test probability of the presence of renal-artery stenosis, patients had to exhibit at least one of the commonly accepted clinical clues for the presence of renalartery stenosis. All included patients were scheduled to have their PC-MRA. CE-MRA, CTA, and ia-DSA within three months after inclusion. Eight observers either fudged the PC-MRA, CE-MRA and CTA exams and were unaware of all other results. Four vascular radiologists judged the ia-DSA exams. Luminal narrowing of $\geq 50 \%$ as well as all cases of fibromuscular dysplasia were defined as clinilcally relevant stenoses.

Due to the variety of manufacturers and models of imaging equipment, each hospital was allowed to use the scan protocols which were considered optimal for its setting. Information about manufacturers, scan protocols, and used contrast agents is shown in table 1, chapter 4. The severity of the stenoses as seen on CE-MRA and CTA was categorized on a five point scale $(0 \%$ to $19 \%$ [scale 1]; $20 \%$ to $49 \%$ [scale 2 ]; $50 \%$ to $74 \%$ or fibromuscular dysplasia [scale 3]; $75 \%$ to $99 \%$ [scale 4]; and total occlusion $100 \%$ stenosis; [scale 5]). Four grades were used to categorize the severity of renovascular disease on PC-MRA: grade 1 was mild disease (stenosis of $<50 \%$ ), defined as mere luminal narrowing; grade 2, moderate disease (stenosis of $50-74 \%$ ), defined as reduction in diameter with focal flow void $(<5 \mathrm{~mm}$ ); grade 3 , sewere disease (stenosis of $75-99 \%$ ), defined as a longer region of signal intensity loss $(>5 \mathrm{~mm}$ ) with distal recurrence of flow signal intensity; and grade 4 , occlusion.

The interobserwer agreement for the evaluation of PC-MRA, CE-MRA and MRA images was calculated using linear kappa statistics. In case an observer found a PC-MRA. CE-MRA or MRA exam to be non-evaluative, this exam was considered as a positive test result in the analyses.

Out of 402 included patients, 356 patients who underwent CE-MRA, CTA and ia-DSA could be evalluated including 333 patients who underwent all four tests (PC-MRA, CE-MRA, CTA and ia-DSA). The prevalence of hemodynamically significant renal artery stenosis (RAS) in the group of 356 patients was $20 \%$ : 45 patients with athenosclerotic lesions and 27 patients with fibromuscular dysplasia. The prevalence of RAS in the 333 patients who underwent all four tests was also $20 \%: 41$ patients with atherosclerotic lesions and 27 patients with fibromuscular dysplasia.

For the detection of renal artery stenosis, moderate interobserver agreement was found with a kappa value of 0.57 for PC-MRA; the kappa values ranged from 0.40 to 0.51 for 
CE-MRA and from 0.59 to 0.64 for CTA. Overall, sensitivity ranged from $51 \%$ to $56 \%$ for PC-MRA, from $57 \%$ to $67 \%$ for CE-MRA and from $61 \%$ to $69 \%$ for CTA. Specificity ranged from $86 \%$ to $91 \%$ for PCMRA, from $77 \%$ to $90 \%$ for CE-MRA and from $89 \%$ to $97 \%$ for CTA. These findings are contrary to the results of all other published studies on the validity of PC.MRA, CEMRA and CTA, which all give much higher estimates for both sensitivity and specificity (up to $100 \%$ ). Phase-contrast MRA showed comparable results to CE-MRA and CTA for the detection of clinically relevant renovascular disease, which again seems in contrast to the internationally accepted, but not well-founded idea that CE-MRA is the preferred $M R$ angiographic technique for assessment of the renal arteries. Potential causes of error for the observed discrepancy include differences in prevalence of both RAS and/or fibromuscular dysplasia, differences in inclusion of supernumerary renal arteries and different definitions of hemodynamically significant renal-artery stenosis. Whichever the cause, these contrasts in outcome warrant further research to establish the place of PC-MRA, CE-MRA and CTA for the assessment of renowasteular disease before widespread clinical application of this technique can be advocated.

It can be expected that both MRA and CTA will improve with the advent of new technologic developments, such as more rapid acquisition by multi detector-row CTA or faster MR hardware and software. These developments may necessitate new prospective diagnostic studies, but until that time la-DSA remains the preferred test for the detection of renal artery stenosis.

M.W. de Haan for the Renal Artery Diagnostic Imaging Study in Hypertension (RADISH) stuidy group.

January 2003 